Frederico Gerlinger Romero

EFEITOS DO BETA HIDROXI BETA METILBUTIRATO SOBRE A EXPRESSÃO DE UBIQUITINA-LIGASES E VIAS DE SÍNTESE PROTÉICA NA MUSCULATURA ESQUELÉTICA DE RATOS ALIMENTADOS E JEJUADOS E SUAS REPERCUSSÕES FUNCIONAIS

Tese apresentada ao Programa de PósGraduação em Fisiologia Humana do Instituto de Ciências Biomédicas da Universidade de São Paulo, para obtenção do Título de Doutor em Ciências 
Frederico Gerlinger Romero

\section{EFEITOS DO BETA HIDROXI BETA METILBUTIRATO SOBRE A EXPRESSÃO DE UBIQUITINA-LIGASES E VIAS DE SÍNTESE PROTÉICA NA MUSCULATURA ESQUELÉTICA DE RATOS ALIMENTADOS E JEJUADOS E SUAS REPERCUSSÕES} FUNCIONAIS

Tese apresentada ao Programa de PósGraduação em Fisiologia Humana do Instituto de Ciências Biomédicas da Universidade de São Paulo, para obtenção do Título de Doutor em Ciências.

Área de Concentração: Fisiologia Humana Orientadora: Prof ${ }^{\underline{a}}$ Dr $\stackrel{\text { a }}{ }$ Maria Tereza Nunes Versão corrigida. A versão original eletrônica encontra se disponível tanto na Biblioteca do ICB quanto na Biblioteca Digital de Teses e Dissertações da USP (BDTD). 
DADOS DE CATALOGAÇÃO NA PUBLICAÇÃO (CIP)

Serviço de Biblioteca e Informação Biomédica do

Instituto de Ciências Biomédicas da Universidade de São Paulo

reprodução não autorizada pelo autor

\section{Romero, Frederico Gerlinger.}

Efeitos do beta hidroxi beta metilbutirato sobre a expressão de ubiquitinaligases e vias de síntese protéica na musculatura esquelética de ratos alimentados e jejuados e suas repercussões funcionais / Frederico Gerlinger Romero. -- São Paulo, 2013.

Orientador: Profa. Dra. Maria Tereza Nunes.

Tese (Doutorado) - Universidade de São Paulo. Instituto de Ciências Biomédicas. Departamento de Fisiologia e Biofísica. Área de concentração: Fisiologia Humana. Linha de pesquisa: Bases moleculares da ação de hormônio tireoideanos no controle da expressão de genes específicos, tais como os do $\mathrm{GH}$.

Versão do título para o inglês: Effects of beta hydroxy beta methylbutyrate on expression of ubiquitin ligases and the pathway of protein synthesis in skeletal muscle of fed and fasted rats and their functional consequences.

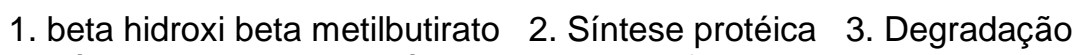
protéica 4. Função contrátil I. Nunes, Profa. Dra. Maria Tereza II. Universidade de São Paulo. Instituto de Ciências Biomédicas. Programa de Pós-Graduação em Fisiologia Humana III. Título. 


\section{UNIVERSIDADE DE SÃO PAULO \\ INSTITUTO DE CIÊNCIAS BIOMÉDICAS}

Candidato(a): $\quad$ Frederico Gerlinger Romero.

Título da Tese: $\quad$ Efeitos do beta hidroxi beta metilbutirato sobre a expressão de ubiquitina-ligases e vias de síntese protéica na musculatura esquelética de ratos alimentados e jejuados e suas repercussões funcionais.

Orientador(a): $\quad$ Profa. Dra. Maria Tereza Nunes.

A Comissão Julgadora dos trabalhos de Defesa da Tese de Doutorado, em sessão pública realizada a considerou
( ) Aprovado(a)
( ) Reprovado(a)

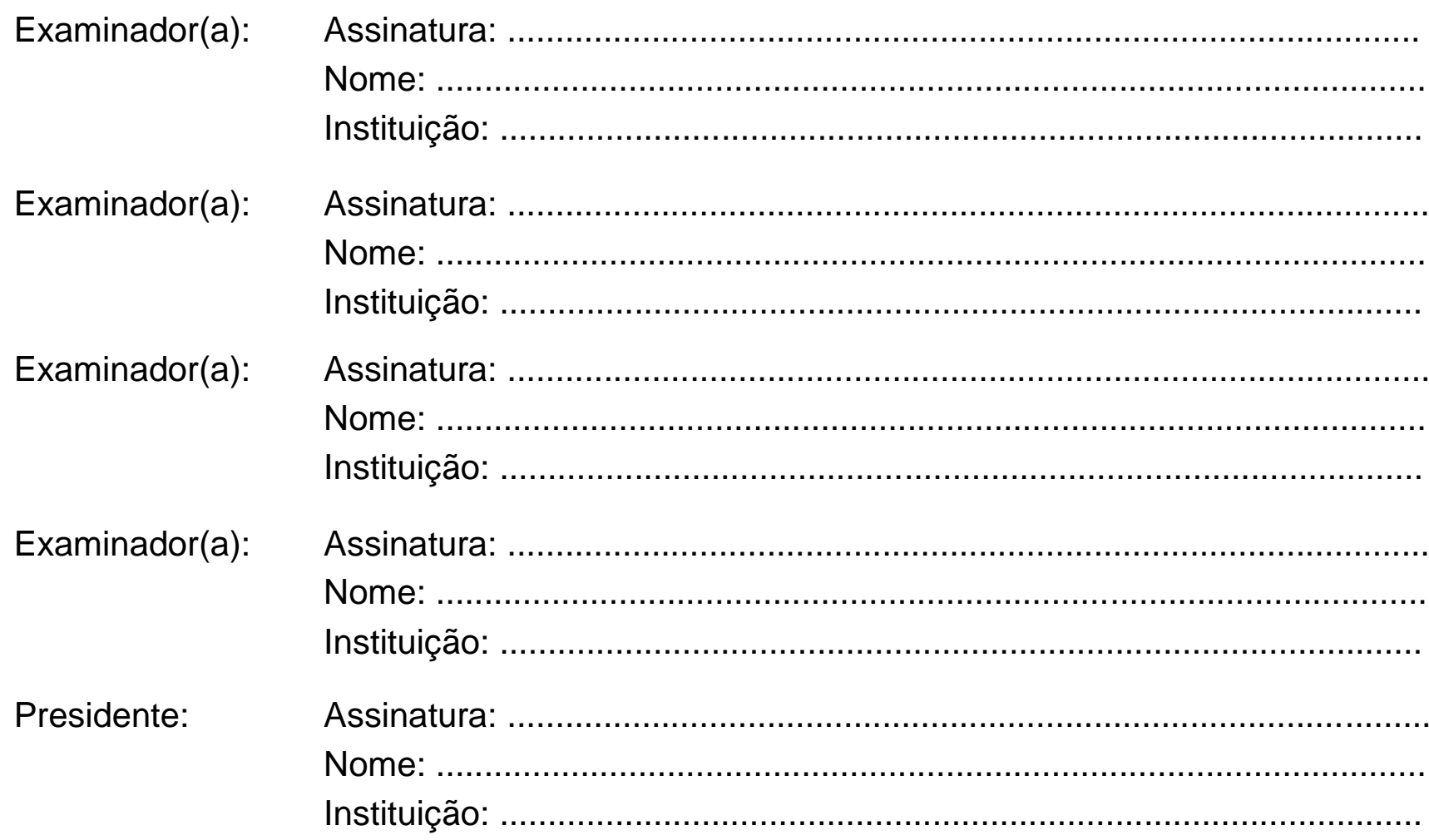




\section{Certificado}

Certificamos que o protocolo registrado sob $n^{\circ} \mathbf{9 3}$ nas fls. 106 do livro 02 para uso de animais em experimentação, sob a responsabilidade do Prof(a) $\operatorname{Dr}($ a) Maria Tereza Nunes, Coordenador(a) da Linha de pesquisa "Bases moleculares dos efeitos do beta hidroxi beta metilbutirato sobre o metabolismo protéico na musculatura esquelética de ratos alimentado e jejuados" do qual participam o(s) alunos Frederico Gerlinger Romero, Lucas Guimaraes, Rafael Salgueiro, Carlos Flores, Caio Yogi Yonamine, está de acordo com os Princípios Éticos de Experimentação Animal adotado pela Sociedade Brasileira de Ciência de Animais de Laboratório (SBCAL) e foi aprovado pela COMISSÃO DE ÉTICA NO USO DE ANIMAIS (CEUA) em 15.07.2011, com validade de 3 anos.

São Paulo, 18 de julho de 2011.
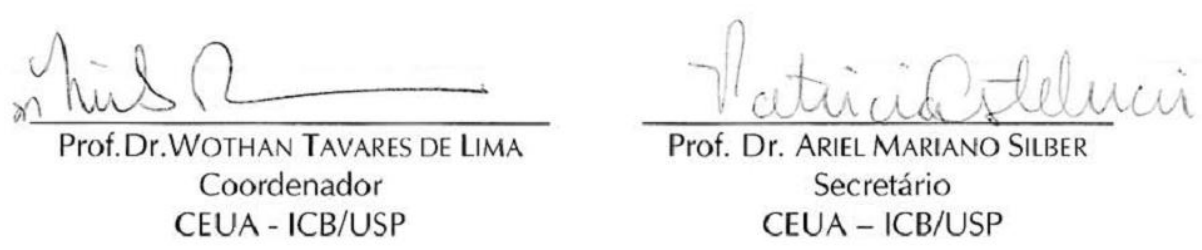
Ao meu querido pai Waldomiro por ter dedicado todo o trabalho e amor por mim.

A minha mãe Sheila, que me trouxe com todo o amor e carinho a este mundo, me ensinando a ter um olhar doce e otimista para os obstáculos da vida.

A minha irmã Vanessa, simplesmente por acreditar em mim e em muitos momentos ser responsável por elevar minha autoestima. E especialmente por ter a Vitória, minha sobrinha adorável.

Aos amigos(as), professores(as) e todos aqueles(as) que cruzaram em minha vida, participando de alguma forma na construção e realização deste tão desejado sonho. 


\section{AGRADECIMENTOS}

Á Profa. Maria Tereza Nunes, pela orientação e incentivo na minha formação e na dedicação impar a ciência.

Á Leonice Lourenço Poyares pela paciência e atenção na condução dos procedimentos de laboratório e por ser essa pessoal amável e especial.

Aos professores Sandro Massao Hirabara, Ubiratan Fabres Machado e Jose Donato Junior pelas contribuições no exame de qualificação.

Aos professores Ubiratan Fabres Machado e Rui Curi por ter proporcionado colaborações e aprendizagens importantes á minha formação.

Ao Carlos Hermano da Justa Pinheiro, por ter me auxiliado na condução dos experimentos funcionais.

Aos amigos e parceiros de jornada, Lucas Guimarães Ferreira, Rafael Vianna Croffi, Mario Alves de Siqueira Filho, Caio Yogi Yonamine e Rafael Barrera Salgueiro pelo incentivo e grande ajuda nos momentos difíceis.

As pessoas especiais do laboratório que tive a oportunidade de conviver e aprender. A todos que de alguma maneira me auxiliaram no decorrer desse período.

Á todos vocês, muito obrigado. 
"A força não vem de vencer. Suas lutas desenvolvem suas forças. Quando você atravessa dificuldades e decide não se render, isso é força." 


\section{RESUMO}

Gerlinger-Romero F. Efeitos do beta hidroxi beta metilbutirato sobre a expressão de ubiquitina-ligases e vias de síntese protéica na musculatura esquelética de ratos alimentados e jejuados e suas repercussões funcionais. [tese (Doutorado em Fisiologia Humana)]. São Paulo: Instituto de Ciências Biomédicas, Universidade de São Paulo; 2013.

A investigação do papel da suplementação de aminoácidos na atividade física e na prática médica tem aumentado nos últimos anos, considerando as evidências de que eles proporcionam ganho de massa muscular, por promoverem aumento da síntese e/ou redução da degradação protéica. Dentre vários agentes, um metabólito do aminoácido leucina, o $\mathrm{HMB}$, vem sendo utilizado para esse fim. O presente estudo tem como objetivo estudar os mecanismos moleculares envolvidos no efeito do HMB sobre o metabolismo proteico na musculatura esquelética frente a um modelo de proteólise, bem como suas consequências funcionais. Para tanto, ratos Wistar adultos $(\sim 250 \mathrm{~g})$ foram tratados com HMB $(320 \mathrm{mg} / \mathrm{Kg}$ de peso corporal $/ \mathrm{mL}$ de salina- $0,9 \%$ ), ou salina (controle), por gavagem, durante 28 dias. Após esse período, uma parcela de ambos os grupos sofreu jejum de 24 horas, com a finalidade de induzir proteólise muscular. Após os tratamentos especificados, parte dos animais destes grupos foi submetida a ensaios funcionais in vivo, por meio de um eletroestimulador acoplado a um transdutor de força. A outra parcela foi sacrificada, sendo os músculos gastrocnêmio (GASTRO) removidos e pesados; sóleo (SOL) e extensor digital longo (EDL), bem como parte do fígado, retirados para avaliação da expressão gênica (realtime PCR) e protéica (Western Blotting) de diversas proteínas envolvidas na síntese e degradação protéica na musculatura esquelética (IGF-l/Akt/mTOR/4E-BP1 e Ub-ligases). Não foram detectadas alterações na expressão dos atrogenes em ambos os músculos (SOL/EDL) com o tratamento; no entanto observamos um indicativo de atenuação dos animais jejuados com o tratamento no jejum no EDL. Com relação à fosforilação da Akt não houve alteração da mesma com o jejum e nem com o tratamento com HMB no músculo SOL. Já no EDL, encontramos elevação da pAkt no grupo jejuado tratado comparado ao jejuado controle. Contudo, surpreendentemente não detectamos alteração nas demais vias de síntese, bem como na expressão e conteúdo proteico de IGF-I. Os dados funcionais revelaram apenas uma melhora no tempo de sustentação de isometria e na taxa de resistência à fadiga no EDL dos animais jejuados com o tratamento, sem qualquer alteração na AST. Esta, no entanto, apresentou-se reduzida no SOL. Os resultados obtidos sugerem que o tratamento crônico com HMB não resultou em alterações nas vias de síntese e degradação protéica nos animais submetidos ao jejum. Contudo, eles apontam respostas músculo-específicas direcionadas principalmente ao EDL, no qual observamos aumento da atividade da Akt, acompanhado de uma melhora funcional, sugerindo que esse metabólito atue protegendo esse músculo do efeito deletério do jejum, sem adicional ganho de massa muscular.

Palavras-chave: HMB. Síntese protéica. Degradação protéica. Função contrátil. 


\begin{abstract}
Gerlinger-Romero F. Effects of beta hydroxy beta methylbutyrate on expression of ubiquitin ligases and the pathway of protein synthesis in skeletal muscle of fed and fasted rats and their functional consequences. [Ph. D. thesis (Human Physiology)]. São Paulo: Instituto de Ciências Biomédicas, Universidade de São Paulo; 2013.

The investigations of role amino acids supplementation on physical activity and on medicinal practices had increased on the latest years, considering the evidence that they both provide muscle mass gain by increasing protein synthesis and / or diminishing its degradations.

Among others factors, the HMB, a leucine metabolite, has been used for this purpose. The aims of this study is to explore the molecular mechanisms involved of the HMB effects over the protein metabolic on skeletal muscle compared to a proteolysis model, as well as their further functional consequences on muscle. For this, Wistar rats $(250 \mathrm{~g})$ were treated with HMB (320 mg/kg body weight $/ \mathrm{mL}$ of saline- $0,9 \%$ ), or only saline (control) daily by gavage for 28 days along. After it, a group of animals were subjected to 24 -hour fast, in order to induce muscle proteolysis. After the specified treatments, another portion of these animals were submitted to performances test in vivo using an electrostimulator coupled to a force transducer. Another portion of animals were sacrificed, and their gastrocnemius (GASTRO) removed and weighed; furthermore, the soleus (SOL), extensor digitorum longus (EDL) and a piece of the liver were removed for evaluation of several genes expression (real-time PCR) and their proteins expression (Western Blotting). Those proteins were involved on protein synthesis and degradation of skeletal muscle (IGF-I/Akt/mTOR/4E-BP1 and Ub ligases). After treatment, no changes were detected on the atrogenes expression in both muscles (SOL / EDL); however it can be observed an indicative attenuation of fasted control animals compared HMB treatment fasted on EDL. In relation of Akt phosphorylation, on soleus muscle, it was not altered by fasting, neither by HMB treatment. We found the pAkt elevated on the EDL's muscle of the HMB group fasted compared to the control fasted. However, surprisingly we detected no changes in the other synthesis pathway, as well on IGF-I expressions and its proteins content. Functional data revealed an improvement on sustained time of the isometric force and the fatigue resistance rate on EDL of animals fasted and HMB treated, without any change on cross-sectional area (CSA). On the other hand, it appeared to be reduced in SOL. Those data suggesting that chronic HMB treatment have no change in the synthesis pathways and protein degradations in animals subjected to fasting. Nevertheless, they indicated responses of muscle-specific, mainly targeted to the EDL, in which was observed an increase of Akt activity, followed by a functional improvement, suggesting that this metabolite acts as a muscle protector of the deleterious fasting effects, without any additional muscle mass gain.
\end{abstract}

Keywords: HMB. Protein synthesis. Protein degradation. Muscle function. 


\section{LISTA DE ILUSTRAÇÕES}

Figura 1-Síntese e metabolismo do HMB............................................................. 17

Figura 2-llustração das fases de iniciação da tradução. .............................................. 20

Figura 3-Resumo das ações descritas para o HMB. .................................................. 25

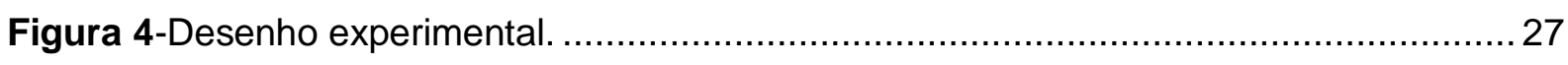

Figura 5-Foto ilustrativa da eletro estimulação in vivo ................................................. 33

Figura 6-Representação das análises funcionais no músculo esquelético. ......................... 34

Figura 7-Efeito do jejum sobre o peso dos músculos Sóleo, EDL e gastrocnêmio. ............. 36

Figura 8-Efeito do jejum sobre a expressão gênica de MuRF-1 e Atrogin-1 no sóleo.......... 37

Figura 9-Efeito do jejum sobre a expressão gênica de MuRF-1 e Atrogin-1 no EDL. ........... 38

Figura 10-Efeito da suplementação do HMB sobre a expressão gênica de MuRF-1 e

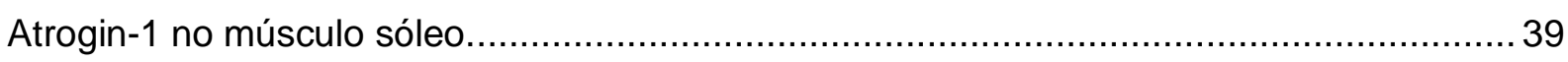

Figura 11-Efeito da suplementação do HMB sobre a expressão gênica de MuRF-1 e

Atrogin-1 no músculo EDL.

Figura 12-Efeito da suplementação do HMB sobre a expressão gênica do IGF-I muscular. 41

Figura 13-Efeito da suplementação do HMB sobre conteúdo do IGF-I hepático.

Figura 14-Efeito da suplementação do HMB sobre a expressão gênica e proteica da Akt no músculo SOL.

Figura 15-Efeito da suplementação do HMB sobre a expressão gênica e proteica da Akt no músculo EDL.

Figura 16-Efeito da suplementação do HMB sobre a expressão gênica e proteica da mTOR no músculo SOL.

Figura 17-Efeito da suplementação do HMB sobre a expressão gênica e proteica da mTOR no músculo EDL.

Figura 18-Efeito da suplementação do HMB sobre a expressão gênica e proteica da 4EBP-1 no músculo SOL.

Figura 19-Efeito da suplementação do HMB sobre a expressão gênica e proteica da 4EBP-1 no músculo EDL.

Figura 20-Efeito da suplementação do HMB sobre o conteúdo proteico da S6 no músculo

SOL.

Figura 21-Efeito da suplementação do HMB sobre o conteúdo protéico da S6 no músculo EDL.

Figura 22-Efeito da suplementação do HMB sobre o peso dos músculos Sóleo, EDL e gastrocnêmio.

Figura 23-Área de secção transversa (AST) do sóleo (SOL) .......................................... 59

Figura 24-Área de secção transversa (AST) do EDL.................................................. 60 
Figura 25-Resistencia a fadiga no músculo SOL 62

Figura 26-Resistencia a fadiga no músculo EDL. .64 


\section{LISTA DE TABELAS}

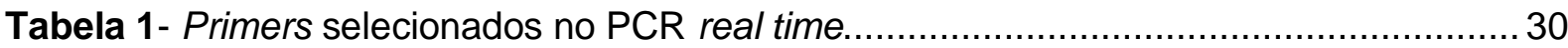

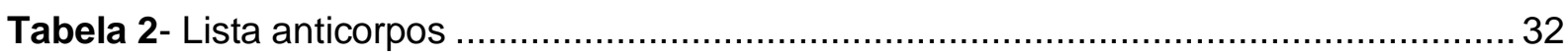

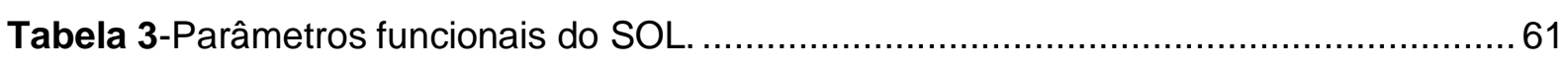

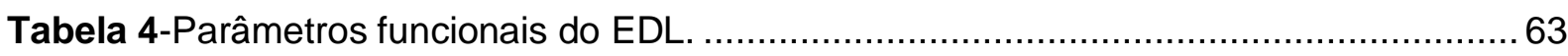




\section{LISTA DE ABREVIATURAS E SIGLAS}

HMB - beta-hidroxi-beta-metilbutirato

EDL - Extensor digital longo

SOL - Sóleo

GASTRO - gastrocnêmio

4E-BP1 - 4E Binding Protein 1

elF - Fator de iniciação eucariótico

EROs - Espécies Reativas de Oxigênio

GH - Hormônio do crescimento

IGF-I - Fator de crescimento semelhante à insulina I

mRNA - RNA mensageiro

mTOR - Mammalian target of rapamicin

MuRF-1 - Muscle Ringer Finger 1

PI3K - fosfatidil inositol 3 quinase

Ub - Ubiquitina

S6K - ribosomal protein S6 kinase

S6 - ribosomal protein S6

GSK-3 - glicogênio sintase quinase - 3

$\mathrm{KIC}$ - a-cetoisocaproato

FoxO - Forkhead box $\mathrm{O}$ 


\section{SUMÁRIO}

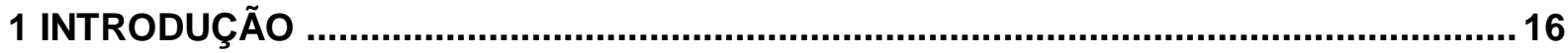

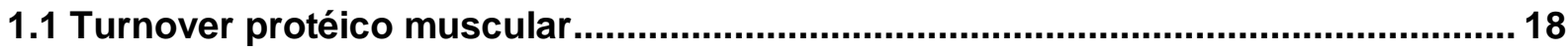

1.2 Controle traducional da síntese protéica .................................................................... 19

1.3 Vias de degradação protéica................................................................................. 21

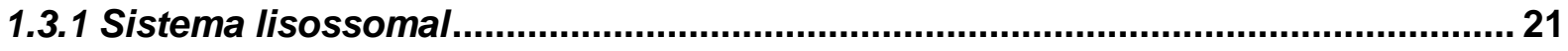

1.3.2 Proteases ativadas por cálcio .............................................................................. 21

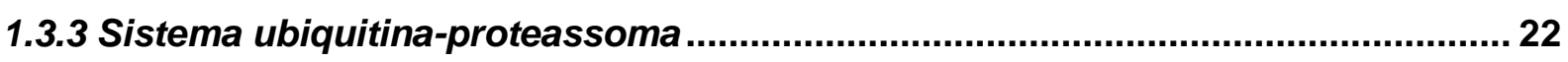

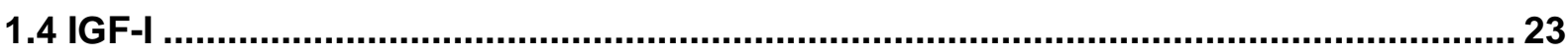

1.5 HMB e metabolismo protéico muscular ............................................................. 24

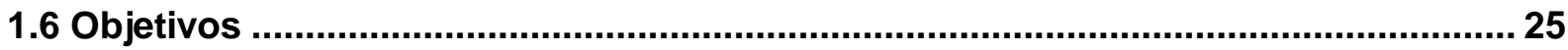

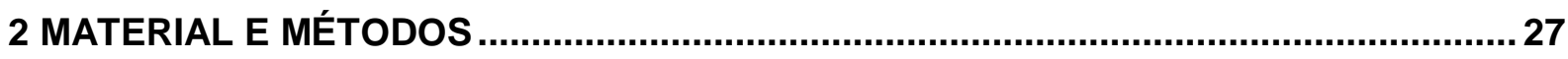

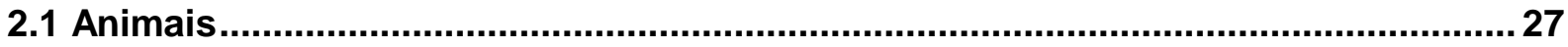

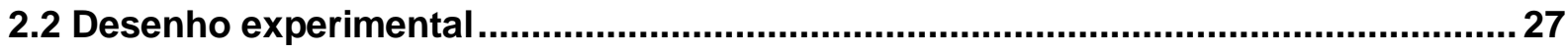

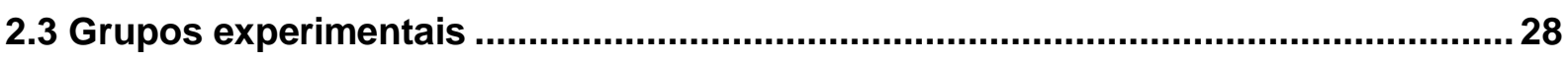

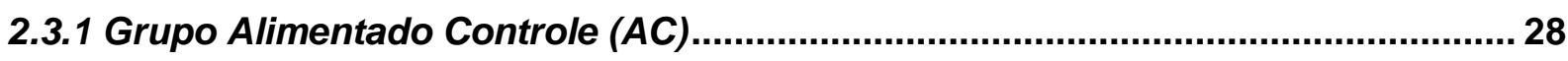

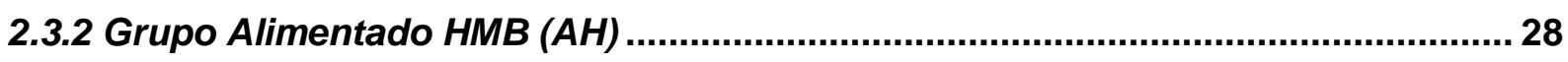

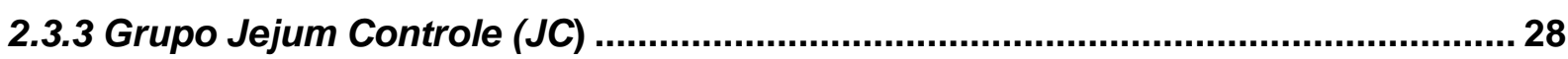

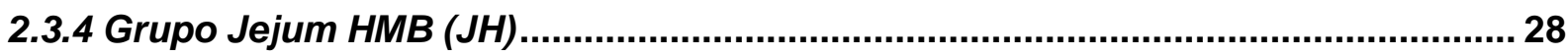

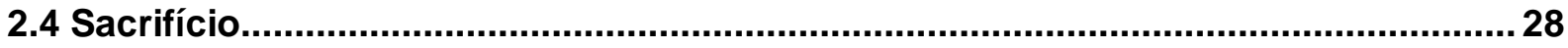

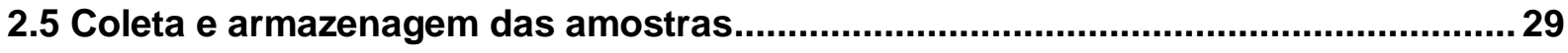

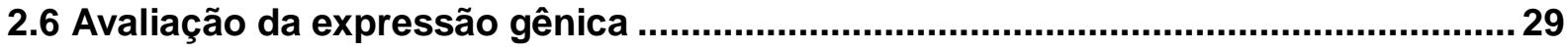

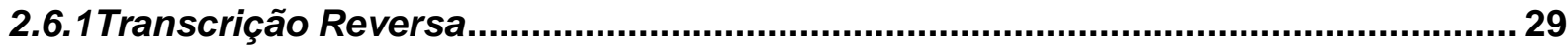

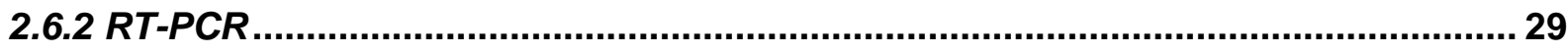

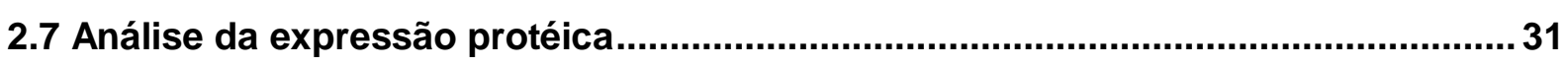

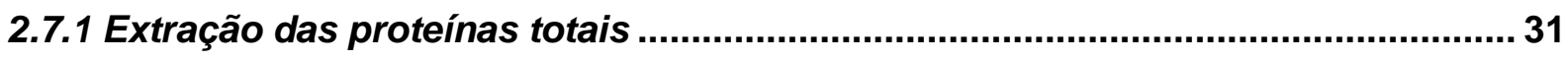

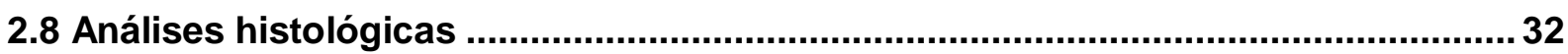

2.9 Análise, in vivo, da força e das propriedades contráteis do músculo esquelético 33

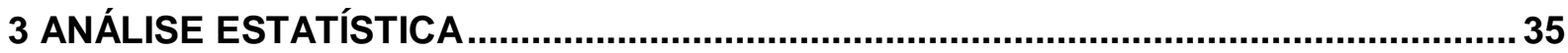

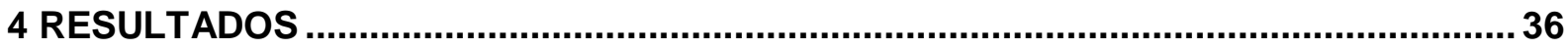

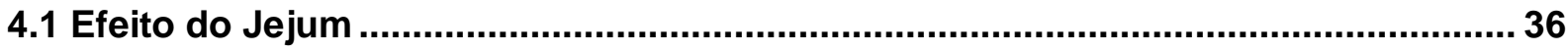

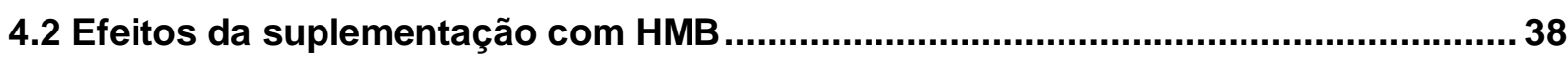

4.2.1 Expressão gênica das ubiquitinas-ligases.......................................................... 38

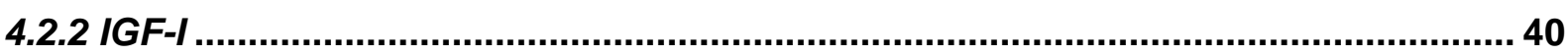

4.2.3 Proteínas das sinalização da síntese proteica...................................................... 42 
4.2.4 Parâmetros morfométricos 56

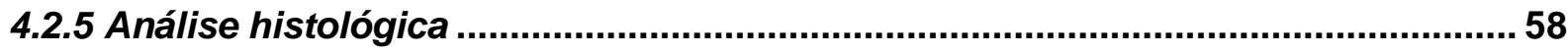

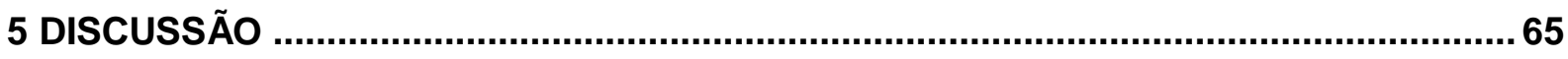

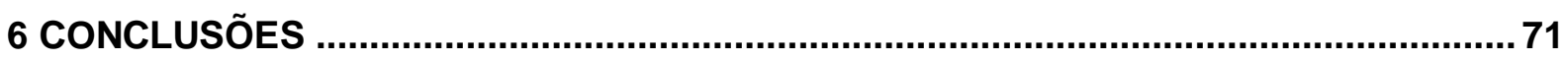

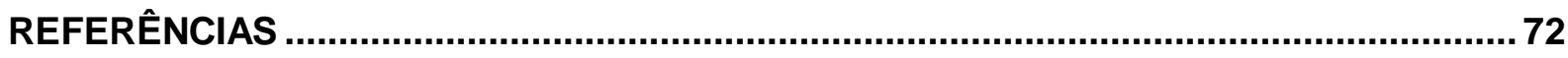

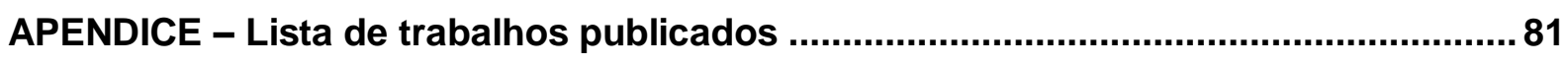




\section{INTRODUÇÃO}

Recentemente, aminoácidos como leucina e seu metabólito a-cetoisocaproato (KIC), conhecidos como anticatabólicos (1), vêm retornando ao foco de vários estudos. Observouse que esses compostos, ou ainda, um subproduto do metabolismo dele, promovem inibição da proteólise muscular em ratos, levando à diminuição da perda urinária de nitrogênio e de proteínas (2). Nissen et al. (3) sugeriram ser o beta-hidroxi-beta-metilbutirato (HMB) o responsável por esses efeitos, já que a utilização de inibidores da transaminação da leucina, processo pelo qual é gerado o HMB, levou à supressão da inibição da degradação protéica (4). Vale ressaltar que outros aminoácidos de cadeia ramificada (BCAAs), como isoleucina ou valina, bem como seus metabólitos, não promoveram esses efeitos, reforçando a possibilidade de que o HMB seja o elemento chave para o desencadeamento dos efeitos citados (5). O aumento da síntese protéica também tem sido associado a esse metabólito, o qual vem sendo empregado no tratamento de pacientes que apresentam caquexia (6), na prevenção da sarcopenia (7), ou mesmo para maximizar os ganhos de massa muscular durante os exercícios $(8,9)$, situações em que o controle fino entre síntese e degradação protéica parece ser afetado pelo metabólito.

Efeitos diretos do HMB inibindo proteólise ( $80 \%)$ e elevando a síntese protéica ( 20\%) foram evidenciados em secções de músculo esquelético de ratos e frangos, incubadas com várias concentrações do HMB (10). Outro estudo de Nissen et al. (3) demonstrou que indivíduos submetidos a treinamento por meio de exercício de força e HMB apresentaram redução de $20 \%$ na concentração de 3 metil histidina (3-MH) na urina e de 20 a $60 \%$ na concentração e atividade de enzimas que são indicadores plasmáticos de proteólise/dano muscular, como a creatina quinase.

Estudos mais recentes mostraram que a suplementação de HMB (11), associada à caquexia, produz um efeito atenuante sobre a degradação e estimulante sobre a síntese protéica, por múltiplos fatores intracelulares relacionados à maquinaria gênica. Essa é uma das razões pelas quais o $\mathrm{HMB}$, associado a arginina e glutamina, vem sendo utilizado na clínica $(6,12)$, observou-se ainda efeitos positivos da associação de HMB, arginina e lisina sobre parâmetros funcionais e ganho de massa muscular em idosos (7). O conjunto desses dados indica, portanto, que o HMB, por diminuir a proteólise e/ou estimular a síntese protéica, pode prevenir ou reduzir o dano muscular consequente a estados de disfunção metabólica em que há grande perda de peso ou ao trabalho muscular intenso.

Esse metabólito da leucina é gerado quando esta sofre transaminação reversível em $\alpha-K I C$, processo que ocorre, principalmente, em tecidos extra-hepáticos (13). O a-KIC pode, então, seguir dois caminhos. No primeiro, ocorre a conversão em HMB por uma reação enzimática no citossol, em que atua a KIC dioxigenase (14), enzima citossólica que difere da 
forma mitocondrial, a KIC desidrogenase $(14,15)$. Essa via de formação de HMB é direta e depende da KIC dioxigenase do fígado. No citossol o HMB é primeiro convertido para betahydroxy-beta-methylglutaryl-CoA (HMG-CoA), sendo então destinado para síntese de colesterol (16) (Fig.1). Na outra via, o a-KIC, no fígado, gera isovaleril-CoA, por meio de uma reação enzimática em que atua a a-cetoácido desidrogenase de cadeia ramificada (branched-chain ketoacid dehydrogenase - BCKD), seguindo-se uma série de reações nas quais é gerada HMG-CoA por meio da enzima HMG-CoA-sintase. No entanto em condições normais, a maioria do $\alpha-K I C$ é metabolizado em HMB que, no fígado, é convertido à HMGCoA, que é direcionado à biossíntese de colesterol. Acredita-se que essa conversão à colesterol possa ser eficaz para reparação rápida das células musculares danificadas (Fig. 3).

Figura 1-Síntese e metabolismo do HMB.

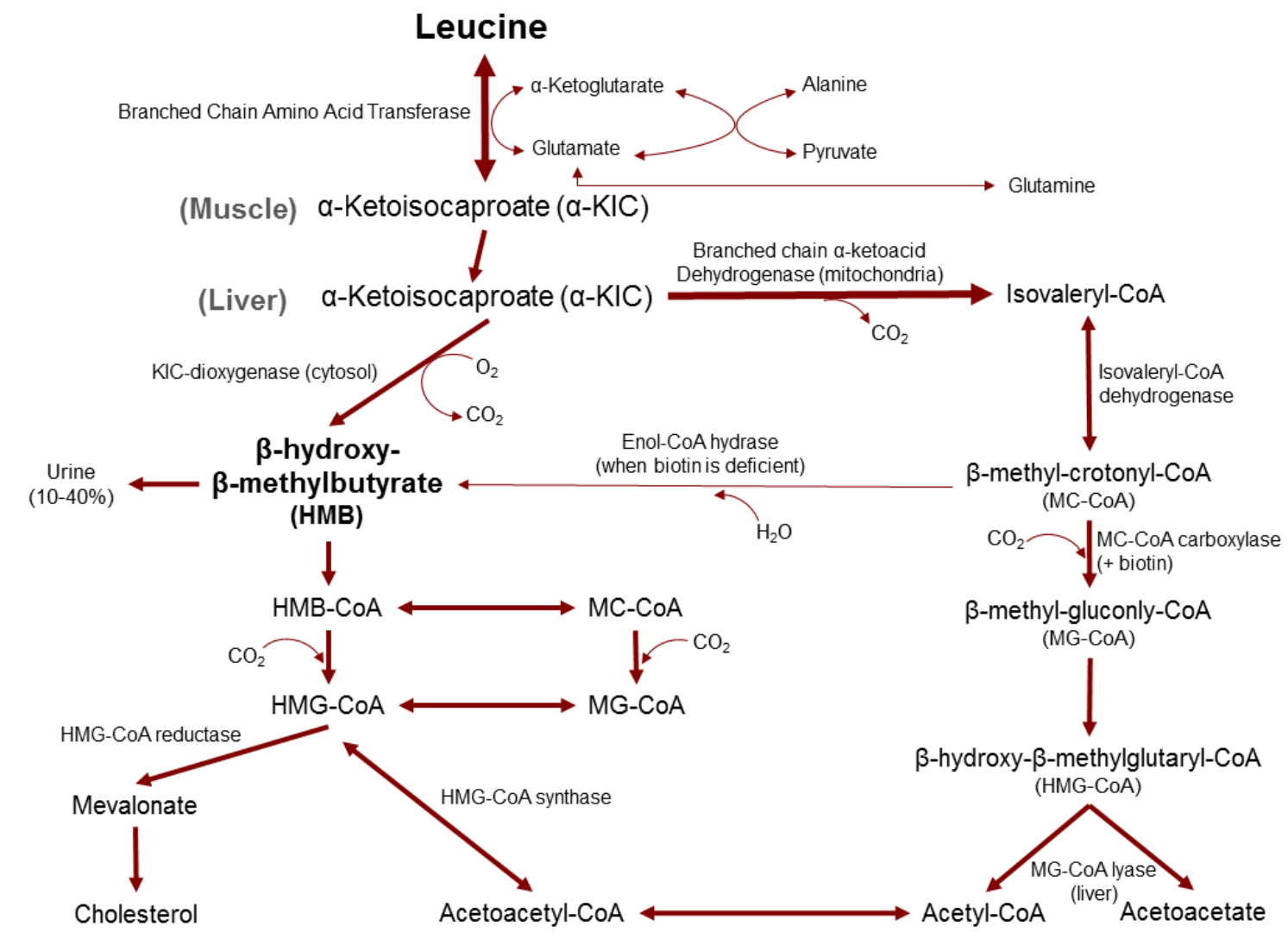

Fonte: (Zanchi et al., 2003) (17).

A produção endógena de HMB é pequena. Um indivíduo de $70 \mathrm{~kg}$ produz cerca de 0,2 - 0,4 g de HMB/dia, a partir do teor de leucina da dieta. Apesar de o fígado ser 0 principal sítio de produção de HMB, por apresentar maior atividade da dioxigenase, estudos 
com homogeneizados e perfusatos também indicam que o músculo e outros tecidos produzem HMB, embora em baixas quantidades (10).

O HMB ainda se encontra presente em alimentos, tais como, frutas cítricas, alguns peixes e no leite materno (3). Entretanto, embora ele possa ser encontrado na natureza, é muito difícil e impraticável conseguir uma base regular de alimentos que forneça as quantidades requeridas para promover inibição da proteólise e ganho de massa muscular. Esta é a razão pela qual a suplementação com HMB tem sido utilizada como alternativa para os praticantes de exercícios de força/musculação, para indivíduos sob extremo estresse muscular, na velhice, ou ainda por portadores de doenças associadas a síndromes de perda muscular, como o câncer (18).

\subsection{Turnover protéico muscular}

Sabe se que a musculatura esqueletica possui caracteristicas distintas quanto a sua composição e função. Alguns músculos, como o sóleo (SOL), expressam predominantemente a isoforma I da cadeia pesada da miosina (MHC-I), que apresenta baixa atividade ATPásica, o que lhes confere menor velocidade de contração, e elevada expressão de mioglobina e enzimas mitocondriais, o que thes confere elevada capacidade oxidativa (19). Essas características fazem com que o SOL seja considerado um músculo de contração lenta e oxidativo. Outros músculos, como o extensor digital longo (EDL), expressam mais a MHC-II, isoforma que apresenta elevada atividade ATPásica, o que lhes confere maior velocidade de contração, e enzimas da via glicolítica; por outro lado apresentam baixa expressão de mioglobina e de enzimas oxidativas, bem como poucas mitocôndrias (19), razões pelas quais são conhecidos como músculos de contração rápida e glicolíticos. Ainda há músculos que expressam MHCII e enzimas oxidativas, sendo conhecidos como músculos e contração rápida e oxidativos (19).

Considerando essas variabilidades, a visão do balanço entre síntese e degradação controlando o turnover proteico que é colocada na literatura de forma genérica, torna-se simplista, pois os diferentes tipos de músculos certamente respondem aos diversos desafios com relação ao turnover protéico de maneira distinta.

Nesse sentido, Li e Goldberg (20) ${ }^{1}$ mostraram que a privação de nutrientes é menos deletéria para os músculos lentos, como o sóleo (SOL) do que para os rápidos, como o EDL.

20 apud Schiaffino S, Dyar KA, Ciciliot S, Blaauw B, Sandri M. Mechanisms regulating skeletal muscle growth and atrophy. FEBS J. 2013 Mar 21. doi: $10.1111 /$ febs. 12253 . 
Essa diferença possivelmente ocorreria devido a sensibilidade distinta entre os músculos (SOL menos sensível) frente ao cortisol, hormônio que induz degradação protéica $(21)^{2}$.

Estudos em ratos demonstraram que o tratamento com corticosteróide, por 11 dias, promoveu atrofia em fibras $2 \mathrm{~B}$ e $2 \mathrm{X}$ (fibras rápidas e glicolíticas), sem repercussões sobre fibras $2 \mathrm{~A}$, rápidas e oxidativas, e fibra I, lenta e oxidativa (22), o que demonstra que esse modelo de proteólise foi capaz de induzir a degradação proteica de maneira distinta, e de forma mais proeminente sobre as fibras rápidas. Ainda, estudos de Goldberg utilizando modelos de hipertrofia em sóleo de ratos hipofisectomizados identificaram diminuição da degradação proteica, bem como aumento da síntese proteica, e quando os mesmos animais eram tratados com Hormônio do Crescimento $(\mathrm{GH})$ observaram aumento da taxa de síntese protéica sem qualquer alteração sobre a taxa de degradação protéica (23) ${ }^{3}$.

Assim, estudos apontam que músculos lentos e rápidos diferem quanto as suas taxas de síntese e degradação protéica e que os diferentes modelos, sejam de indução da síntese proteica ou de degradação proteica, atingem os diferentes tipos de músculos de maneira distinta.

\subsection{Controle traducional da síntese protéica}

Alterações no conteúdo protéico muscular resultam de um desequilíbrio entre os processos de síntese e degradação protéica. Os processos de síntese de proteínas compreendem etapas que vão da transcrição gênica à tradução do mRNA, sendo esse ultimo um passo fundamental e complexo que se divide em três etapas: a) iniciação, na qual o metionil-tRNA iniciador (met-tRNAi - RNA transportador contendo o primeiro aminoácido, Metionina, da cadeia polipeptídica a ser formada) e o mRNA são ligados às subunidades ribossomais $40 S$ e 60S; b) alongamento, o passo no qual os aminoácidos são incorporados à cadeia peptídica nascente; e c) término, quando o peptídeo completo é liberado do ribossomo. Esses processos dependem de proteínas conhecidas como fatores de iniciação eucarióticos (elFs), fatores de alongamento e fatores de liberação $(24,25)$.

A tradução é um processo que envolve a interação de pelo menos 12 fatores de iniciação, met-RNAi, mRNA, subunidades ribossomais e nucleotídeos ATP e GTP (24). Dos passos descritos dois são reguladas de forma importante. No primeiro a ligação do mettRNAi à subunidade ribossomal $40 \mathrm{~S}$ é mediada pelo elF2 e regulada por modificações na

\footnotetext{
21 apud Schiaffino S, Dyar KA, Ciciliot S, Blaauw B, Sandri M. Mechanisms regulating skeletal muscle growth and atrophy. FEBS J. 2013 Mar 21. doi: $10.1111 /$ febs. 12253 .

23 apud Schiaffino S, Dyar KA, Ciciliot S, Blaauw B, Sandri M. Mechanisms regulating skeletal muscle growth and atrophy. FEBS J. 2013 Mar 21. doi: $10.1111 /$ febs. 12253 .
} 
atividade de troca de guanina-nucleotídeo da elF2B. A segunda etapa regulatória ocorre ligação do mRNA à subunidade $40 \mathrm{~S}$ envolvendo a proteína elF4. Lembrando que o grau de fosforilação de fatores como elF4E, elF4G e 4E-BP1 controlam os passos da iniciação (24).

Figura 2-llustração das fases de iniciação da tradução.

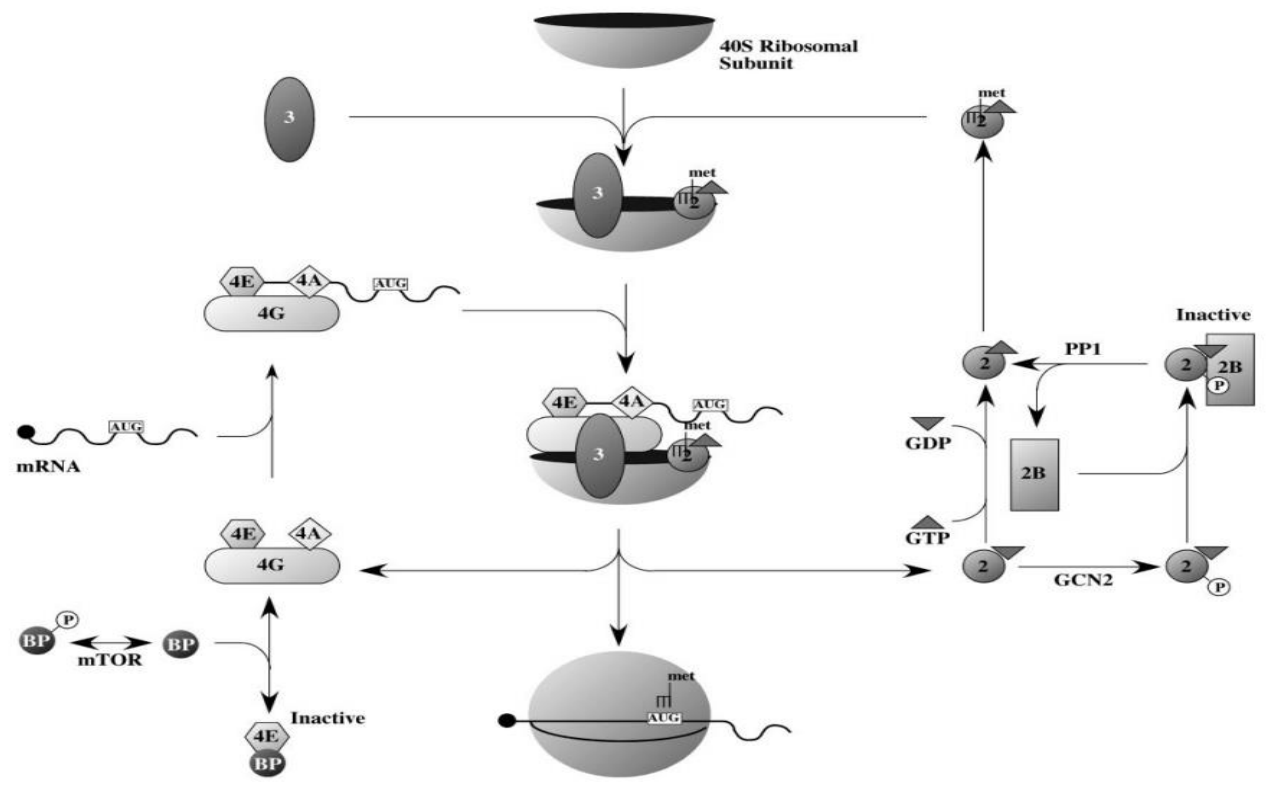

A figura ilustra os passos da iniciação da tradução que envolvem a ligação de metionil-tRNAi (met) e mRNA na subunidade $40 S$ dos ribossomas. Os fatores de iniciação de tradução que participam nas fases individuais são descritos como formas geométricas diferentes e são marcadas com um número ou letra e com base na identidade do fator. Por exemplo, o fator de iniciação eucariótico (elF) elF4E é descrito como um hexágono com o rótulo $4 \mathrm{E}$ no centro da forma. Além disso, a regulação da atividade elF2B por fosforilação da subunidade alfa da elF2 e o sequestro de elF4E por elF4E binding protein-1 (4E-BP1) estão ilustradas. mTOR, mammalian target of rapamycin; AUG, (adenosina, uridina, guanosina); GCN2, controle geral da não repressão, elF2a, protein kinase 2. Fonte: (Kimball et al., 2002) (25).

Demonstrou-se que, em ratos diabéticos ocorre uma redução na taxa de síntese protéica muscular em consequência da diminuição da iniciação da tradução. Provavelmente isso ocorre devido a uma diminuição na atividade da elF2B, bem como a inibição da ligação do mRNA ao complexo de iniciação 43S, pela menor fosforilação da 4E-BP1, com diminuição da disponibilidade de elF4E ativa; esse processo é revertido totalmente com o tratamento de insulina, que restabeleceu os valores da taxa de tradução próximos aos do 
grupo controle (25). Sabe-se que a administração de aminoácidos, hormônios e o treinamento de força acionam vias de sinalização que ativam os fatores de iniciação da tradução, gerando um aumento na taxa de síntese protéica (25). Assim, possíveis alterações sobre esse fino processo podem levar a um aumento na taxa de síntese proteica, resultando em uma hipertrofia, ou até a uma redução nessa taxa, gerando uma atrofia muscular.

O conteúdo protéico muscular pode ainda ser alterado por meio de ativação/inativação de vias envolvidas na proteólise, na qual se encontram envolvidos três mecanismos, que a seguir descreveremos sucintamente.

\subsection{Vias de degradação protéica}

\subsubsection{Sistema lisossomal}

O sistema lisossomol foi o primeiro sistema proteolítico descoberto e contribui de forma importante para a proteólise em diversos processos. Sabe-se que ele é parte do sistema endocítico da célula responsável pela degradação de proteínas. Seu interior apresenta uma acidez elevada $(\mathrm{pH} 4,5)$ e diversas enzimas digestivas, responsáveis por digerir proteínas extracelulares e de membrana endocitada. No músculo, várias proteases lisossomais são expressas, como as catepsinas B, H, L e D (24). Corroborando esses dados, Lowell e colaboradores (26) em um estudo clássico com músculos de ratos jejuados por $24 \mathrm{~h}$ e incubados com inibidores de proteases lisossomais, não observaram qualquer alteração na proteólise total, sugerindo assim que essa via teria pouca ou nenhuma participação no processo proteolítico muscular.

\subsubsection{Proteases ativadas por cálcio}

Este sistema depende da ação de cisteína-proteases ativadas por cálcio, denominadas calpaínas (27). Existem ao menos seis isoformas delas no músculo esquelético, sendo duas as principais: a microcalpaina ( $\mu$-calpaína) e a milicalpaína ( $m$ calpaína) (28), que, embora possuam duas subunidades e várias propriedades similares, são produtos de genes distintos. A diferença entre estas isoformas está relacionada à concentração e afinidade dos íons cálcio necessárias para a sua ativação. Esta denominação faz referência à concentração de cálcio necessária para sua ativação.

No entanto, essas isoformas precisam se tornar ativas para exercerem seus efeitos. Essa ativação é modulada pela sensibilidade das calpaínas ao cálcio citossólico (29), 
processo esse chamado de autoproteolítico. Importante ressaltar que as células possuem um inibidor endógeno dessa protease, que é a calpastatina $(30,31)$.

Estudo com desuso de 10 dias em animais que superexpressam o gene da calpastatina mostrou uma redução na perda da massa muscular do sóleo de apenas aproximadamente $30 \%$ (28), o que indica que as calpaínas não se mostraram eficientes em degradar todas as classes de proteínas sarcoméricas (31), demonstrando a importância de outros mecanismos proteolíticos nesse processo.

\subsubsection{Sistema ubiquitina-proteassoma}

Sabe-se que esse é o principal mecanismo envolvido na quebra de proteínas miofibrilares (32). Demonstrou-se que em modelos de inibição desse sistema frente a condições de proteólise, tais como desnervação e sepse, ocorreu atenuação desse quadro, caracterizando assim a importância desse mecanismo no estado de proteólise muscular intenso (33).

Esse sistema envolve a participação de um complexo enzimático citossólico chamado proteassoma, composto de duas subunidades regulatórias (19S) e uma catalítica (20S), que é ativado na presença de ATP, diferentemente dos outros processos proteolíticos (34).

Os substratos protéicos destinados à degradação pelo proteassoma são marcados por um componente de 76 aminoácidos, chamado ubiquitina (35). As ubiquitinas E1, conhecidas como ativadoras, e a E2, chamadas de conjugadoras, têm a função de preparar esse complexo, enquanto a E3 (chamadas ub-ligases), enzima chave desse sistema, identifica a proteína destinada ao complexo proteolítico proteassoma $(35,36)$. Importante ressaltar que existe apenas uma proteína E1, algumas E2 e cerca de milhares de E3. No entanto, essas ultimas conferem especificidade ao complexo (36) e se mostram importantes no processo de atrofia muscular; entre essas estão a: atrogin-1 (MAFbx), MuRF-1 e E3a (37, 38).

Sabe-se que o sistema ubiquitina-proteassoma não é capaz de hidrolisar as proteínas miofibrilares de maneira direta, necessitando da mediação da caspase-3, (30), a qual cliva essas proteínas em peptídeos menores ( $14 \mathrm{kDa})$, sendo assim possível serem destinadas ao proteassoma (39).

O sistema ubiquitina-proteassoma também está relacionado à degradação de uma série de proteínas anormais que sofreram, dentre outras coisas, mutações, oxidações e desnaturações (34). 
Em paralelo aos mecanismos que induzem proteólise muscular, há mecanismos envolvidos com o aumento de síntese protéica. Dentre esses fatores vamos destacar o IGFI.

\subsection{IGF-I}

O IGF-I apresenta uma estrutura similar à molécula de pró-insulina, mas difere da insulina na sua regulação, receptores e efeitos biológicos. É produzido na maioria dos tecidos e exportado para as células vizinhas, agindo de maneira parácrina/autócrina. Dessa forma, este fator de crescimento atua praticamente em quase todas as células do organismo, promovendo efeitos generalizados sobre o ganho de massa muscular e reparação (40), por meio do aumento da replicação de células satélites, consequentemente, do número de mionucleos, evidenciado pelo aumento do conteúdo total de DNA (41). Estudos em ratos com inativação tecido- especifica do receptor do IGF-I prejudicou o crescimento muscular e reduziu o número e tamanho das fibras, bem como a função muscular (42).

Estudos in vitro em miotubos em modelo de hipertrofia induzida por IGF-I mostraram ser o efeito hipertrófico dependente da via da PI3K/Akt, e da subsequente ativação da via da mTOR (43), proteína essa capaz de ser ativada pelo aminoácido leucina (44) do qual o HMB é um metabolito. A ativação dessa via é importante para os processos de iniciação de tradução, assim como para a p70s6k e a 4E-BP1, citadas anteriormente. Sabe-se ainda, que um importante inibidor seletivo da via da mTOR, a rapamicina, mostrou-se eficaz em bloquear os mecanismos de síntese proteica, em modelos de indução de aumento da síntese (38).

Ainda, a administração desse fator de crescimento em animais jejuados provocou redução da expressão dos atrogenes, como atrogin-1 e MuRF1, relacionadas à proteólise. O efeito do IGF-I em atenuar a expressão desses genes também foi observado em modelos in vitro de indução proteólise (45). Portanto, além dos seus efeitos sobre vias especificas relacionadas ao aumento da síntese protéica, o IGF-I exerce um importante papel sobre a inibição da proteólise por ser capaz de ativar Akt e esta ser capaz de reter a Foxo1 e 3 no citossol, impedindo que esta migre para o núcleo e ative a transcrição de genes relacionados a proteólise, como atrogin-1 e MuRF1 (46).

Estudos com camundongos desnervados que superexpressam IGF-I muscular mostraram redução ( 30\%) na atrofia muscular quando comparados com os controles (47); 
ainda, verificou-se que a administração desse fator de crescimento em animais desnervados atenuou a proteólise mantendo a capacidade funcional contrátil (48).

No entanto, estudos de Yakar et al. (49) identificaram, por meio de uma deleção especifica do gene do IGF-I hepático em camundongos, que estes apresentavam uma redução nos níveis séricos de IGF-I em comparação aos controles, sem que fossem observadas alterações no seu crescimento e desenvolvimento, mostrando assim que esse fator de crescimento exerce seus maiores efeitos sobre o controle da síntese protéica quando produzido localmente.

\subsection{HMB e metabolismo protéico muscular}

Resultados de estudos desenvolvidos no nosso laboratório demonstraram que ratos tratados com HMB, por 30 dias, apresentam aumento da atividade do eixo somatotrófico, caracterizado por aumento da expressão gênica e protéica de $\mathrm{GH}$ na hipófise, da expressão hepática de mRNA de IGF-I, e da sua concentração sérica, sendo os últimos dois parâmetros reconhecidamente apontados como dependentes do aumento da secreção de GH (50). A relação do HMB com o eixo somatotrófico também foi observada por Tatara et al. (51) que tratou porcas durante a gestação com HMB e observou que a prole apresentou aumento da atividade deste eixo.

Estudos com indução de proteólise em miotubos tratados com HMB mostraram a eficiência desse metabólito em atenuar o aumento da expressão de atrogenes, bem como em ativar a síntese proteica via PI3k/Akt (7). Outros estudos, em que foram utilizados animais intactos e com sepse, a fim de induzir proteólise, evidenciaram um efeito do HMB de atenuação sobre a proteólise em comparação com os animais intactos, via sistema ubiquitina-proteassoma, sem que efeitos sobre a síntese fossem detectados. Esses efeitos foram encontrados somente no músculo sóleo (52). O tratamento crônico com esse suplemento promoveu uma atenuação da redução do tamanho das células musculares que ocorre em função da idade, em jovens adultos e idosos, bem como do aumento da expressão dos atrogenes (53). Recentes estudos evidenciaram uma melhora no quadro de perda de massa muscular em idosos acamados tratados com HMB, bem como na reabilitação muscular dos mesmos (54).

Em suma, há evidências de que esse metabólito age sistemicamente, bem como diretamente sobre a musculatura esquelética, exercendo seus efeitos anabólicos e anticatabólicos sobre o metabolismo protéico.

Essas ações poderiam envolver a redução da atividade do sistema ubiquitinaproteasoma, responsável pela degradação de proteínas $(53,55,56)$; ou ainda uma a 
ativação de vias intracelulares especificas, como mTOR e fosforilação da p70S6k e 4EBP1, aumentando a síntese e inibindo a degradação protéica $(11,56,57)$, efeitos que poderiam ser melhor caracterizados em modelo experimental de jejum alimentar, onde intensa proteólise é evidenciada nas primeiras 24 horas.

Figura 3-Resumo das ações descritas para o HMB.

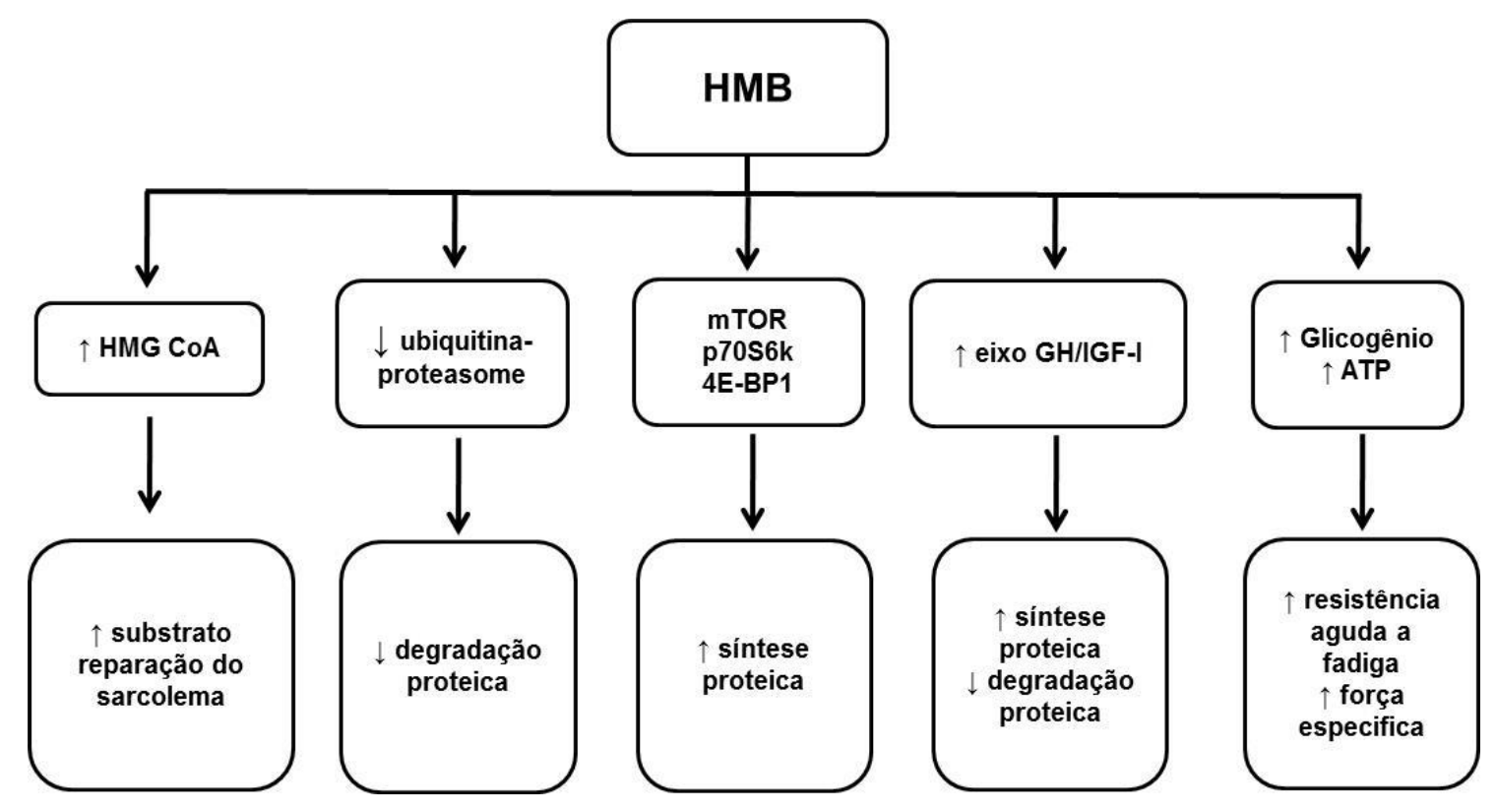

Fonte: Adaptado de Hermano et al. 2013 (58).

\subsection{Objetivos}

Sabe-se que a atrofia muscular é induzida em diversas situações como no câncer, caquexia, AIDS, imobilização, envelhecimento e jejum, circunstâncias em que o processo de perda de massa muscular está diretamente relacionado à qualidade de vida e à sobrevida dos indivíduos. Desta maneira, possíveis intervenções farmacológicas, nutricionais ou terapêuticas se tornam importantes para diminuir a morbidade em situações de intenso catabolismo protéico muscular.

O presente estudo teve como objetivo avaliar a influência da administração crônica do beta-hidroxi-beta-metilbutirato (HMB) de ratos alimentados e submetidos ao jejum de 24 horas, sobre:

- o sistema ubiquitina proteassoma da musculatura esquelética, através da expressão genica dos atrogenes; 
- as vias especificas da sinalização celular envolvidas na síntese proteica muscular (Akt, mTOR, 4E-BP1 e S6);

- os parâmetros morfométricos, bem como histológicos da musculatura;

- a função contrátil dos músculos estudados. 


\section{MATERIAL E MÉTODOS}

\subsection{Animais}

Foram utilizados ratos Wistar (200-250 g) provenientes do biotério do Instituto de Ciências Biomédicas da USP, onde foram mantidos em gaiolas coletivas (máximo de 5 animais por gaiola) sob condições padronizadas de temperatura ambiental $\left(23 \pm 1^{\circ} \mathrm{C}\right) \mathrm{e}$ ciclo claro/escuro (12/12 horas diárias). A água e alimentação foram fornecidas ad libitum.

\subsection{Desenho experimental}

Inicialmente os animais foram separados nos grupos controle e tratado, sendo este último submetido por 29 dias à administração de $320 \mathrm{mg} / \mathrm{Kg}$ de peso corporal de HMB, diluídos em $1 \mathrm{ml}$ de salina, e o controle tratado com veiculo (salina) por via sonda intragástrica (gavagem).

No vigésimo oitavo $\left(28^{\circ}\right)$ dia, uma parcela dos animais de ambos os grupos foi separada para ser submetida a um período de jejum de 24 horas, a fim de induzir proteólise muscular. $O$ jejum teve seu inicio as 8:00 horas da manhã do vigésimo oitavo dia, se estendendo por 24 horas. Durante esse período ainda foi realizada uma gavagem em ambos os grupos, conforme ilustrado na fig.4. Esse estudo foi aprovado pela Comissão de Ética no Uso de Animais (CEUA) conforme certificado número 93, folha 106 do livro 02.

Figura 4-Desenho experimental.

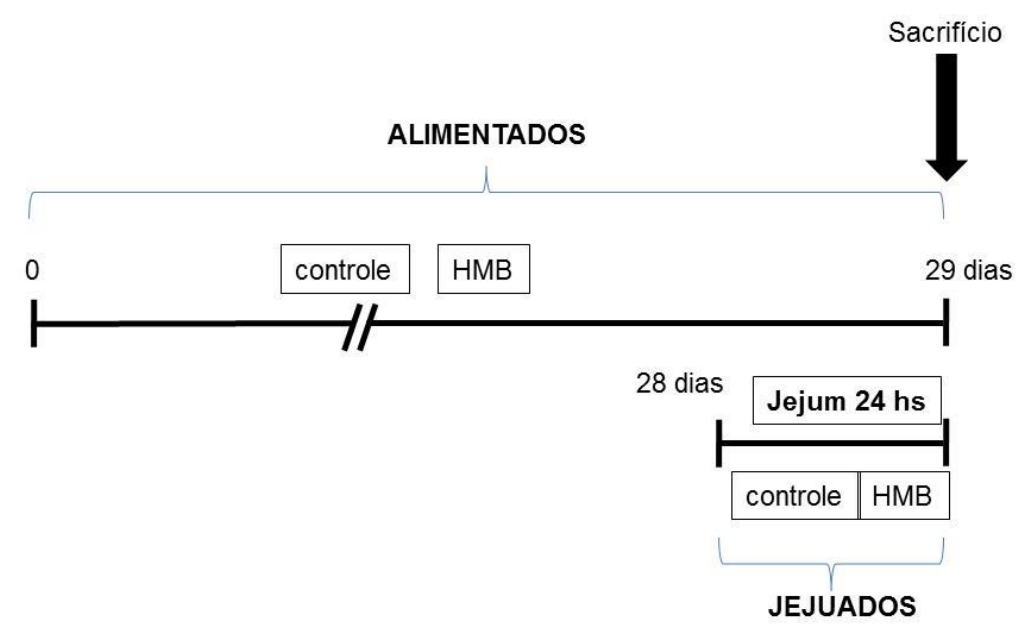




\subsection{Grupos experimentais}

\subsubsection{Grupo Alimentado Controle (AC)}

Grupo constituído de animais que receberam $1 \mathrm{~mL}$ de salina, via sonda intragástrica (gavagem), por 29 dias, sempre no mesmo horário (14 h).

\subsubsection{Grupo Alimentado HMB (AH)}

Constituído de animais que receberam suplementação de HMB (320 mg/Kg de peso corporal) dissolvido em $1 \mathrm{~mL}$ de salina, via sonda intragástrica (gavagem), pelo mesmo período (29 dias).

\subsubsection{Grupo Jejum Controle (JC)}

Constituído de ratos que receberam $1 \mathrm{~mL}$ de salina, via sonda intragástrica (gavagem), por 28 dias, seguindo-se um jejum de 24 horas.

\subsubsection{Grupo Jejum HMB (JH)}

Constituído de ratos que receberam suplementação de HMB $(320 \mathrm{mg} / \mathrm{Kg}$ de peso corporal) dissolvido em $1 \mathrm{~mL}$ de salina, via sonda intragástrica (gavagem), por 28 dias, seguindo-se um jejum de 24 horas, período em que se manteve o tratamento.

\subsection{Sacrifício}

Os animais foram sacrificados por decapitação, após um período de restrição alimentar de 2 horas, no vigésimo nono (29) dia após o inicio do tratamento, sempre às 8 h, critérios esses estabelecidos para minimizar os efeitos de variações circadianas nos parâmetros avaliados. 


\subsection{Coleta e armazenagem das amostras}

Tecidos como o fígado e os músculos sóleo (SOL) e extensor digital longo (EDL) da pata direita foram rapidamente removidos, imediatamente colocados em solução apropriada para extração de RNA e, subsequentemente, homogeneizados e estocados no freezer $-80 \stackrel{\circ}{-} \mathrm{C}$.

Os músculos SOL, EDL e gastrocnêmico (GASTRO) da pata esquerda foram removidos e pesados, sendo os dois primeiros colocados em solução apropriada, para extração de proteínas totais, homogeneizados e estocados em freezer - $20 \stackrel{\circ}{\circ}$. Após a excisão dos músculos da tíbia esquerda, o comprimento máximo da mesma foi medido entre a eminência intercondilar e o maléolo medial utilizando um paquímetro (59), a fim de verificarmos a relação do peso dos músculos e comprimento da tíbia.

\subsection{Avaliação da expressão gênica}

A extração do RNA total foi realizada pela metodologia da guanidina-fenolclorofórmio e precipitação com isopropanol (60). A integridade do RNA foi confirmada pela verificação do padrão das bandas do RNA ribossomal $28 \mathrm{~S}$ e 18S, por eletroforese em gel de agarose $1 \%$, visualizado em luz ultravioleta.

\subsubsection{Transcrição Reversa}

As amostras de RNA foram tratadas com DNAse (RNase free DNase I - Invitrogen $N Z$ Ltd, Auckland, New Zealand), na presença de inibidor de RNAses, antes do Real TimePCR (RT-PCR), para eliminar qualquer resíduo de DNA genômico. Foram usadas $2 \mu \mathrm{g}$ do RNA total para a reação, adicionando-se: oligo dT (100 $\mu \mathrm{g} / \mathrm{mL}), 10 \mathrm{mM}$ de cada dNTP, 5X First-Strand buffer e $2 \mu \mathrm{l}$ de enzima (200U/ $\mu \mathrm{l})$ M-MLV Reverse Transcriptase (Promega). A reação de transcrição reversa foi realizada num ciclo de $65^{\circ} \mathrm{C}$ por10 min, seguido por $37^{\circ} \mathrm{C}$ por $60 \min$ e $10 \min$ a $95^{\circ} \mathrm{C}$.

\subsubsection{RT-PCR}

A técnica utilizada para estimar a abundância dos valores relativos dos mRNAs dos genes dos animais suplementados e jejuados tratados ou não com HMB foi baseada na detecção em tempo real do produto do PCR pela quantificação de fluorescência avaliada pelo detector de seqüência ABI Prism 7700 (Applied Biosystems, Foster City, CA, USA), 
baseado na metodologia corrente. As amplificações do RT-PCR foram executadas com $2 \mu \mathrm{l}$ do produto da reação de transcrição reversa, diluídos em um tampão de reação contendo: 5 $\mu$ S SYBR® Green PCR master mix e $900 \mathrm{nM}$ primers. Os primers foram otimizados para análise por Real time RT-PCR (temperatura de anelamento para todos os primers: $58^{\circ} \mathrm{C}$ ) e encontram-se listados abaixo (Tabela 1). Os ciclos foram constituídos de: duas fases a 50 ${ }^{\circ} \mathrm{C}$, por $2 \mathrm{~min}$, e $95{ }^{\circ} \mathrm{C}$, por $10 \mathrm{~min}$, seguidos por 45 ciclos de duas fases: $20 \mathrm{~s}$ de desnaturação a $95^{\circ} \mathrm{C}$ e 20 seg de anelamento a $58^{\circ} \mathrm{C}$.

Tabela 1- Primers selecionados no PCR real time.

\begin{tabular}{cc}
\hline Primers & Seqüência \\
\hline Sense: IGF-I & 5'-AAGCCTACAAAGTCAGCTCG - 3' \\
Antisense: IGF-I & 5'-GGTCTTGTTTCCTGCACTTC - 3' \\
Sense: Akt1 & 5'-GCCCAAGCACCGTGTGACCA-3' \\
Antisense: Akt1 & 5'-GCGACCTGTGGCCTTCTCCT-3' \\
Sense: mTOR & 5'-AGGGACCACTGTGCCAGAATCCA-3' \\
Antisense: mTOR & 5'-TGAGAGAAATCCCGACCAGTGAGC-3' \\
Sense: MuRF-1 & 5'TGACCAAGGAAAACAGCCACCAG 3' \\
Antisense: MuRF-1 & 5'TCACTCCTTCTTCTCGTCCAGGATGG 3' \\
Sense: Atrogin-1 & 5'TACTAAGGAGCGCCATGGATACT 3' \\
Antisense: Atrogin-1 & 5'GTTGAATCTTCTGGAATCCAGGAT 3' \\
Sense: GAPDH & 5'-GATGGGTGTGAACCACGAGAAA-3' \\
Antisense: GAPDH & 5'ACGGATACATTGGGGGTAGGA-3' \\
Sense: 4EBP1 & 5'-TCCCATGCAGGCCAGCCAGA-3' \\
Antisense: 4EBP1 & 5'ACTCTTCACCACCTGCCCGC-3' \\
\hline
\end{tabular}

O ponto inicial do ciclo (CT) do real-time RT-PCR foi avaliado em triplicata para cada amostra. Os valores de CT corresponderam ao número do ciclo do PCR e representaram a intensidade da fluorescência emitida pelo produto do RT-PCR amplificado do gene alvo e são inversamente proporcionais ao conteúdo de mRNA da amostra. O valor da variação de CT $(\triangle \mathrm{CT})$ foi calculado subtraindo-se o valor do CT dos genes de interesse do valor do CT do gene usado como controle interno. Para verificar a igualdade na quantidade de RNA total entre as amostras, todas elas foram normalizadas pela média da variação do valor de CT $(\Delta \mathrm{CT})$ dos animais controle, originando um valor chamado de $\Delta \Delta \mathrm{CT}$. A expressão relativa 
dos genes de interesse foi calculada usando-se a expressão $2^{-\Delta \Delta C T}$ e foram representadas em unidades arbitrárias (61).

\subsection{Análise da expressão protéica}

\subsubsection{Extração das proteínas totais}

Os músculos foram homogeneizados, utilizando o Polytron, a 25.000 rpm durante 30 segundos em tampão composto por cloreto de sódio $137 \mathrm{mM}$; cloreto de potássio 2,7 mM; cloreto de magnésio $1 \mathrm{mM}$; EDTA $1 \mathrm{mM}$; pirofosfato de sódio $5 \mathrm{mM}$; fluoreto de sódio 10 $\mathrm{mM}$; Triton X-100 1\%; glicerol 10\%; Tris pH 7,8 20 mM; PMSF (phenylmethanesulfonylfluoride) 0,2 $\mathrm{mM} ; \mathrm{Na}_{3} \mathrm{VO}_{4}$ (ortovanadato de sódio) 0,5 mM e PIC 1:100 (Protease Inhibitor Cocktail)

O homogeneizado foi transferido para um tubo de polipropileno, seguindo-se incubação por 15 minutos no gelo e centrifugação a $14.000 \mathrm{~g}$, por 40 minutos, a $4^{\circ} \mathrm{C}$. Após a centrifugação, o sobrenadante foi removido (fração citossólica), sendo utilizado para a dosagem de proteínas totais, pelo método de Bradford (Bio-Rad, Dye Reagent Concentrate). As amostras, então, foram submetidas à eletroforese em gel de poliacrilamida e transferidas (western blot) à membrana de nitrocelulose ou PVDF. Esta, após bloqueio em solução basal (10 mM Trizma, pH 7.5; $150 \mathrm{mM} \mathrm{NaCl}$; e $0.05 \%$ Tween 20) contendo albumina (5\%), por aproximadamente 2 horas, a fim de eliminar o aparecimento de bandas inespecíficas, foi incubada com anticorpo primário (Tabela 2) contra a proteína de interesse, seguindo-se 3 lavagens de 10 minutos cada com solução basal e incubação com o anticorpo secundário especifico por mais 1 hora. Após esse período, as membranas foram novamente lavadas 3 vezes por 10 minutos. A detecção das bandas foi obtida por quimioluminescência, após exposição em filmes de raios $X$ por tempo aproximado de 2 min.

Após análise das proteínas fosforiladas foi feito stripping das membranas (PVDF) para avaliação das respectivas proteínas totais. Para o stripping as membranas foram lavadas duas vezes por 10 minutos com solução basal, seguida de incubação em shaker por 30 minutos a $50^{\circ} \mathrm{C}$ com solução de stripping (Tris $6,25 \mathrm{mM}$, SDS $2 \%$ e beta-mercaptoetanol $100 \mathrm{mM}$ ) em seguida realizou se duas lavagens com solução basal por 5 minutos, seguindo novo período de bloqueio, e incubação com o anticorpo primário das proteínas totais, conforme descrito anteriormente.

A intensidade do sinal correspondente aos blots foi expressa em unidades arbitrárias (U.A.) após análise densitométrica (método semi-quantitativo), na qual a área correspondente ao sinal foi integrada usando o programa Phosphorlmage, sendo a 
intensidade relativa de cada banda avaliada pelo programa de imagem ImageQuant. (Molecular Dynamics, Sunnyvale, CA). As densidades das bandas foram normalizadas pelas membranas coradas com Ponceau.

Tabela 2- Lista anticorpos

\begin{tabular}{lc}
\hline \multicolumn{1}{c}{ Anticorpos Primários } & Anticorpos Secundários \\
\hline IGF-I $(1: 300)$ & Anti-mouse $(1: 5000)$ \\
Akt $(1: 1000)$ & Anti-rabbit $(1: 5000)$ \\
p-Akt Ser473 $(1: 1000)$ & Anti-rabbit $(1: 5000)$ \\
mTOR $(1: 500)$ & Anti-rabbit $(1: 5000)$ \\
p-mTOR Ser2448 $(1: 500)$ & Anti-rabbit $(1: 5000)$ \\
S6 $(1: 1000)$ & Anti-rabbit $(1: 5000)$ \\
p-S6 Ser240/244 $(1: 1000)$ & Anti-rabbit $(1: 5000)$ \\
4E-BP1 $(1: 1000)$ & Anti-rabbit $(1: 5000)$ \\
p-4E-BP1 Thr37/46 $(1: 1000)$ & Anti-rabbit $(1: 5000)$ \\
\hline
\end{tabular}

\subsection{Análises histológicas}

Para a realização das análises histológicas, uma parte dos músculos da pata esquerda de SOL e EDL foi retirada cuidadosamente do animal anestesiado e submersa em um tubo contendo isopentano, por aproximadamente 30 segundos, para crioproteção do tecido, o qual foi colocado em Nitrogênio Líquido e a seguir armazenado no freezer à - 80 ${ }^{\circ} \mathrm{C}$ até o seu processamento. Posteriormente, foram feitos cortes transversais nos músculos (12 $\mu \mathrm{m}$ de espessura) na sua região ventral usando um criostato (Jung Frigocut $2800 \mathrm{~N}$ Leica). As amostras foram, então, fixadas em lâminas histológicas de vidro, gelatinizadas e

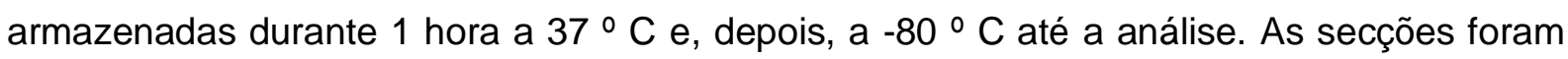
coradas com hematoxilina e eosina para exame da área da secção transversal da fibra (AST) (62). Os cortes foram fotografados usando um microscópio vertical (objetiva 5x) (Aristoplan) com a câmera (modelo ponto 1.3.0; instrumentos de diagnóstico, Sterling Heights, MI, EUA) controlada por um software (Spot Diagnostic versão 2.1; Diagnostic Instruments). Imagens digitalizadas foram analisadas de maneira duplo-cego usando um software (Image-Pro Plus). A AST mediana da fibra foi determinada pela medição da circunferência de não menos de 800 fibras adjacentes por animal, e 5 animais foram analisados em cada grupo. 


\subsection{Análise, in vivo, da força e das propriedades contráteis do músculo esquelético}

Foram avaliados, por eletro estimulação in vivo, a produção de força máxima, capacidade de contração e relaxamento dos músculos SOL e EDL. Detalhes da avaliação da função contrátil in vivo foram previamente descritos (63-66). Os animais foram anestesiados, via intraperitoneal, com pentobarbital $(75 \mathrm{mg} / \mathrm{Kg})$ e ambas as patas posteriores foram fixadas numa plataforma de acrílico. A pata estimulada foi colocada na plataforma com a articulação do quadril a um angulo de $60^{\circ}$ e a articulação do joelho a um anglo de 60․ . Um gancho foi colocado abaixo do tendão de Aquiles (Calcâneo) e conectado a um transdutor de força isométrica (Grass Technologies, West Warwick, Rhode Island, USA). A pele foi retirada e o nervo ciático acessado. Os músculos antagonistas foram tenotomizados, conforme apresentado na figura 5.

Figura 5-Foto ilustrativa da eletroestimulação in vivo .

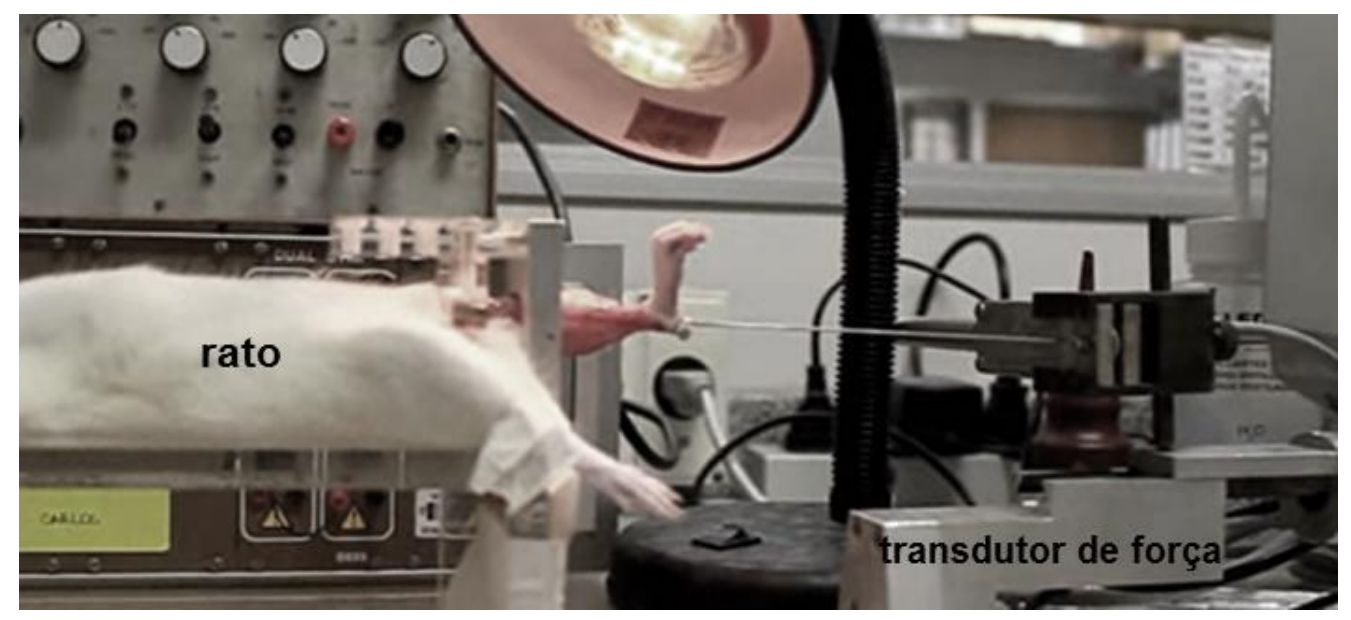

Contrações isotônicas máximas (abalos musculares) foram induzidas por eletro estimulação numa baixa frequência usando um eletrodo de platina colocado no nervo ciático. O comprimento de repouso $(L O)$ dos músculos avaliados foi ajustado para obter a tensão máxima (a articulação do tornozelo ao ângulo de aproximadamente $90^{\circ}$ ). Para a determinação do abalo da força muscular, foi utilizado o estímulo de $500 \mu$ s de duração do pulso a $1 \mathrm{~Hz}$ ajustado para produzir força máxima (Contração Máxima). Para determinação de força tetânica, a frequência da estimulação elétrica foi de $100 \mathrm{~Hz}$ (Força tetânica), conforme exemplificado na figura 6 . A força do abalo muscular (tensão máxima gerada durante a contração máxima) e a força tetânica (tensão máxima durante o tétano), bem 
como o tempo para atingir o pico da tensão máxima (tempo de duração entre 0 e $100 \%$ força - TP) e tempo de sustentação da força isométrica (tempo para perder $50 \%$ força TSF) foram registradas e analisadas usando software AqDados ${ }^{\circledR}$ (version 4.16, Lynx Tecnologia Eletrônica Ltda, São Paulo, Brazil).

Para avaliação do desempenho contrátil intermitente (isometria), determinamos a resistência à fadiga por meio da área sob a curva (força $x$ número de contrações) do decaimento da força ao longo de dez (10) contrações tetânicas sucessivas com intervalo de 10 segundos entre elas.

Figura 6-Representação das análises funcionais no músculo esquelético.
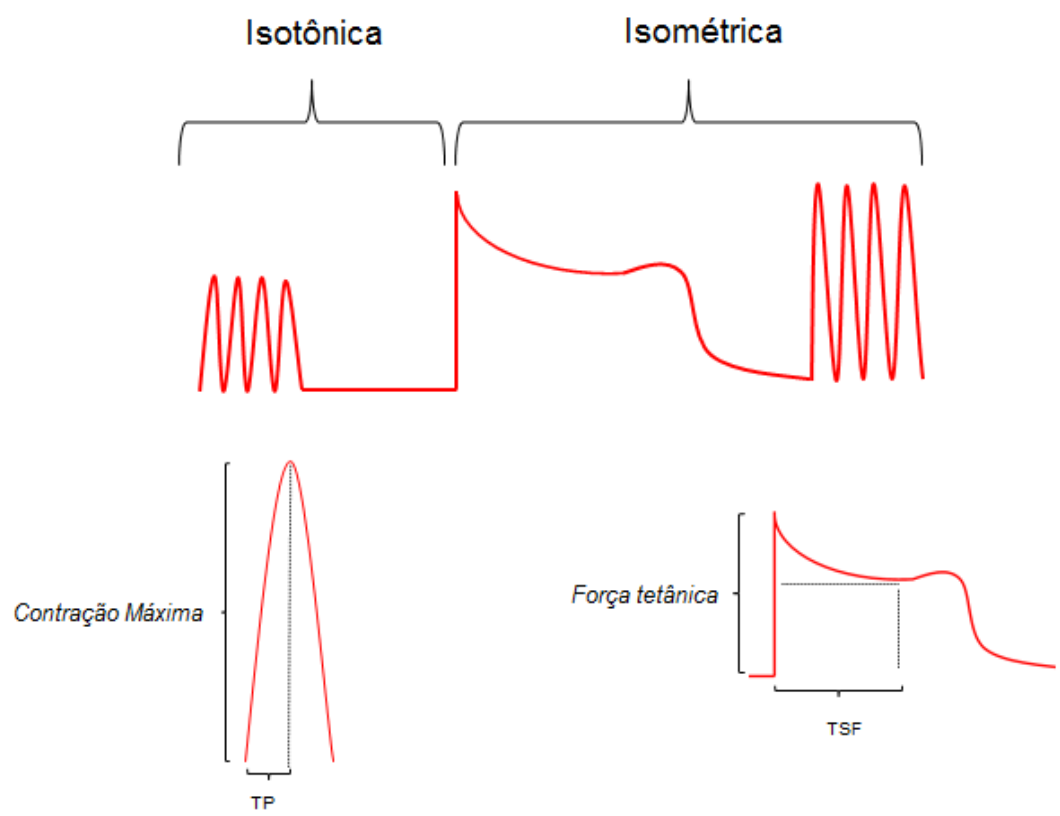

TP - tempo de duração entre 0 e 100\% força; TSF (Tempo de sustentação da força isométrica ) tempo para perder $50 \%$ força. 


\section{ANÁLISE ESTATÍSTICA}

Os dados obtidos foram avaliados por teste $\mathrm{t}$ de Student (jejum vs alimentado) ou análise de variância (ANOVA) duas vias, com o pós-teste Tukey, com o objetivo de avaliar o efeito do jejum, da suplementação e da interação de ambos os fatores. 


\section{RESULTADOS}

\subsection{Efeito do Jejum}

A relação do peso úmido e comprimento da tíbia de todos os músculos analisados [SOL (A), EDL (B) e GASTRO (C)] esteve reduzida significativamente, quando comparada à dos animais alimentados (figura 7 ).

Figura 7-Efeito do jejum sobre o peso dos músculos Sóleo, EDL e gastrocnêmio.

A

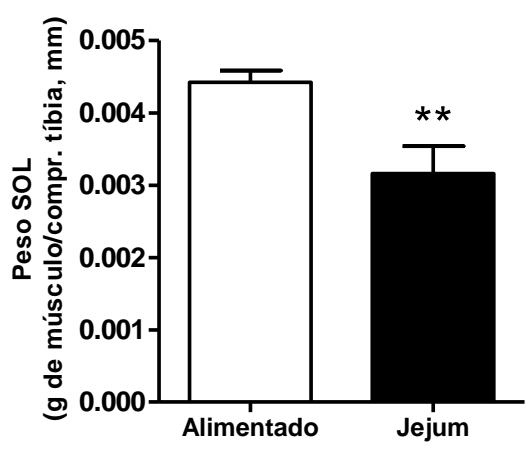

B

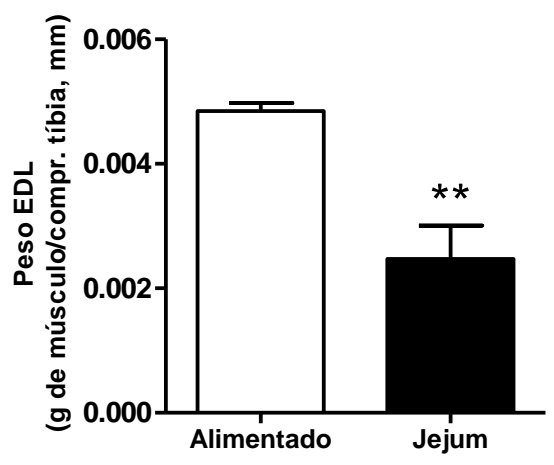

C

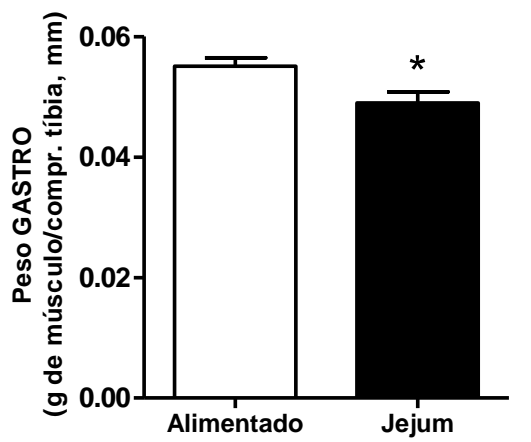

Avaliação da relação peso do músculo/ comprimento da tíbia dos animais alimentos vs. jejum de 24 horas, para o músculo sóleo - SOL (A), extensor digital longo - EDL (B) e gastrocnêmio - GASTRO (C). $(n=9-14) ;{ }^{*} p<0,05{ }^{* *} p<0,001$ vs. alimentados. 
A expressão gênica da ubiquitina-ligase MuRF-1 no musculo sóleo (A) não se alterou frente ao jejum, no entanto Atrogin-1 (B) se mostrou significativamente aumentada na condição de jejum em relação aos alimentados (figura 8).

Figura 8-Efeito do jejum sobre a expressão gênica de MuRF-1 e Atrogin-1 no sóleo.

A

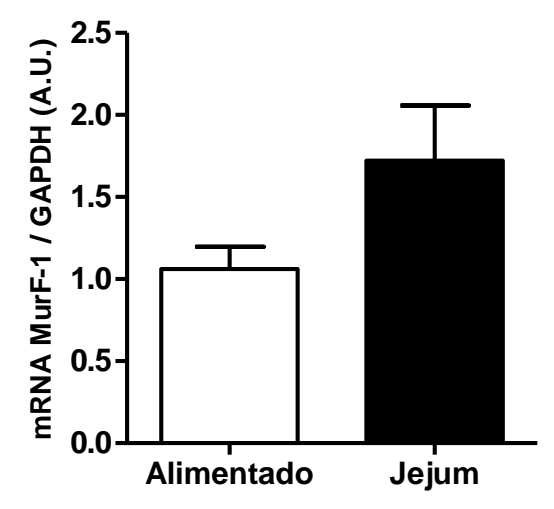

B

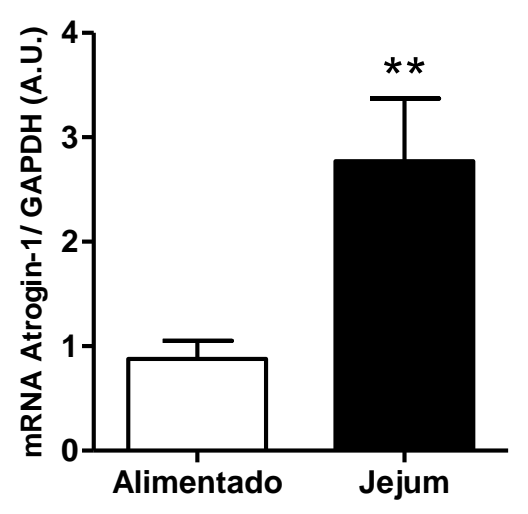

Avaliação da expressão do mRNA de MuRF-1 (A) e de Atrogin-1 (B), por Real-Time PCR, no músculo sóleo de animais alimentados e jejuados. $(n=8-11) ;{ }^{* \star} p<0,001$ vs. alimentados.

No músculo EDL, a expressão gênica de MuRF-1 (A) e Atrogin-1 (B) apresentou um aumento significativo no grupo jejum vs. alimentado. (figura 9). 
Figura 9-Efeito do jejum sobre a expressão gênica de MuRF-1 e Atrogin-1 no EDL.

A

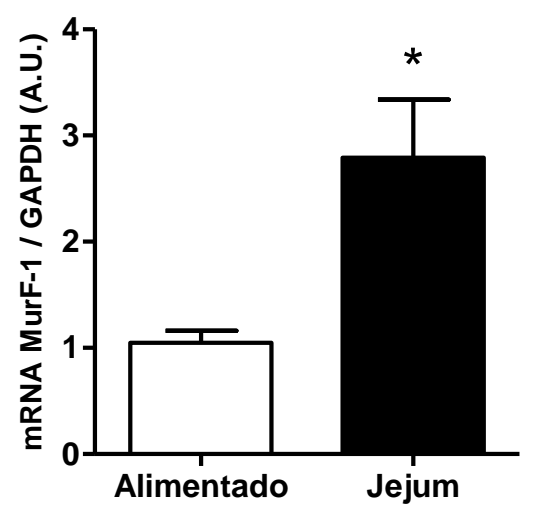

B

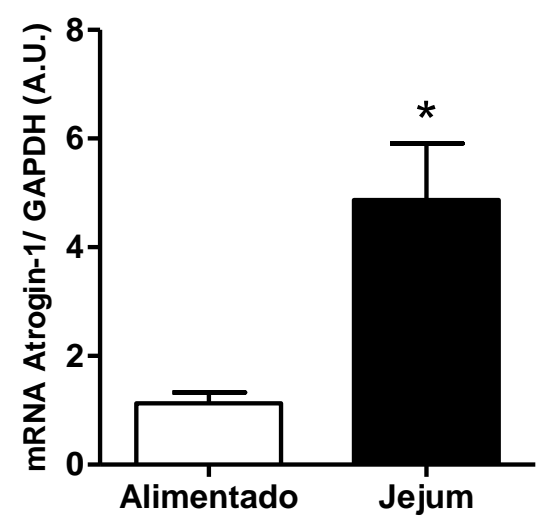

Avaliação da expressão do mRNA de MuRF-1 (A) e de Atrogin-1 (B), por Real-Time PCR, no músculo EDL de animais alimentados e jejuados. $(n=8-11) ;{ }^{*} p<0,05$ vs. alimentados.

\subsection{Efeitos da suplementação com HMB}

Os resultados apresentados a seguir levam em conta: o efeito do jejum (\&);0 efeito da suplementação com HMB (\#) e a interação desses dois fatores nos parâmetros estudados (c).

\subsubsection{Expressão gênica das ubiquitinas-ligases}

A expressão gênica da MuRF-1 (A) no músculo sóleo não se mostrou alterada pelo jejum nem pelo tratamento com HMB. No entanto, houve aumento do mRNA do Atrogin$1(B)$ nos animais jejuados vs alimentados $(\& p<0,05)$, e uma redução (não significativa) da expressão deste transcrito pelo tratamento com HMB. Observamos também, para o mesmo gene (pós-teste), um aumento do conteúdo deste transcrito nos animais jejuados (JC) vs alimentados tratados com HMB (AH) ou não $(A C)$ (figura 10). 
Figura 10-Efeito da suplementação do HMB sobre a expressão gênica de MuRF-1 e Atrogin-1 no músculo sóleo.

A

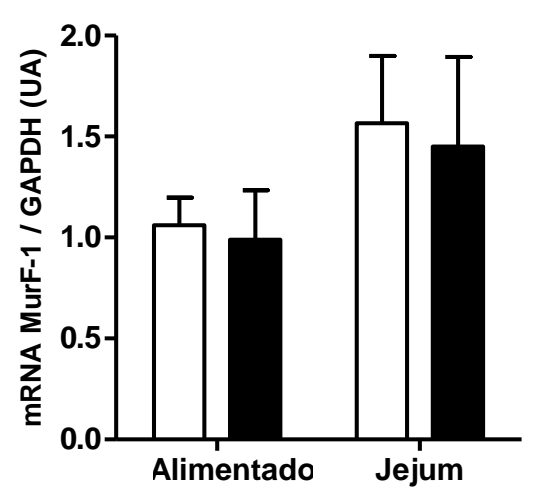

B

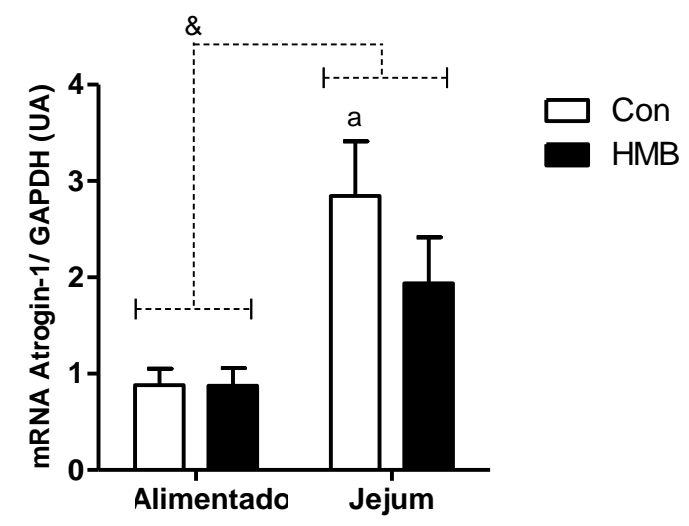

Avaliação da expressão do mRNA de MuRF-1 (A) e de Atrogin-1 (B), por Real-Time PCR, no músculo sóleo de animais jejuados e alimentados tratados ou não com HMB. $(n=8-11)$. AC: alimentados controle; AH: alimentados tratados com HMB; JC: jejuados controle e JH: jejuados tratados com HMB. Efeito do jejum vs.alimentados com relação ao Atrogin-1 ( $\&=p<0,05) ; a=p<0,05$ vs. $A C$ e AH.

No EDL a expressão gênica de MuRF-1 (A) e Atrogin-1 (B) (figura 11) apresentou-se elevada no jejum vs alimentado $(\& p<0,05)$. $O$ tratamento de ratos jejuados com $H M B$ reduziu a expressão de ambos os genes (vs jejum controle), embora esta redução não tenha atingido os níveis de significância estabelecidos. Detectamos uma diferença significativa, através do pós-teste, entre os animais jejuados controle (JC) vs. alimentados controle (AC). para ambos os genes. 
Figura 11-Efeito da suplementação do HMB sobre a expressão gênica de MuRF-1 e Atrogin-1 no músculo EDL.

A

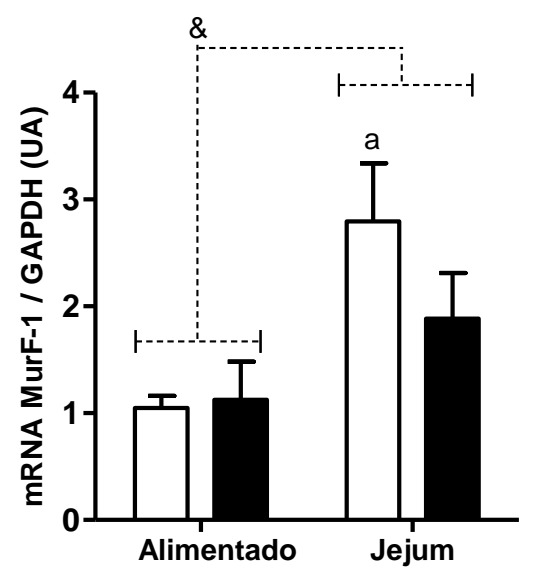

B

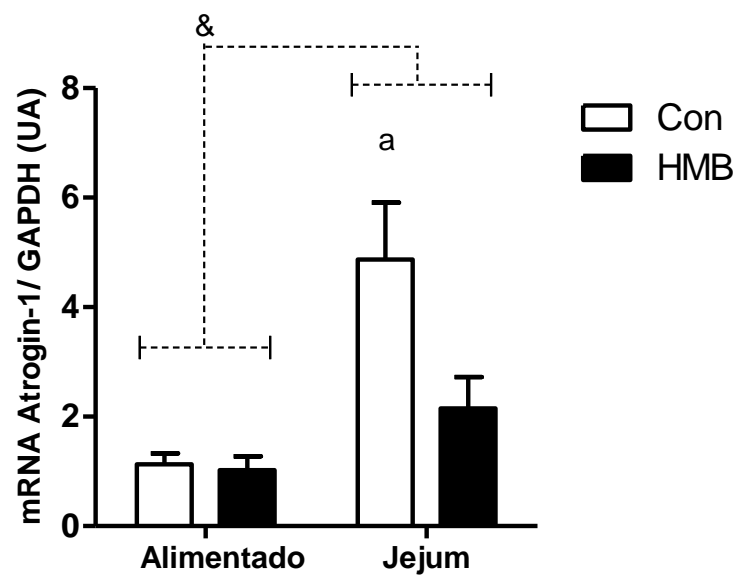

Avaliação da expressão do mRNA de MuRF-1 (A) e de Atrogin-1 (B), por Real-Time PCR, no músculo EDL de animais jejuados e alimentados tratados ou não com HMB. $(n=8-11)$. AC: alimentados controle; $\mathrm{AH}$ : alimentados tratados com HMB; JC: jejuados controle e JH: jejuados tratados com HMB. Efeito do jejum vs. alimentados com relação ao MurF-1 e Atrogin-1 ( $\& p<0,05)$; $a=p<0,05$ vs. AC.

\subsubsection{IGF-I}

A expressão gênica do IGF-I no músculo sóleo (A) apresentou-se elevada significativamente nos animais jejuados tratados com HMB (JH) comparado com os jejuados controle (JC) (pós-teste). Com relação ao músculo EDL (B) observamos um efeito de redução da mesma no jejum vs. alimentado $(\& p<0,05)$ (figura 12). 
Figura 12-Efeito da suplementação do HMB sobre a expressão gênica do IGF-I muscular.

A

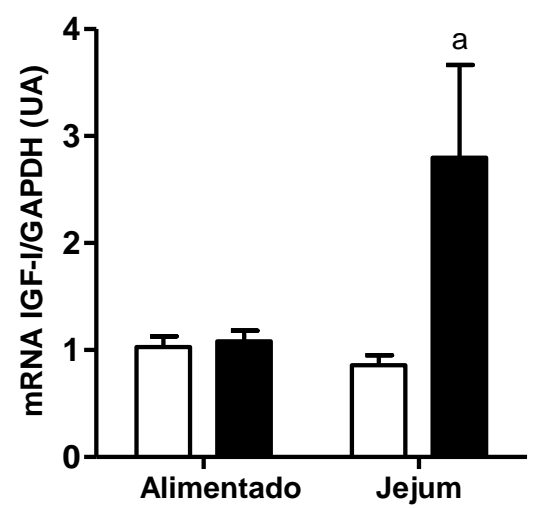

B

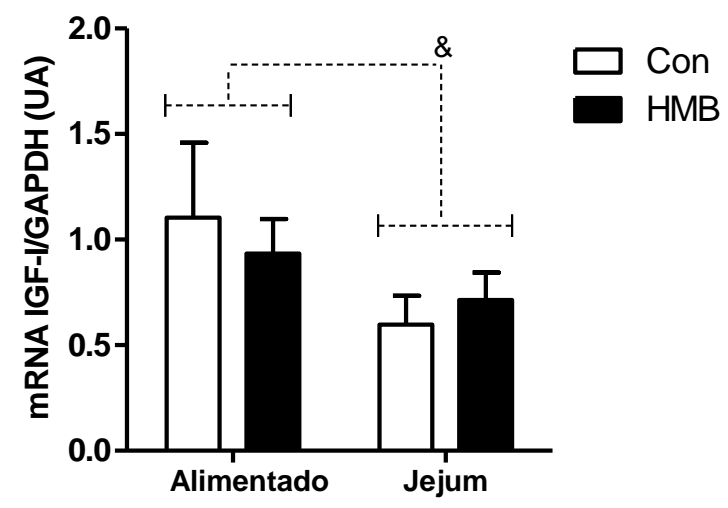

Avaliação da expressão do mRNA do IGF-I no sóleo (A) e EDL (B), por Real-Time PCR, em animais jejuados e alimentados tratados ou não com HMB. $(n=8-11)$. AC: alimentados controle; $A H$ : alimentados tratados com HMB; JC: jejuados controle e $\mathrm{JH}$ : jejuados tratados com HMB. (A) efeito da suplementação $(p=0,06) ; a=p<0,05$ vs. JC; (B) efeito do jejum $(\& p<0,05)$.

O conteúdo hepático do IGF-I não apresentou qualquer alteração frente ao jejum e a suplementação (figura 13). 
Figura 13-Efeito da suplementação do HMB sobre conteúdo do IGF-I hepático.

A

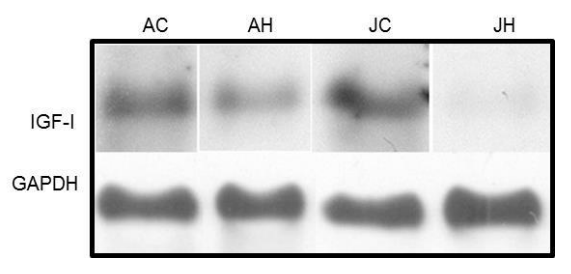

B

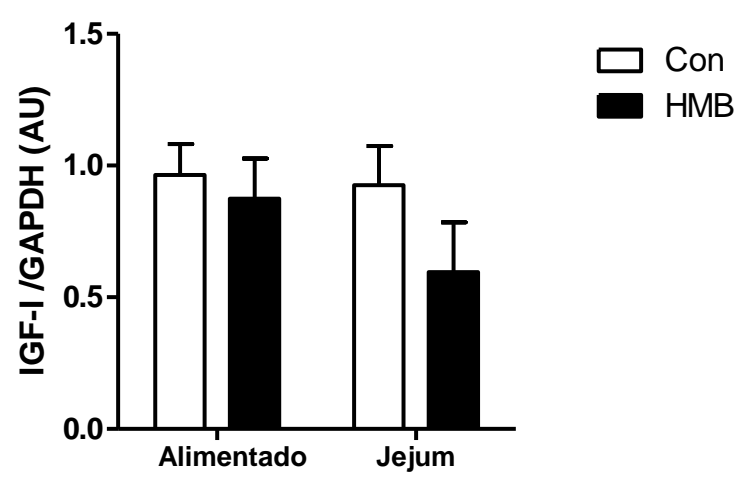

Avaliação do conteúdo hepático do IGF-I, por Western blot, em animais jejuados e alimentados. $(n=8)$. AC: alimentados controle; $\mathrm{AH}$ : alimentados tratados com HMB; JC: jejuados controle e JH: jejuados tratados com HMB.

\subsubsection{Proteínas da sinalização da síntese proteica}

A expressão gênica da Akt no músculo sóleo $(A)$ foi reduzida pela suplementação (\# $p<0,05)$. Com relação ao conteúdo da proteína total $(B)$ não foi constatada qualquer alteração, assim como para os dados do conteúdo da proteína fosforilada (C). A relação entre Akt fosforilada e total (D) mostrou-se reduzida no jejum $(\& p<0,05)$ (figura 14). 
Figura 14-Efeito da suplementação do HMB sobre a expressão gênica e proteica da Akt no músculo SOL.

A

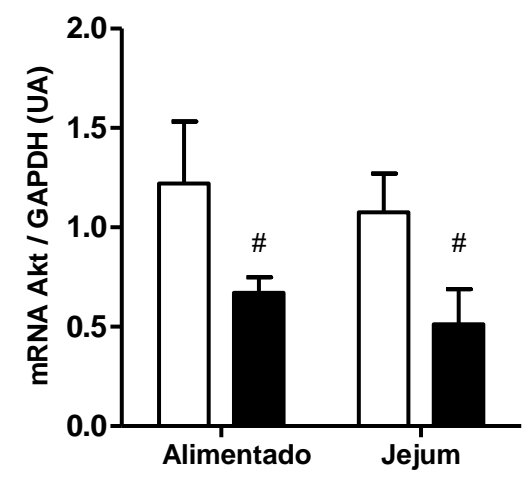

B

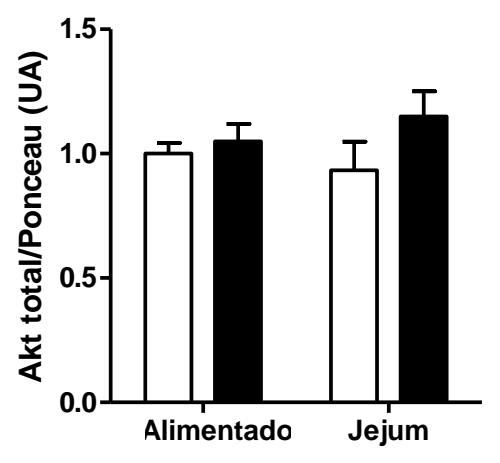

D

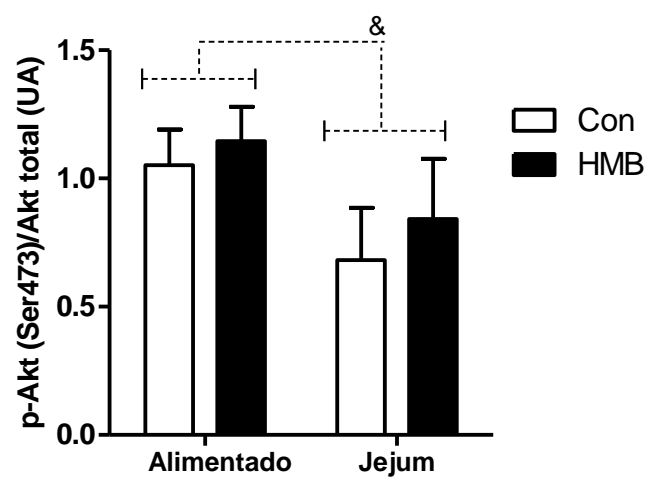

C

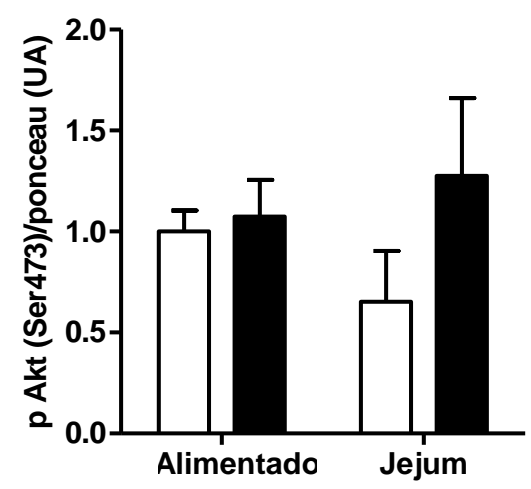

E

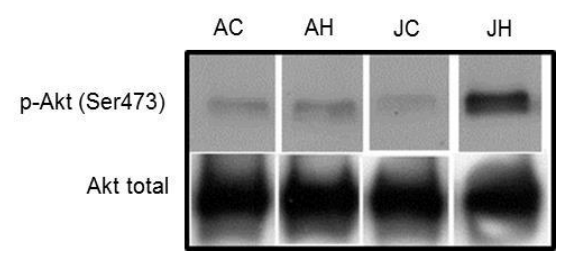

Avaliação da expressão do mRNA da Akt em SOL (A), por Real-Time PCR, do conteúdo protéico, por western blot, da Akt total (B), fosforilada (C), da relação fosforilada e total, (D) e a representação dos blots $(E)$ dos animais jejuados e alimentados tratados ou não com HMB. $(n=10-14)$. AC: alimentados controle; AH: alimentados tratados com HMB; JC: jejuados controle e JH: jejuados tratados com HMB. (A) efeito da suplementação ( $\# p<0,05)$; (D) efeito do jejum $(\& p<0,05)$. 
A expressão gênica da Akt no músculo EDL $(A)$ foi reduzida pelo jejum $(\& p<0,05)$. Com relação ao conteúdo da proteína total $(B)$ não foi constatado qualquer alteração, assim como para os dados do conteúdo da proteína fosforilada $(C)$. Os dados da relação entre Akt fosforilada e total (D) demonstram efeito da interação entre a suplementação e o jejum, efeito esse que se caracteriza em um comportamento diferente da suplementação nos animais alimentados em comparação com os jejuados. Observamos também no pós-teste, um aumento significativo dos animais jejuados tratados com HMB vs. jejuados controle (figura 15). 
Figura 15-Efeito da suplementação do HMB sobre a expressão gênica e proteica da Akt no músculo EDL.

A

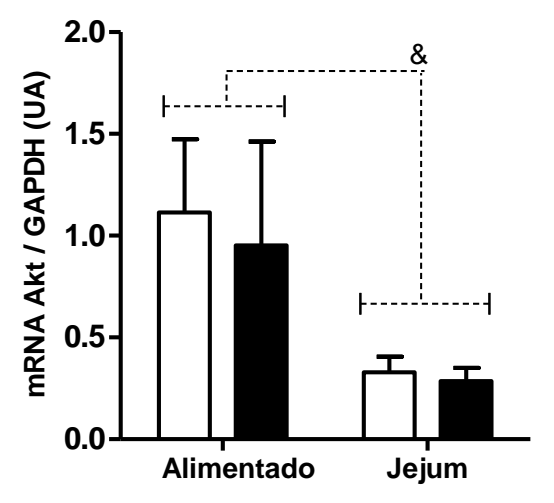

B

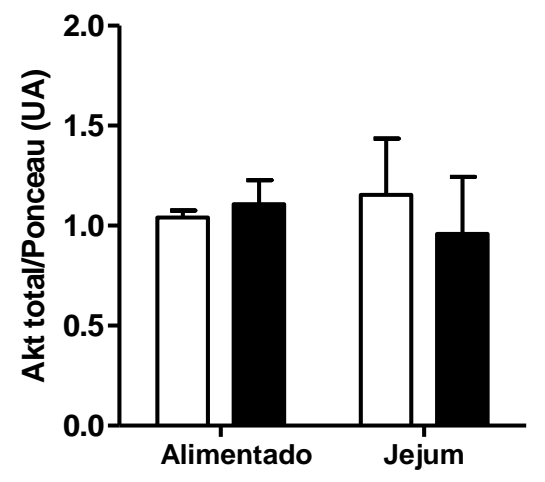

D

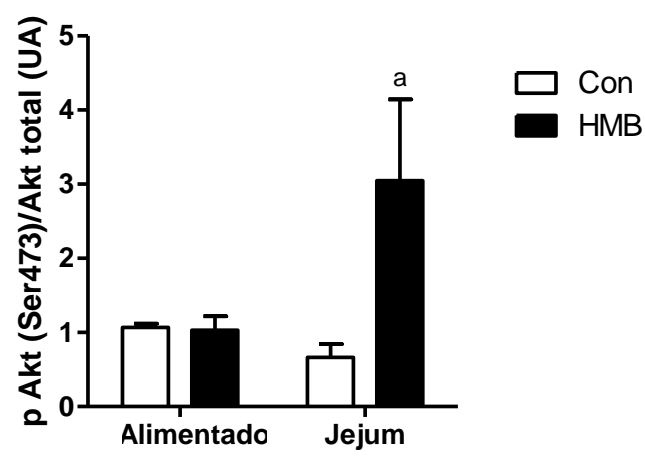

C

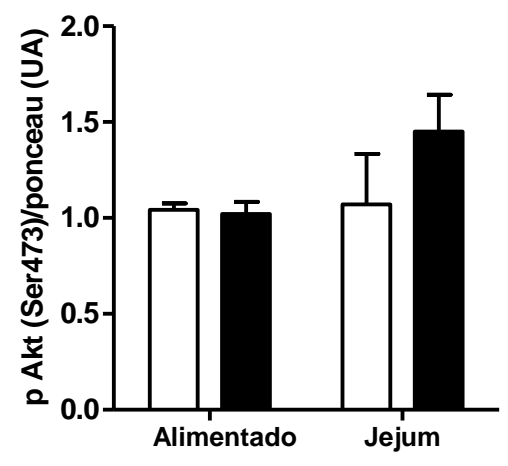

$E$

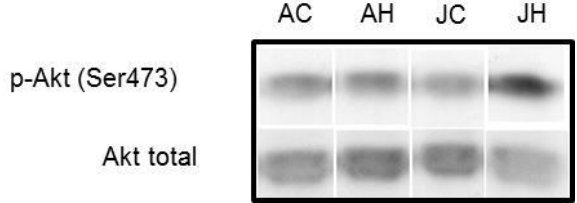

Avaliação da expressão do mRNA da Akt no EDL (A), por Real-Time PCR, do conteúdo protéico, por Western blot, da Akt total (B), fosforilada (C), da relação fosforilada e total (D) e a representação dos blots (E) dos animais jejuados e alimentados tratados ou não com HMB. (n=7-10). AC: alimentados controle; AH: alimentados tratados com HMB; JC: jejuados controle e JH: jejuados tratados com HMB. (A) efeito do jejum ( $\& p<0,05)$; (D) interação suplementação e jejum $(p=0,07)$. $a=p=0,07$ vs. JC. 
Os dados de expressão gênica da mTOR no músculo SOL (A) não mostraram qualquer alteração frente ao jejum e a suplementação (figura 16A). Do mesmo modo, não foi constatado qualquer alteração no conteúdo da proteína total (B) e fosforilada (C). Com relação aos dados da relação entre mTOR fosforilada e total (D) encontramos redução nos animais jejuados vs. alimentados $(\& p<0,05)$, bem como uma interação, embora não significativo, se encontra no limite da significância entre a suplementação e o jejum, além de uma redução significativa (pós-teste) entre os animais jejuados tratados com HMB (JH) vs. alimentados tratados com HMB (figura 16). 
Figura 16-Efeito da suplementação do HMB sobre a expressão gênica e proteica da mTOR no músculo SOL.

A

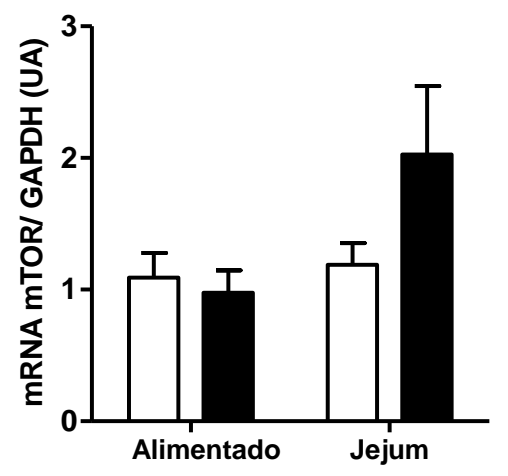

B

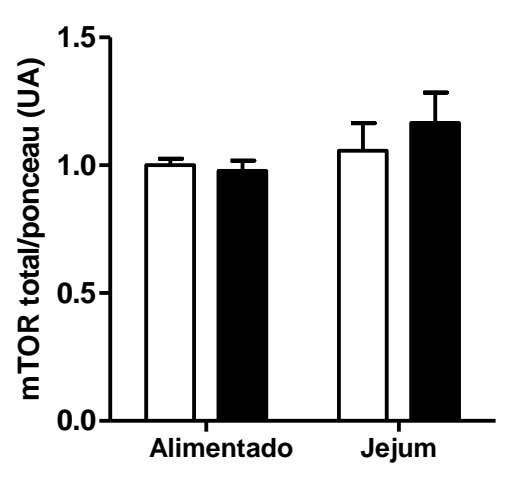

D

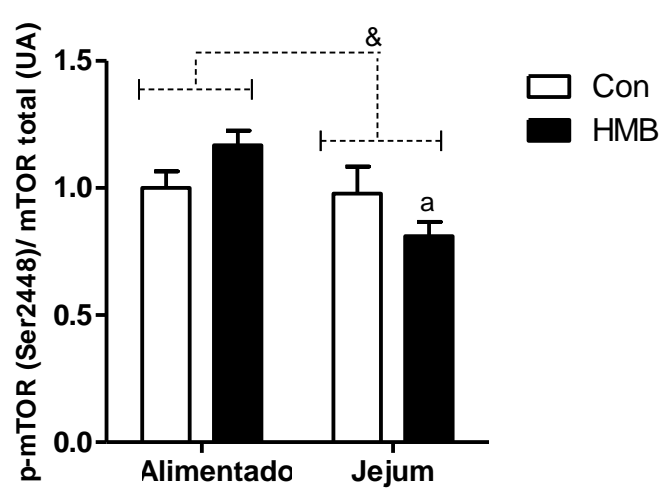

C

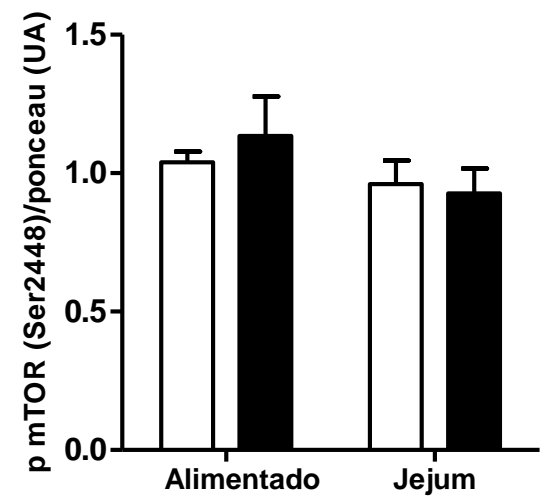

$\mathbf{E}$

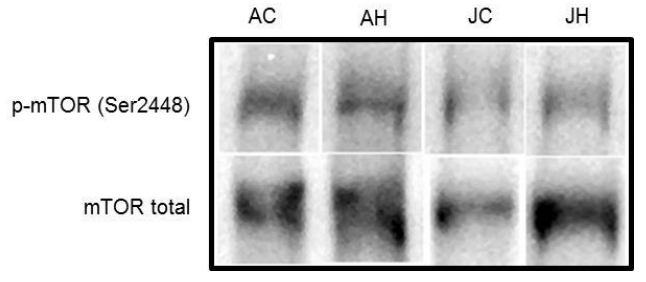

Avaliação da expressão do mRNA da mTOR no SOL (A), por Real-Time PCR, do conteúdo protéico, por Western blot, da mTOR total (B), fosforilada (C), da relação fosforilada e total (D) e a representação dos blots $(E)$ dos animais jejuados e alimentados tratados ou não com HMB. ( $n=5-10)$. AC: alimentados controle; AH: alimentados tratados com HMB; JC: jejuados controle e JH: jejuados tratados com HMB. (D) efeito do jejum ( \& $p<0,05)$; interação suplementação e jejum $(p=0,06)$. $a=$ $\mathrm{p}<0,05$ vs. $\mathrm{AH}$. 
A expressão gênica da mTOR no músculo EDL (figura 17A) mostrou-se aumentada pelo jejum $(\& p<0,05)$. Observamos também interação da suplementação e jejum, bem como um aumento no jejum tratado com HMB (JH) vs. alimentado tratado $(\mathrm{AH})$ (pós-teste). O conteúdo da proteína total (B) apresentou-se reduzido nos animais jejuados $(\& p<0,05)$. Quanto aos dados da proteína fosforilada (C) não constatamos qualquer alteração. No entanto a relação da fosforilada e total (D) demonstramos um efeito do jejum (aumentado), bem como uma interação da suplementação e jejum, ou seja, efeito diferente da suplementação entre os animais alimentados e jejuados. Observamos ainda (pós-teste) uma diferença significativa neste paramentro entre os animais controle alimentado (AC) vs. jejuados controle $(\mathrm{JC})$ e alimentados tratados $(\mathrm{AH})(\mathrm{a}=\mathrm{p}<0,05)$, bem como entre jejuados controle $(\mathrm{JC})$ vs. alimentados tratados $(\mathrm{AH})$ e jejuados tratados $(\mathrm{JH})(\mathrm{b}=\mathrm{p}<0,05)$. 
Figura 17-Efeito da suplementação do HMB sobre a expressão gênica e proteica da mTOR no músculo EDL.

A

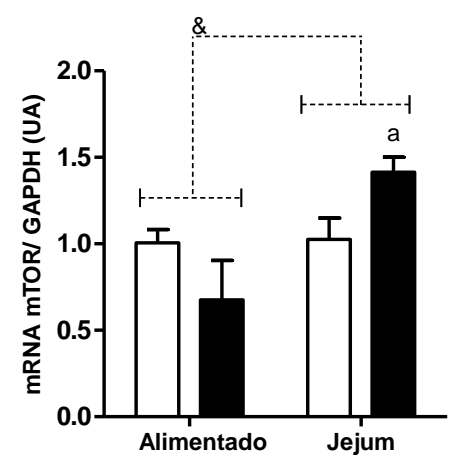

B

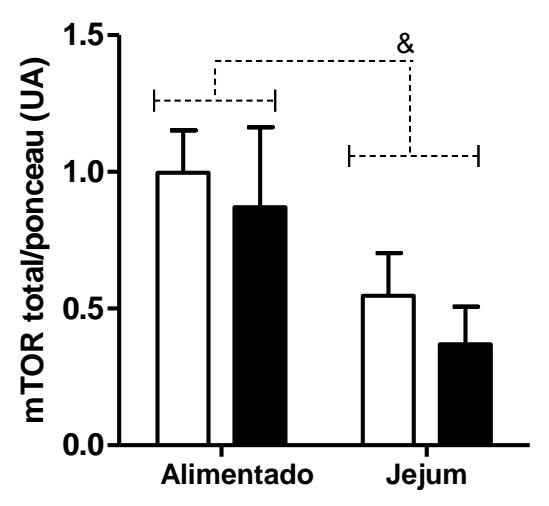

D

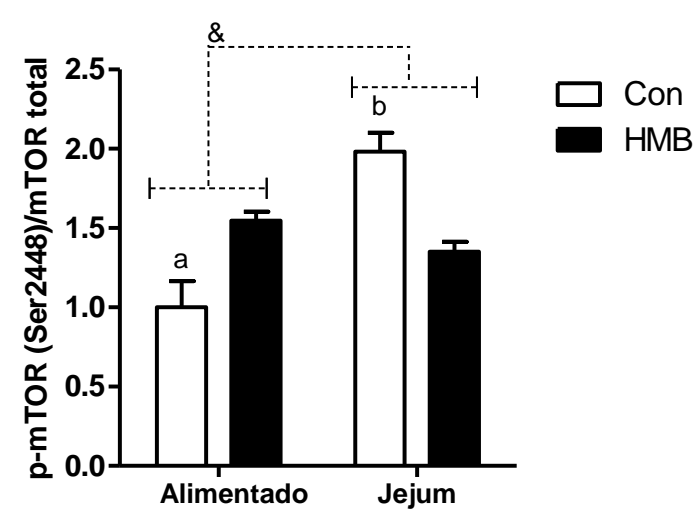

C

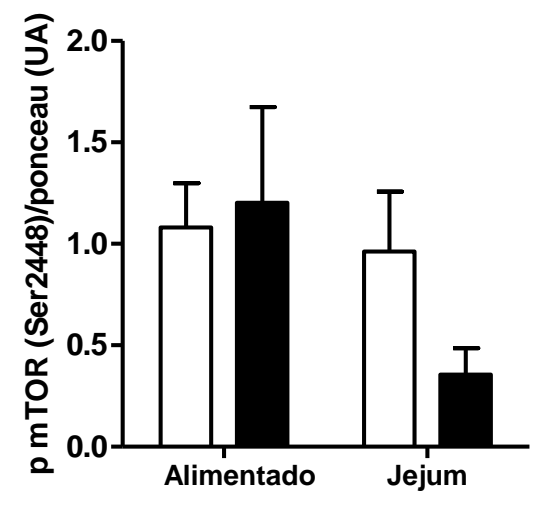

E

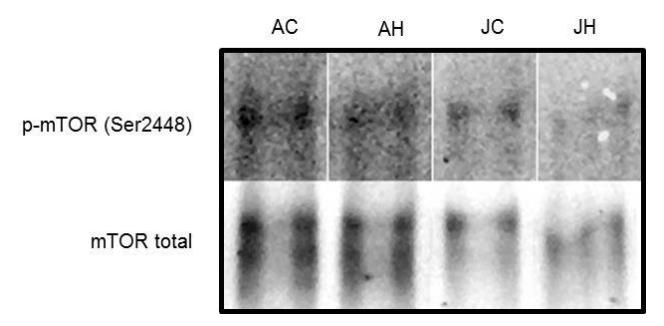

Avaliação da expressão do mRNA da m TOR no EDL (A), por Real-Time PCR, do conteúdo proteico, por Western blot, da mTOR total (B), fosforilada (C), da relação fosforilada e total (D) e a representação dos blots $(E)$ dos animais jejuados e alimentados tratados ou não com HMB. ( $n=5-10)$. AC: alimentados controle; $\mathrm{AH}$ : alimentados tratados com HMB; JC: jejuados controle e JH: jejuados tratados com HMB. (A e B) efeito do jejum $(\& p<0,05) \quad a=p<0,05$ vs. $A H$; (D) efeito do jejum (\& $p<0,05)$ e interação da suplementação e jejum $(p<0,05) a=p<0,05$ vs. $A H$ e JC; $b=p<0,05$ vs. AH e $\mathrm{JH}$. 
A expressão gênica da 4EBP-1 no músculo SOL (figura 18A) foi aumentada pelo jejum $(\& p<0,05)$. O conteúdo da proteína total $(B)$ assim como o da proteína fosforilada (C) não apresentaram qualquer alteração. No entanto a relação entre fosforilada e total (D) mostrou-se reduzida pela suplementação $(\# p<0,05)$. 
Figura 18-Efeito da suplementação do HMB sobre a expressão gênica e proteica da 4EBP-1 no músculo SOL.

A

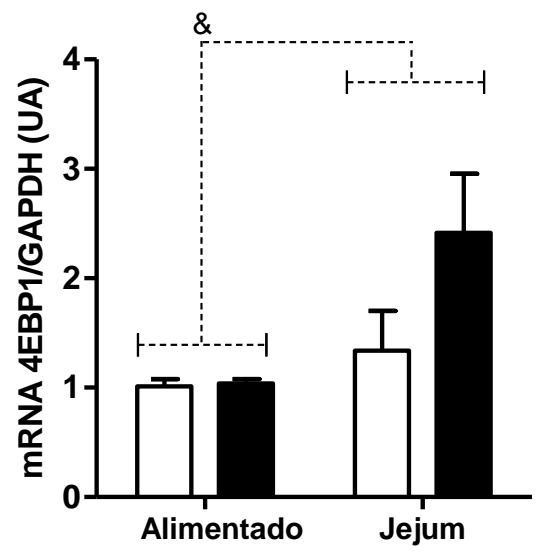

B

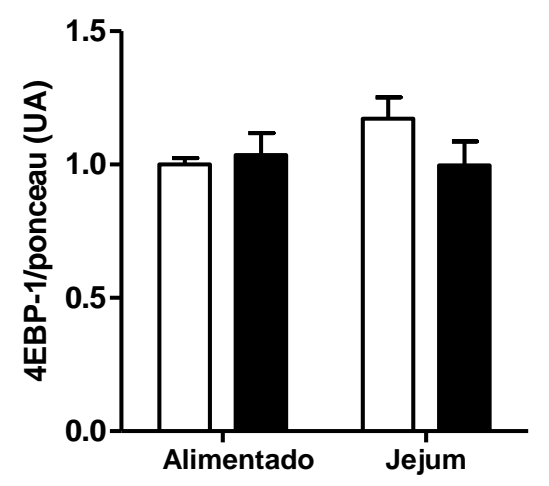

D

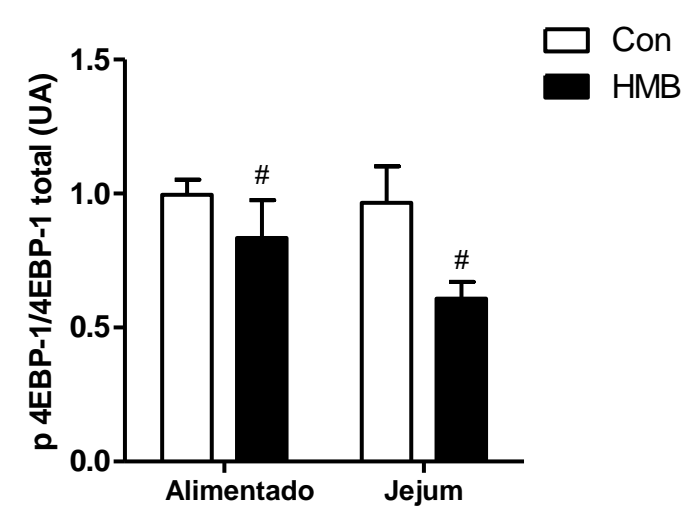

C

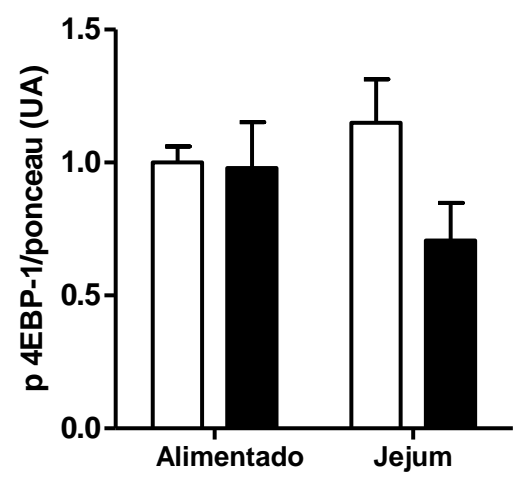

E

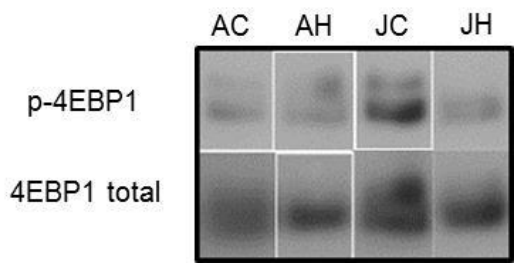

Avaliação da expressão do mRNA da 4EBP-1 no SOL (A), por Real-Time PCR do conteúdo proteico, por Western blot, da 4EBP-1 total (B), fosforilada (C), da relação fosforilada e total (D) e a representação dos blots $(E)$ dos animais jejuados e alimentados tratados ou não com HMB. $(n=5-10)$. AC: alimentados controle; $\mathrm{AH}$ : alimentados tratados com HMB; JC: jejuados controle e JH: jejuados tratados com HMB. (A) efeito do jejum $(\& p<0,05) ;(D)$ efeito da suplementação $(\# p<0,05)$. 
A expressão gênica da 4EBP-1 no músculo EDL (19A) mostrou-se aumentada pelo jejum $(\& p<0,05)$. Detectamos também (pós-teste) uma diferença significativa entre os grupos alimentado controle $(A C)$ vs jejuados tratados $(J H)$ ou não $(J C)(a=p<0,05)$, e alimentados tratados $(\mathrm{AH})$ vs jejuados tratados $(\mathrm{JH})$ ou não $(\mathrm{JC})(b=\mathrm{p}<0,05)$. O conteúdo da proteína total $(B)$ assim como os da proteína fosforilada $(C)$ apresentaram interação entre a suplementação e jejum $(p<0,05)$. A relação entre fosforilada e total $(D)$ apresentou-se aumentada no jejum $(\& p<0,05)$. 
Figura 19-Efeito da suplementação do HMB sobre a expressão gênica e proteica da 4EBP-1 no músculo EDL.

A

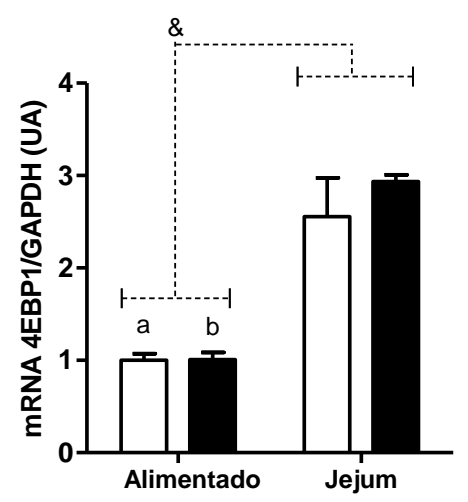

B

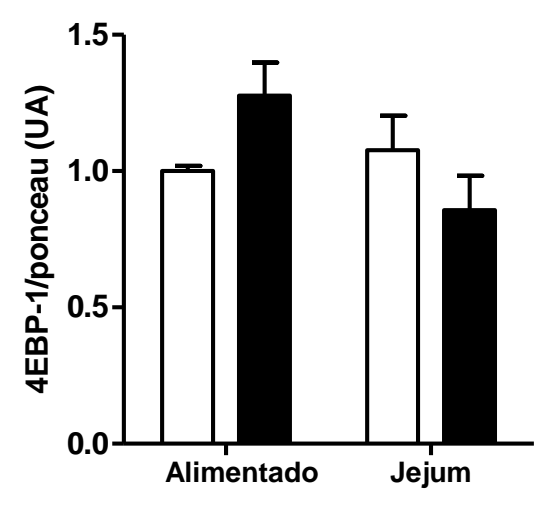

D

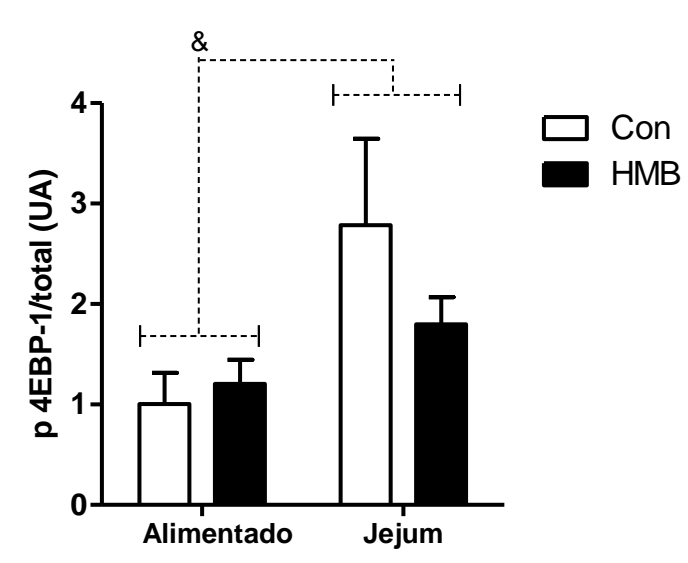

C

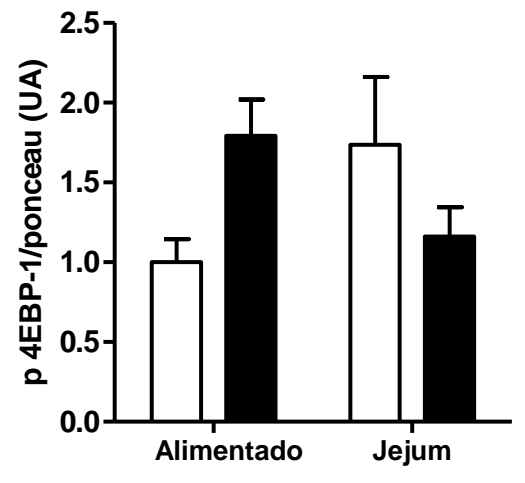

E

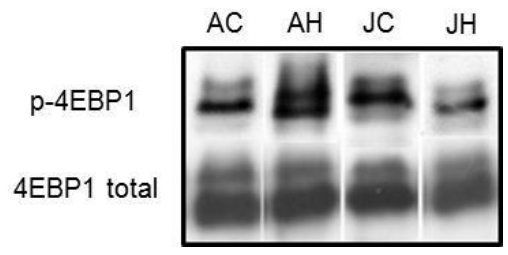

Avaliação da expressão do mRNA da 4EBP-1 no EDL (A), por Real-Time PCR do conteúdo protéico, por Western blot, da 4EBP-1 total (B), fosforilada (C), da relação fosforilada e total (D) e a representação dos blots $(E)$ dos animais jejuados e alimentados suplementados ou não com HMB. $(n=5-10)$. AC: alimentados controle; $A H$ : alimentados tratados com HMB; JC: jejuados controle e JH: jejuados tratados com HMB. (A ; D) efeito do jejum ( \& $p<0,05), a=p<0,05$ vs. JC e JH, b=p<0,05 vs. $\mathrm{JC}$ e JH; (B e C) interação entre suplementação e jejum $(p<0,05)$. 
O conteúdo total da S6 (figura 20A) no músculo SOL foi reduzido pela suplementação $(\# p<0,05)$. Com relação ao conteúdo fosforilado (B) não observamos qualquer alteração frente ao jejum e a suplementação. A analise da relação entre a fosforilada e total (C) revela um aumento sob a condição de jejum $(\& p<0,05)$, bem como diferenças significativas entre jejum controle (JC) em relação ao alimentado controle (AC) e alimentado tratado com HMB $(\mathrm{AH})(\mathrm{a}=\mathrm{p}<0,05)$.

Figura 20-Efeito da suplementação do HMB sobre o conteúdo proteico da S6 no músculo SOL.

A

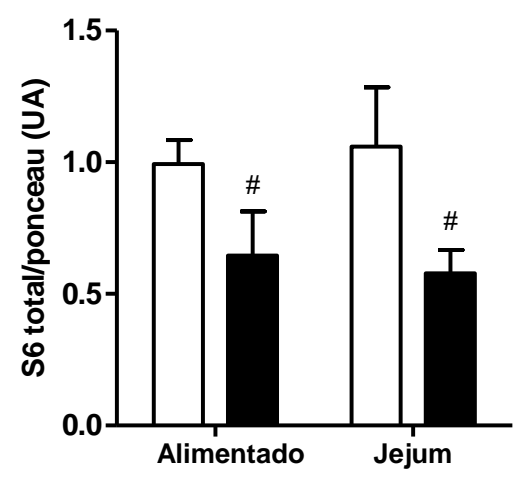

C

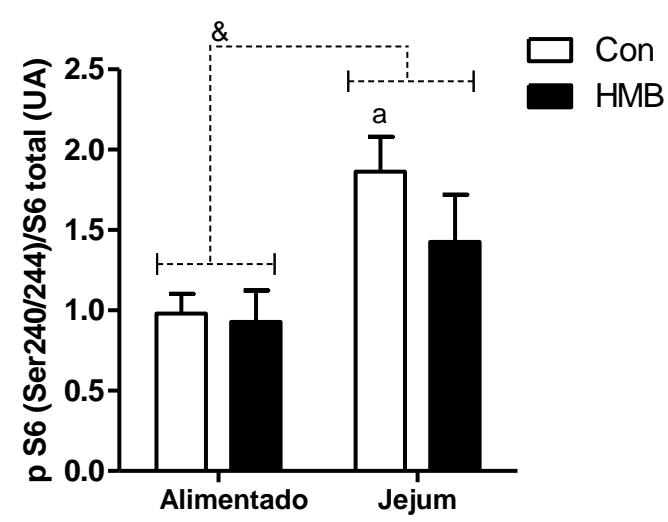

B

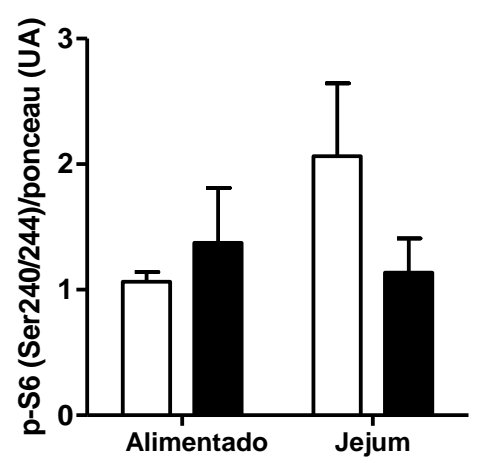

D

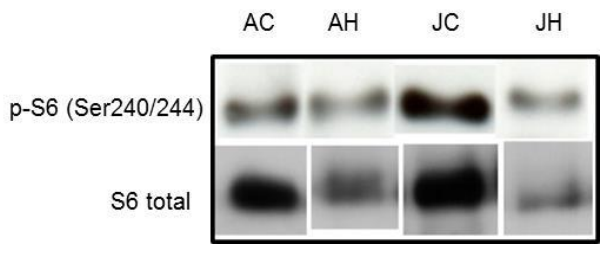

Avaliação do conteúdo protéico da S6 total (A), S6 fosforilada (B) e (C) da relação fosforilada pela total por Western blot, no músculo SOL e a (D) representação dos blots dos animais jejuados e alimentados tratados ou não com HMB $(n=10-11)$. $A C$ : alimentados controle; $A H$ : alimentados tratados com HMB; JC: jejuados controle e $\mathrm{JH}$ : jejuados tratados com HMB. (A) efeito da suplementação (\# $p<0,05)$; (C) efeito do jejum ( $\& p<0,05), a=p<0,05$ vs. $A C$ e $A H$. 
Não observamos qualquer efeito do jejum e da suplementação sobre o conteúdo da S6 total $(A)$, fosforilada $(B)$, e da relação da fosforilada pela total $(C)$ no músculo EDL (figura $21 \mathrm{~A}, \mathrm{~B}$ e C, respectivamente).

Figura 21-Efeito da suplementação do HMB sobre o conteúdo protéico da S6 no músculo EDL.

A

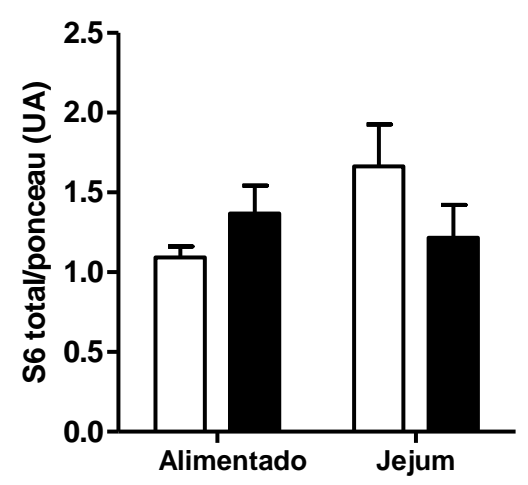

C

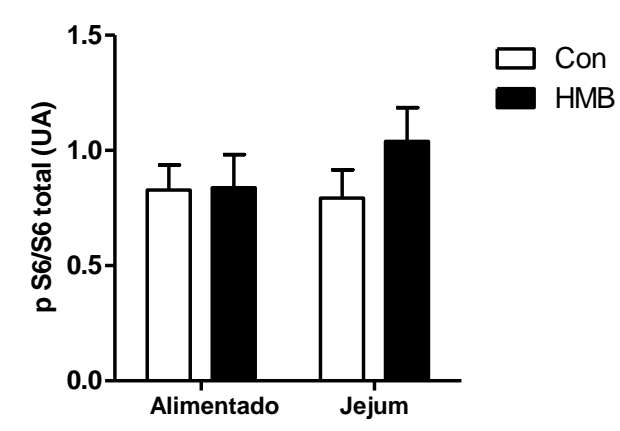

B

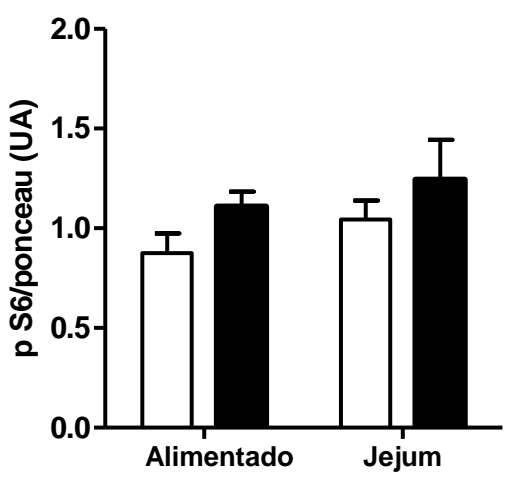

D

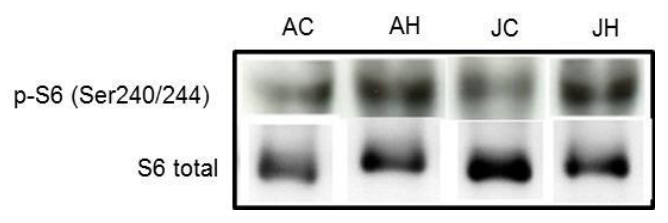

Avaliação do conteúdo proteico da S6 total (A), S6 fosforilada (B) e (C) da relação fosforilada pela total por Western blot, (D) representação dos blots no músculo EDL em animais jejuados e alimentados tratados ou não com HMB $(n=10-11)$. AC: alimentados controle; $A H$ : alimentados tratados com HMB; JC: jejuados controle e JH: jejuados tratados com HMB. 


\subsubsection{Parâmetros morfométricos}

A relação entre o peso do músculo e comprimento da tíbia para o SOL (figura 22A) mostrou-se reduzida no jejum ( \& $p<0,05)$, e aumentada (pós-teste) no grupo alimentado controle $(\mathrm{AC})$ vs jejuados tratados $(\mathrm{JH})$ ou não $(\mathrm{JC})$. No músculo EDL (B) essa relação apresentou-se reduzida nos animais jejuados vs. alimentados $(\& p<0,05)$, bem como um efeito da suplementação $(\# p<0,05)$ e interação entre essas duas variáveis. Observamos ainda uma diferença (pós-teste) dos animais jejuados controle (JC) vs alimentados tratados $(\mathrm{AH})$ ou não $(\mathrm{AC})$ e jejum tratado $(\mathrm{JH})(\mathrm{a}=\mathrm{p}<0,05)$. No músculo GASTRO observamos redução dos animais jejuados vs alimentados $(\& p<0,05)$ e uma redução, no pós-teste, entre o jejum tratado com $\mathrm{HMB}(\mathrm{JH})$ vs alimentado controle $(\mathrm{AC})$. 
Figura 22-Efeito da suplementação do HMB sobre o peso dos músculos Sóleo, EDL e gastrocnêmio.

A

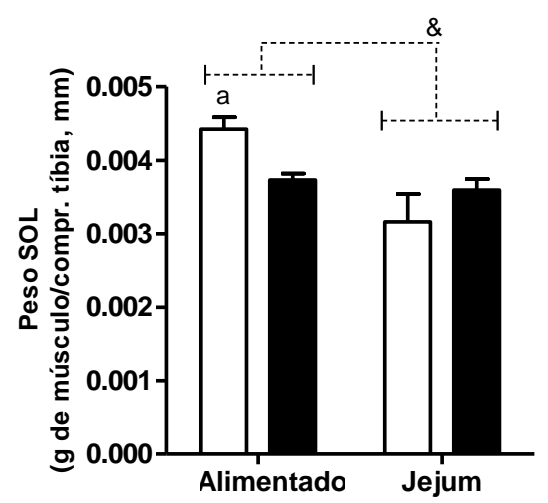

B

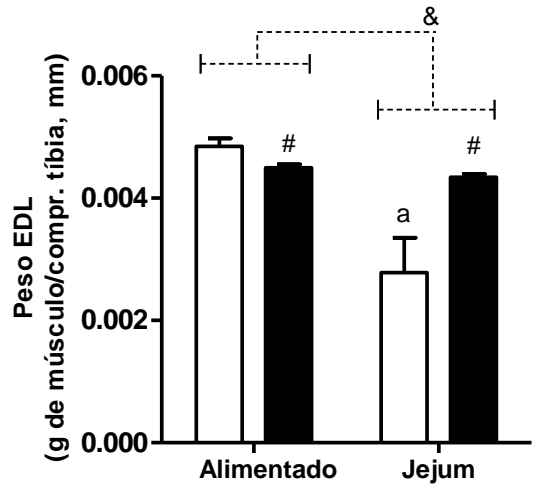

C

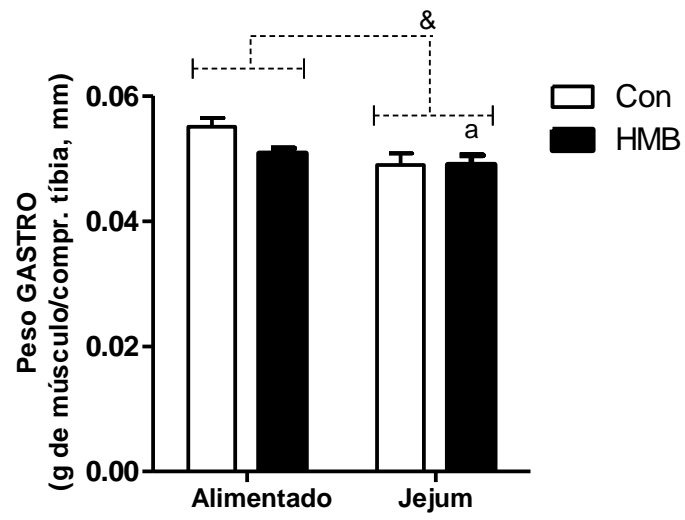

Avaliação da relação peso do músculo/ comprimento da tíbia para: sóleo (SOL) (A), EDL (B) e gastrocnêmio (GASTRO) (C). ( $n=9 \sim 14)$. AC: alimentados controle; $A H$ : alimentados tratados com HMB; JC: jejuados controle e JH: jejuados tratados com HMB. (A) efeito do jejum $(\& p<0,05) ; a=$ $\mathrm{p}<0,05$ vs. JC e JH; (B) efeito do jejum $(\& p<0,05)$, suplementação $(\# p<0,05)$ e interação entre suplementação e jejum $(c=p<0,05) ; a=p<0,05$ vs. $A C, A H$ e $J H ;(C)$ efeito do jejum $(\& p<0,05)$; $a=p<0,05$ vs. AC. 


\subsubsection{Análise histológica}

Os resultados de área de secção transversa (AST) do músculo sóleo mostram-se reduzidas nos animais jejuados vs. alimentados $(\& p<0,05)$, bem como uma redução dos animas suplementados vs controles $(\# p<0,05)$. Observa-se também uma redução significativa, pós-teste, do jejum tratado com HMB (JH) comparado com o alimentado controle (AC) (figura 23). 
Figura 23-Área de secção transversa (AST) do sóleo (SOL).

A

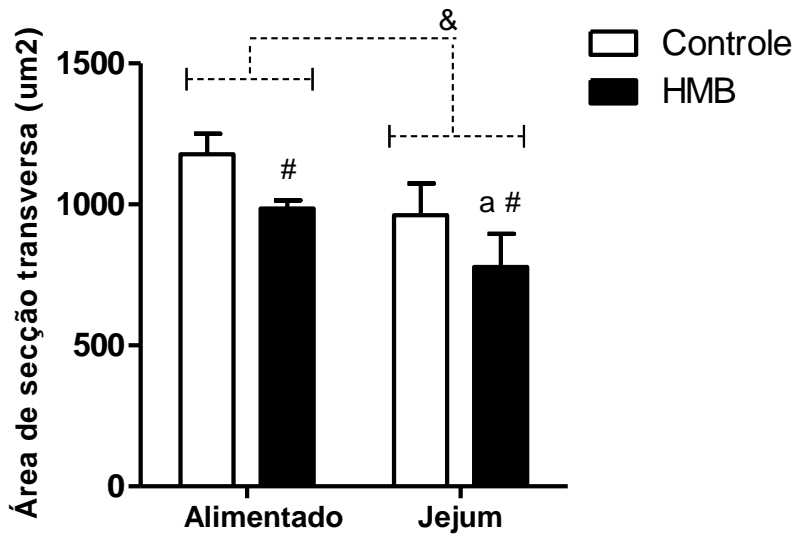

B

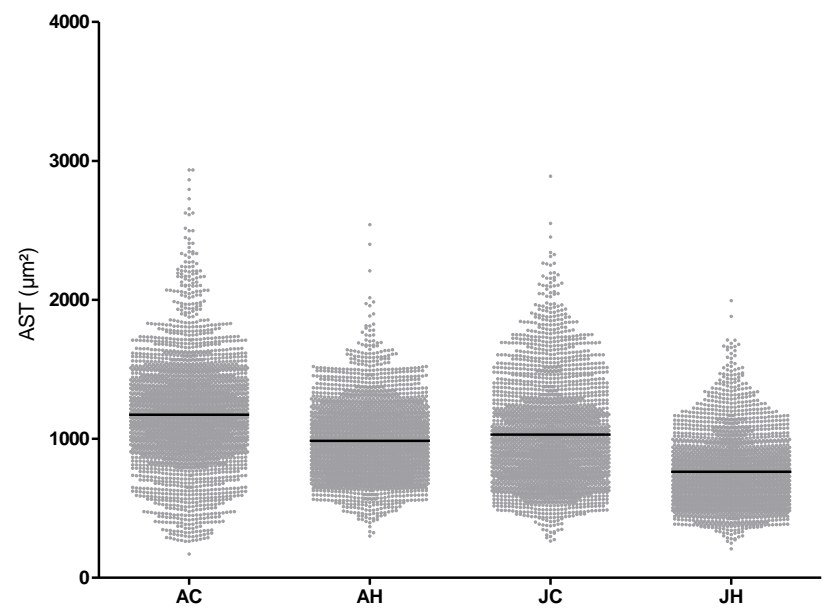

Os cortes foram corados por hematoxilina e eosina. Em $(A)$ temos representada a media das áreas $\left(u^{2}{ }^{2}\right)$ respectivamente do músculo $\mathrm{SOL}$; onde se observa o efeito do jejum $(\& p<0,05)$ e da suplementação (\# $p<0,05) ; a=p<0,05$ vs. alimentado controle $(A C)$ ( $n=5$ animais por grupo). (B) imagem da distribuição das fibras dos grupos: alimentados controle (AC); alimentados tratados com HMB (AH); jejuados controle (JC) e jejuados tratados com HMB (JH).

Com relação aos resultados de área de secção transversa do músculo EDL não encontramos qualquer alteração (figura 24). 
Figura 24-Área de secção transversa (AST) do EDL.

A

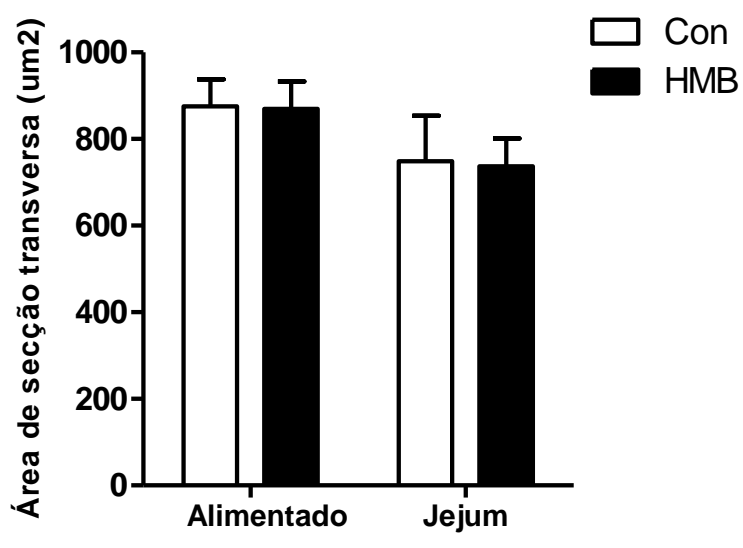

B

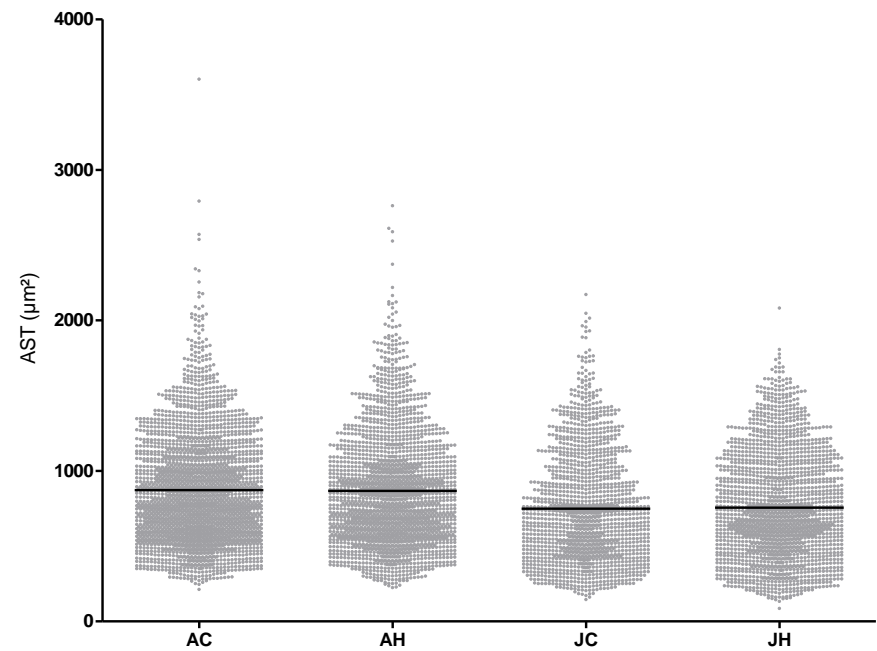

Os cortes foram corados por hematoxilina e eosina. Em (A) temos representada a media das áreas $\left(u^{2}{ }^{2}\right.$ ) respectivamente do músculo EDL ( $n=5$ animais por grupo). (B) imagem da distribuição das fibras dos grupos: alimentados controle (AC); alimentados tratados com HMB (AH); jejuados controle (JC) e jejuados tratados com HMB (JH). 


\subsubsection{Parâmetros funcionais}

A análise funcional do sóleo, responsável pelo movimento de flexão plantar na articulação do tornozelo, está descrita na tabela 3. Observamos uma redução nos animais que sofreram jejum vs alimentados $(\& p<0,05)$ nos parâmetros de força isotônica máxima absoluta (FIMA) e força tetânica máxima absoluta (FTMA).

Tabela 3-Parâmetros funcionais do SOL.

\begin{tabular}{ccccc}
\hline Parâmetro & AC & AH & JC & JH \\
\hline $\begin{array}{c}\text { Força isotônica máxima } \\
\text { absoluta (mN) }\end{array}$ & $687,32 \pm 192,55$ & $874,62 \pm 179,80$ & $231,57 \pm 20,657^{\&}$ & $614,59 \pm 154,12^{\&}$ \\
$\begin{array}{c}\text { Força isotônica especifica } \\
\text { (mN/g) }\end{array}$ & $4697,84 \pm 1299,43$ & $5364,709 \pm 1287,75$ & $1550,13 \pm 150,39$ & $4379,01 \pm 1266,08$ \\
$\begin{array}{c}\text { Tempo para o pico de } \\
\text { força isotônica (ms) }\end{array}$ & $31,54 \pm 3,17$ & $31,92 \pm 6,35$ & $26,40 \pm 3,32$ & $29,57 \pm 3,33$ \\
$\begin{array}{c}\text { Força tetânica máxima } \\
\text { absoluta (mN) }\end{array}$ & $2368,91 \pm 711,57$ & $3126,35 \pm 590,37$ & $906,76 \pm 154,96^{\&}$ & $1913,01 \pm 404,32^{\&}$ \\
$\begin{array}{c}\text { Força tetânica especifica } \\
\text { (mN/g) }\end{array}$ & $16136,34 \pm 4689,56$ & $18810,37 \pm 3675,68$ & $6389,36 \pm 1108,31$ & $13527,54 \pm 3511,95$ \\
\hline $\begin{array}{c}\text { Tempo de sustentação da } \\
\text { isometria (ms) }\end{array}$ & $4,74 \pm 0,404$ & $4,77 \pm 0,39$ & $5,32 \pm 0,76$ & $3,94 \pm 0,68$ \\
\hline
\end{tabular}

Dados de força isotônica, tetânica e tempo de sustentação isométrica no músculo SOL. AC: alimentados controle; $\mathrm{AH}$ : alimentados tratados com HMB; JC: jejuados controle e JH: jejuados tratados com HMB; efeito do jejum $(\& p<0,05)$.

Ao analisarmos os resultados de índice de resistência à fadiga, que compreende a resistência às sucessivas contrações tetânicas, não observamos alteração frente ao jejum e nem à suplementação com HMB (figura 25). 
Figura 25-Resistencia a fadiga no músculo SOL.

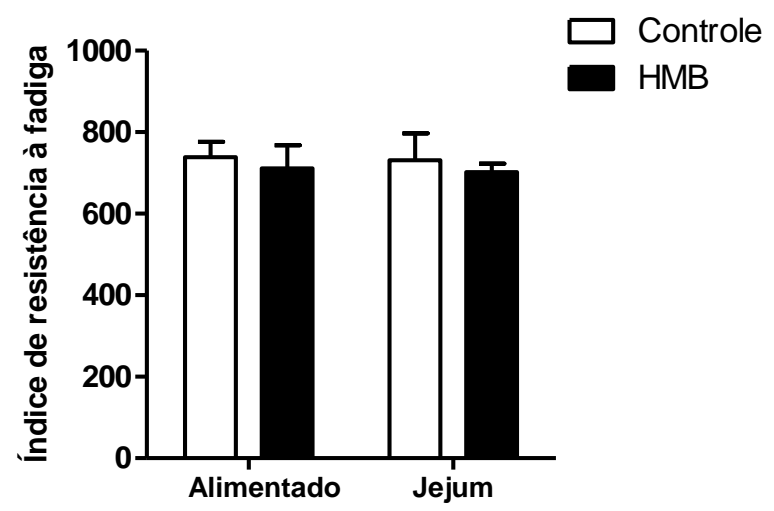

Desempenho das 10 contrações tetânicas máximas do sóleo, intervaladas por 10 segundos de recuperação. Os dados representam a media dos valores de área sob a curva de cada animal dos respectivos grupos.

A análise funcional do EDL está descrita na tabela 4. Observamos aumento no tempo de sustentação da isometria nos animais jejuados vs alimentodos $(\& p<0,05)$, bem como um aumento mais acentuado (pós-teste) no grupo jejum tratado com HMB (JH) em comparação com os animais tratados com HMB (AH) ou não (AC). 
Tabela 4-Parâmetros funcionais do EDL.

\begin{tabular}{ccccc}
\hline Parâmetro & AC & AH & JC & JH \\
\hline $\begin{array}{c}\text { Força isotônica } \\
\text { máxima absoluta } \\
(\mathbf{m N})\end{array}$ & $592,08 \pm 104,97$ & $673,82 \pm 164,55$ & $506,53 \pm 62,58$ & $465,97 \pm 86,60$ \\
$\begin{array}{c}\text { Força isotônica } \\
\text { especifica (mN/g) }\end{array}$ & $3659,08 \pm 598,07$ & $4440,75 \pm 990,28$ & $3183,16 \pm 374,18$ & $3223,72 \pm 524,6$ \\
$\begin{array}{c}\text { Tempo para o pico de } \\
\text { força isotônica (ms) }\end{array}$ & $43,1 \pm 6,02$ & $36,11 \pm 3,81$ & $48,43 \pm 7,14$ & $37,97 \pm 2,19$ \\
$\begin{array}{c}\text { Força tetânica } \\
\text { máxima absoluta } \\
\text { (mN) }\end{array}$ & $1876,55 \pm 241,78$ & $2871,69 \pm 566,02$ & $2223,06 \pm 263,05$ & $1908,10 \pm 198,81$ \\
$\begin{array}{c}\text { Força tetânica } \\
\text { especifica (mN/g) }\end{array}$ & $11852,23 \pm 1448,61$ & $19565,58 \pm 4393,89$ & $17273,3 \pm 2516,33$ & $13402,16 \pm 1067,29$ \\
$\begin{array}{c}\text { Tempo de } \\
\text { sustentação da } \\
\text { isometria (ms) }\end{array}$ & $5,10 \pm 0,61$ & $5,23 \pm 0,83$ & $6,03 \pm 0,71^{\&}$ & $9,37 \pm 1,33^{\& a}$ \\
\hline
\end{tabular}

Dados de força isotônica, tetânica e tempo de sustentação isométrica no músculo EDL. AC: alimentados controle; $\mathrm{AH}$ : alimentados tratados com HMB; JC: jejuados controle e $\mathrm{JH}$ : jejuados tratados com HMB. Efeito do jejum $(\& p<0,05) a=p<0,05$ vs $A C$ e $A H$.

Ao analisarmos os resultados de índice de resistência à fadiga, que compreende a resistência às sucessivas contrações tetânicas, observamos que suplementação promoveu aumento desse parâmetro que, embora não significativo, se encontra no limite da significância $(p=0,08)$ (figura 26 ). 
Figura 26-Resistencia a fadiga no músculo EDL.

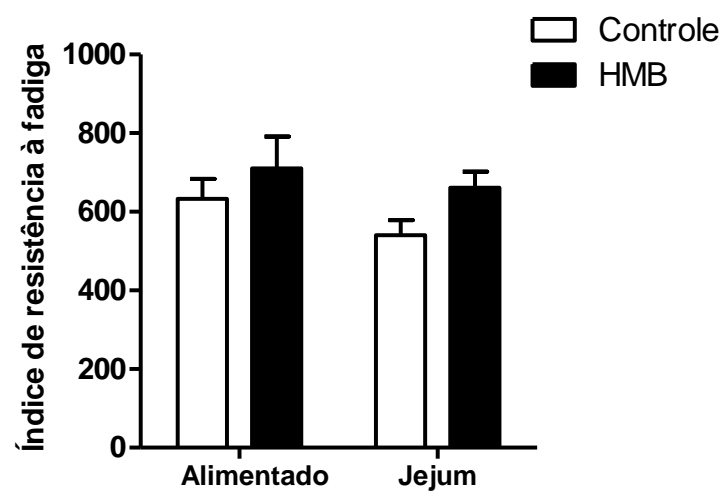

Desempenho das 10 contrações tetânicas máximas do EDL, intervaladas por 10 segundos de recuperação. Os dados representam a media dos valores de área sob a curva de cada animal dos respectivos grupos. 


\section{DISCUSSÃo}

Sabe-se que a hipertrofia muscular ocorre quando a taxa de síntese supera a taxa de degradação protéica. Quando a última se sobrepõe à primeira ocorre diminuição da massa muscular e tamanho da fibra, o que é conhecido como atrofia muscular. Esta se encontra presente em situações como: envelhecimento, câncer, AIDS, imobilização, repouso absoluto (pacientes acamados), e aumento da produção/uso de glicocorticóides (67). Dentre as diversas situações, o jejum, além de ter a propriedade de aumentar a taxa de degradação, promove redução da síntese protéica tanto em músculos de contração rápida como lenta (67).

Na literatura há evidências de que a suplementação de aminoácidos, ou de produtos do seu metabolismo, promove aumento de massa muscular, trazendo benefícios para indivíduos que se encontram em situações como as citadas acima, bem como para atletas.

O HMB é um produto do metabolismo da leucina e tem sido considerado um importante indutor de ganho de massa muscular esquelética. Nesse contexto, buscamos com esse estudo avaliar tal efeito em ratos controles e submetidos a jejum de $24 \mathrm{~h}$, condição em que o efeito proteolítico foi demonstrado por uma redução significativa do peso dos músculos esqueléticos de ratos (68).

Assim, observamos na condição de jejum de 24 h que os pesos dos músculos SOL, EDL e GASTRO (fig. 7) apresentaram reduções significativas, o que corroborou os dados da literatura (60).

Como durante os diversos processos de atrofia muscular ocorre aumento da expressão das ubiquitina-ligases (MuRF-1, Atrogin-1), que são atrogenes marcadores da proteólise muscular $(38,69)$, também avaliamos a expressão gênica desses atrogenes nos animais controle e jejuados. Observamos aumento expressivo do conteúdo de mRNA de Atrogin-1 no músculo SOL e um indicativo de aumento próximo do limite de significância $(p=0,08)$ com relação ao MuRF-1 (fig.8). No músculo EDL observamos aumento significativo na expressão gênica de MuRF-1 e Atrogin-1 (fig. 9). Esses dados reforçam que o modelo de jejum de $24 \mathrm{~h}$ utilizado foi eficiente em causar aumento da degradação protéica nos músculos estudados, corroborando os estudos de Whitehouse et al. (32) e Lecker et al. (70).

Desta maneira, avaliamos, posteriormente, a expressão gênica desses atrogenes marcadores de proteólise no nosso modelo experimental de indução da proteólise muscular em ratos tratados ou não com HMB.

No músculo sóleo a expressão gênica do MuRF-1 não apresentou alteração frente ao tratamento com HMB (fig. 10A); no entanto, observamos um indicativo de redução do 
conteúdo de mRNA de Atrogin-1 nos animais jejuados tratados com HMB em relação ao grupo jejum controle (fig. 10B). No EDL, os dados da suplementação com o HMB também indicam que esse tratamento esteja atenuando o efeito do jejum, que é de promover aumento da expressão do mRNA de MuRF-1 e de Atrogin-1, conforme mostra a figura 11A e B. Esses dados sugerem que o HMB esteja exercendo uma ação "protetora" da proteólise apenas na condição de jejum, já que sua administração mascarou a elevação da expressão de Atrogin-1 e/ou MuRF-1 característica deste estado nutricional e que ele não provocou efeito similar nos animais alimentados. Os dados também apontam para uma resposta diferencial do SOL e EDL ao HMB, o que também foi detectado ao longo dos estudos que foram desenvolvidos. Esses dados, embora tenham sido obtidos em modelo experimental diferente, vão ao encontro dos de Aversa et al. (56), que incubou células musculares L6 com dexametasona e HMB e identificou efeito positivo do HMB em atenuar a expressão desses atrogenes.

Esse efeito de atenuação sobre o Atrogin-1 no músculo sóleo também foi detectado por Smith et al. (55) e Kovarik et al. (52), sendo este último estudo realizado em modelo de sepse, onde foi observada uma atenuação da proteólise miofibrilar induzida pelo HMB. No entanto, essa atenuação ocorreu especialmente no músculo sóleo, enquanto nossos estudos apontaram uma resposta mais acentuada do músculo EDL frente a esse tratamento, o que pode se dever à especificidades do modelo experimental utilizado.

Nesse sentido vale comentar que Li e Goldberg $(20)^{4}$ sugerem que músculos rápidos e lentos diferem em suas taxas de síntese e degradação de proteínas, sendo que os músculos lentos mostram taxas mais elevadas tanto de síntese quanto degradação protéica, enquanto os rápidos seriam mais acometidos frente a um jejum agudo com diminuição da taxa de síntese. No músculo EDL detectamos os aumentos mais expressivos de mRNA de MuRF-1 e Atrogin-1 frente ao jejum (3 e 4 vezes, respectivamente), indicando, assim, um aumento mais proeminente da degradação proteica nesse músculo em comparação com o SOL nesta situação.

Sabe-se que a hipertrofia de miotubos induzida in vitro por IGF-I depende da ativação das vias da PI3K e Akt (38), e que situações em que ocorre redução dos níveis de insulina e IGF-I, como o jejum, levam a diminuição da atividade dessas vias, e a consequentemente a menor ativação da Akt (67).

Nesse contexto, o aumento de cerca de 3 vezes no conteúdo do mRNA do IGF-I no SOL nos animais jejuados tratados com HMB comparado com os jejuados controle (fig. 12A), acompanhado de um indicativo de aumento nos mesmos parâmetros no EDL

\footnotetext{
${ }^{4} 20$ apud Schiaffino S, Dyar KA, Ciciliot S, Blaauw B, Sandri M. Mechanisms regulating skeletal muscle growth and atrophy. FEBS J. 2013 Mar 21. doi: $10.1111 /$ febs. 12253.
} 
(fig.12B) sugere que a síntese de IGF-I está sendo incrementada. Sabe-se que o fígado é um órgão-alvo muito importante do $\mathrm{GH}$ e que uma das ações mais rápidas que ele desencadeia no tecido hepático é o aumento da expressão gênica de IGF-I. Embora não tenhamos detectado um aumento do conteúdo de IGF-I (fig.13), nossos dados revelando um aumento do conteúdo de mRNA de IGF-I, e resultados anteriores que mostram elevação do IGF-I circulante com a tratamento com HMB (50) são altamente sugestivos de que nessa condição experimental a secreção de GH esteja sendo estimulada e que o HMB seja o mediador desse efeito.

Em consonância com nossos estudos, há os de Kraemer et al. (71) que mostrou aumento tanto de GH como do IGF-I em humanos suplementados com HMB e submetidos a treinamento de força. Esses dados indicam a possibilidade do aumento da atividade do eixo GH-IGF-I, desencadeado pelo uso de HMB na promoção de um aumento da síntese protéica. Reforçam essa hipótese, os estudos in vitro desenvolvidos por Kornasio et al. (57), que mostraram que mioblastos incubados com HMB também apresentam aumento do mRNA de IGF-I.

Não se pode descartar a possibilidade de que esse metabólico da leucina tenha uma ação independente da ativação do eixo GH-IGF-I, como postulado por Eley et al.(11), que mostra, por meio de estudos in vitro, que o HMB promove diretamente a ativação de vias de sinalização especificas de aumento de síntese protéica.

Nesse contexto, partimos para a avaliação da Akt. Observamos que o conteúdo de mRNA da Akt foi reduzido pelo tratamento de HMB, tanto nos animais alimentados como nos jejuados em ambos os músculos, embora o conteúdo total de Akt não tenha sofrido alterações, sugerindo que a tradução do transcrito ou a meia vida da proteína possa estar sendo incrementada. De fato, o conteúdo de pAkt apresentou-se elevado, embora não significativamente, no SOL e EDL de ratos jejuados tratados com HMB (fig. 14 e 15, respectivamente). Também houve um aumento de 3 vezes na relação entre pAkt/Akt total no EDL dos animais jejuados tratados com HMB vs jejuados controle $(p=0,07)$.

Esse efeito poderia ser decorrente da ativação do eixo somatotrófico, e consequente elevação da secreção e dos níveis séricos de IGF-I, observada pelo nosso grupo em ratos submetidos à suplementação com HMB (50).

Podemos especular que esse aumento da fosforilação da Akt, em especial no EDL (fig.15), seja um indicativo de que o processo de síntese protéica esteja sendo estimulado pelo HMB, pelo menos parcialmente neste momento.

Ainda, o aumento do conteúdo de Akt fosforilada poderia explicar a atenuação da expressão gênica de MuRF-1 e Atrogin-1, observada mesmo que sem efeito significativo em ambos os músculos SOL e EDL dos ratos jejuados e tratados com HMB, já que a Akt 
ativa leva à fosforilação da FoxO, o que impede que ela migre ao núcleo, onde atua induzindo a expressão dos atrogenes (72).

Sabe-se que a via da mTOR é acionada pela ativação da Akt, e que ambas possuem papéis-chave no processo de síntese protéica (38). Nesse sentido, observamos tanto em SOL como EDL que o tratamento dos animais alimentados com HMB exerceu um efeito indutor da fosforilação da mTOR (fig.16D e 17D, respectivamente), dado que, embora não significativo, vai de encontro aos da literatura, que mostram que o HMB tem um efeito de ativar vias de síntese protéica, assim como a mTOR $(11,57)$.

Como esperado, o efeito do jejum foi significativo em reduzir a fosforilação da mTOR no músculo sóleo (fig.16D). No entanto para nossa surpresa os dados da fosforilação em Serina 2448 da mTOR em ambos os músculos (fig.16 e 17) mostrou-se reduzida nos animais jejuados tratados comparados com o jejum controle, mesmo diante de aumentos do conteúdo do mRNAs, de ambos os músculos, embora tenha sido significativo somente no caso do EDL (fig. 17D).

Com relação à mTOR, no músculo EDL (fig. 17D) identificamos efeito de aumento da forma fosforilada dessa proteína no jejum em relação aos demais grupos. Embora inesperado, não podemos deixar de mencionar que no jejum há intensa proteólise, evento que depende da ação de enzimas proteolíticas, que certamente tem sua síntese/atividade aumentada nessa condição, processos que poderiam envolver a via da sinalização de mTOR. Por outro lado, a ativação dessa via pode não ter relação alguma com a ativação das etapas subsequentes de sinalização relacionadas à síntese proteica, como S6K e 4EBP1. Nesse sentido, Khamzina et al. (73) também demonstraram aumento da atividade da via da mTOR em músculo esquelético e fígado de ratos obesos, e postularam um possível envolvimento da mesma na resistência à insulina. Estudos de Dann et al. (74) também reportam que em situações de resistência a insulina e obesidade essa via encontra-se ativada, levando assim a aumento da concentração plasmática de aminoácidos, em particular os de cadeia ramificada. Sabe-se que em situações de jejum a liberação de aminoácidos é aumentada (68) e esses são capazes de ativa a mTOR per se. Portanto, é possível também que, no jejum, o aumento da aminoacidemia tenha promovido a ativação dessa via, pelo menos nesse músculo especifico (EDL).

Embora os resultados obtidos com relação à mTOR tenham sido inesperados, partimos para a investigação das vias que se encontram mais abaixo da mTOR, já que elas parecem ser mais representativas para evidenciar os efeitos sobre a síntese protéica. Sendo assim analisamos a 4E-BP1 e a S6, proteínas diretamente relacionadas à síntese protéica. Sabe-se que a leucina, aminoácido do qual o HMB é um metabolito, exerce um efeito estimulatório sobre a fosforilação da S6k e p70S6k, resultando em um aumento da 
fosforilação da S6, bem como ao aumento da fosforilação da 4E-BP1, que ativa os fatores de iniciação da tradução (elFs) $(25,44)$. No entanto, observamos aumento da expressão gênica da 4E-BP1 nos animais jejuados tratados com HMB, que, embora não tenha sido significativo, foi expressivo ( 2X), vs jejuados controle no músculo SOL (fig.18A). No entanto não foi observado qualquer alteração do proteína fosforilada; pelo contrário observamos redução dessa proteína frente ao tratamento.

No caso do músculo EDL (fig.19) as observações foram semelhantes, no entanto o conteúdo do mRNA da 4E-BP1 nas situações de jejum (controle e tratados) se apresentou aumentado, não causando reflexo sobre a proteína fosforilada, embora na condição de alimentação e tratamento tenhamos observado um indicativo de aumento, embora não significativo. A literatura mostra que a suplementação de HMB ativa essas vias intracelulares (fosforilação da p70S6k e 4E-BP1), aumentando a síntese protéica $(11,57)$. No entanto, nossos dados não apontam nesse sentido, sendo possível que o tratamento prévio com HMB não tenha exercido efeito adicional esperado desse metabólito na situação aguda de jejum.

Quanto aos dados de S6 em SOL (fig.20) não detectamos efeito do tratamento tanto em animais controle como nos jejuados. No entanto, observamos aumento da relação pS6/S6 total nos animais jejuados controle em relação ao alimentado controle, o que poderia ser explicado pelo fato desse músculo apresentar uma alta taxa de turnover $(20)^{5}$.

No músculo EDL (fig. 21), observamos um tendência ao aumento da S6 fosforilada nos jejuados tratados com HMB comparados como os jejuados controle, o que é um indício de um estimulo da síntese proteica. Esses dados corroboram a literatura que mostra que o tratamento com HMB é capaz de promover aumentos nas proteínas diretamente relacionadas com a síntese proteica $(11,57)$.

É interessante comentar que embora tenhamos detectado redução da AST no músculo SOL (fig. 23) frente ao jejum e à suplementação, acompanhado de redução do peso do SOL nos animais jejuados tratados (JH) ou não (JC) (fig.22A), a força isotônica máxima absoluta do grupo jejuado tratado com HMB foi comparável à do controle (tabela 3). O mesmo ocorreu com a força tetânica máxima absoluta, o que sugere que a presença do HMB evitou que as alterações citadas acima promovessem efeitos deletérios na função contrátil.

No músculo de composição mista (fig. 22C), GASTRO (parte composta de fibras lentas- porção vermelha, e fibras rápidas - porção branca), como esperado, observamos uma redução do seu peso no jejum, parâmetro que não foi alterado com a suplementação.

\footnotetext{
${ }^{5} 20$ apud Schiaffino S, Dyar KA, Ciciliot S, Blaauw B, Sandri M. Mechanisms regulating skeletal muscle growth and atrophy. FEBS J. 2013 Mar 21. doi: 10.1111/febs. 12253.
} 
No entanto a AST no músculo EDL não se apresentou alterada pelo jejum, suplementação e nem pela associação de ambos (fig. 24). Contudo, os resultados relacionados ao seu peso úmido são bastante promissores (fig.22B), já que observamos efeito da suplementação e interação da suplementação e jejum, uma vez que o peso do EDL apresentou-se superior no grupo jejuado tratado com HMB vs jejuado controles, o que é um indicativo de que, de alguma maneira, o tratamento atenuou a degradação proteica no jejum. Ainda, o aumento do tempo de sustentação da isometria no grupo jejum HMB vs jejuados controle (tabela 4), e um aparente efeito positivo da suplementação sobre o índice de resistência á fadiga (fig. 26) sugerem que alterações funcionais parecem estar sendo induzidas. Isto poderia ser efetivamente evidenciado caso o tempo de suplementação fosse incrementado, visto que um estudo recente (69) utilizando desuso e tratamento com um outro metabolito da leucina, $\alpha-K I C$, evidenciou que o tratamento embora na tenha alterado a taxa de proteólise, foi capaz de acelerar a recuperação muscular após o período de desuso com aumentos na taxa de síntese protéica. É possível também que a Akt ativada nesse músculo esteja mais relacionada a alterações no metabolismo intramuscular, como por exemplo, a inativação da GSK-3 via Akt (75). A GSK-3 quando fosforilada é inativada, de modo que a glicogênio sintase se torna ativa, o que eleva o conteúdo de glicogênio intramuscular (76), como mostrado em um estudo sobre a função contrátil diante da suplementação de HMB (77). Esses dados justificariam a melhora no quadro funcional do músculo EDL, em função do aumento do conteúdo de glicogênio e ATP, como constatado em estudo de nosso grupo (77). Ainda, esse efeito traria ganhos de peso do músculo, sem qualquer alteração na AST, como constatado. 


\section{CONCLUSÕES}

Dentre as principais evidências deste trabalho, destaca se:

- Efeito do HMB na atenuação da expressão do atrogene, Atrogin-1 no músculo SOL frente ao jejum;

-Efeito na atenuação da expressão dos atrogenes, MuRF-1 e Atrogin-1 no músculo EDL frente a esse modelo;

-Aumento da fosforilação da Akt no músculo EDL tratado com HMB e submetido ao jejum;

-Nenhuma alteração sobre as vias estudadas relacionadas à síntese, incluindo a 4E-BP1 e a S6;

-Efeito indutor no ganho de peso úmido do músculo EDL, frente ao jejum e o tratamento, sem repercussões sobre a AST;

-Melhora no tempo de sustentação da isométria dos animais jejuados tratados comparados com jejuados controle;

-Efeito positivo do tratamento no modelo de jejum sobre a taxa de resistência a fadiga;

Em suma, nossos dados não corroboram totalmente os da literatura que apontam efeitos importantes do HMB na indução de síntese proteica em modelos de proteólise, já que ao menos no modelo utilizado nesse estudo, que foi o de jejum de $24 \mathrm{~h}$, não pudemos constatar eventos significativos nessa direção. Os efeitos apontam respostas músculoespecíficas, sendo que os mais importantes estiveram presentes no EDL, em que observamos um aumento do grau de fosforilação da Akt, e da razão pAkt/Akt total, que aparentemente não estiveram relacionadas a um aumento da síntese proteica, mas possivelmente à uma redução na proteólise, como aponta a atenuação da expressão dos atrogenes, e à um possível aumento do conteúdo de glicogênio intramuscular, eventos que poderiam explicar o aumento do tempo de sustentação da isometria e da taxa de resistência à fadiga. Esses eventos coexistiram sem nenhuma alteração da AST, mas resultaram em um efeito positivo do HMB no jejum sobre a reversão da perda de peso do EDL comparado ao grupo jejuado controle. Postulamos, assim, que o HMB esteja promovendo ajustes metabólicos, possivelmente no aumento do conteúdo de glicogênio e ATP, de forma a proteger o músculo de um prejuízo adicional na sua capacidade funcional, sem resultar em adicional ganho de massa muscular, até 0 momento. 


\section{REFERÊNCIAS ${ }^{6}$}

1. Hider RC, Fern EB, London DR. Relationship between intracellular amino acids and protein synthesis in the extensor digitorum longus muscle of rats. The Biochemical Journal. 1969;114(2):171-8.

2. Nissen S. Measurement of muscle proteolysis and the impact on muscle wasting. The Proceedings of the Nutrition Society. 1997;56(2):793-9.

3. Nissen S, Sharp R, Ray M, Rathmacher Ja, Rice D, Fuller JC, et al. Effect of leucine metabolite beta-hydroxy-beta-methylbutyrate on muscle metabolism during resistanceexercise training. Journal of Applied Physiology (Bethesda, Md : 1985). 1996;81(5):2095104.

4. Slater GJ, Jenkins D. Beta-hydroxy-beta-methylbutyrate (HMB) supplementation and the promotion of muscle growth and strength. Sports Medicine (Auckland, NZ). 2000;30(2):105-16.

5. Holecek M, Muthny $T$, Kovarik M, Sispera L. Effect of beta-hydroxy-betamethylbutyrate $(\mathrm{HMB})$ on protein metabolism in whole body and in selected tissues. Food and chemical toxicology : an international journal published for the British Industrial Biological Research Association. 2009;47(1):255-9.

6. Clark RH, Feleke G, Din M, Yasmin T, Singh G, Khan FA, et al. Nutritional treatment for acquired immunodeficiency virus-associated wasting using beta-hydroxy betamethylbutyrate, glutamine, and arginine: A randomized, double-blind, placebo-controlled study. Jpen-Parenter Enter. 2000;24(3):133-9.

7. Fuller JC, Baier S, Flakoll P, Nissen SL, Abumrad NN, Rathmacher Ja. Vitamin D status affects strength gains in older adults supplemented with a combination of $\beta$-hydroxy- $\beta$ methylbutyrate, arginine, and lysine: a cohort study. JPEN Journal of parenteral and enteral nutrition. 2011;35(6):757-62.

\footnotetext{
${ }^{6}$ De acordo com:

International Committeeof Medical Journal Editors. [Internet]. Uniform requirements for manuscripts submitted to Biomedical Journal: sample references. [updated 2011 Jul 15]. Available from: http://www.icmje.org
} 
8. Kraemer WJ, Hatfield DL, Volek JS, Fragala MS, Vingren JL, Anderson JM, et al. Effects of amino acids supplement on physiological adaptations to resistance training. Medicine and science in sports and exercise. 2009;41(5):1111-21.

9. Wilson JM, Kim JS, Lee SR, Rathmacher JA, Dalmau B, Kingsley JD, et al. Acute and timing effects of beta-hydroxy-beta-methylbutyrate $(\mathrm{HMB})$ on indirect markers of skeletal muscle damage. Nutr Metab (Lond). 2009;6:6.

10. Nissen SL, Abumrad NN. Nutritional role of the leucine metabolite $\beta$-hydroxy $\beta$ methylbutyrate (HMB). The Journal of Nutritional Biochemistry. 1997;8(6):300-11.

11. Eley HL, Russell ST, Baxter JH, Mukerji P, Tisdale MJ. Signaling pathways initiated by beta-hydroxy-beta-methylbutyrate to attenuate the depression of protein synthesis in skeletal muscle in response to cachectic stimuli. Am J Physiol Endocrinol Metab. 2007;293(4):E923-31.

12. May PE, Barber A, D'Olimpio JT, Hourihane A, Abumrad NN. Reversal of cancerrelated wasting using oral supplementation with a combination of beta-hydroxy-betamethylbutyrate, arginine, and glutamine. American journal of surgery. 2002;183(4):471-9.

13. Block KP, Buse MG. Glucocorticoid regulation of muscle branched-chain amino acid metabolism. Med Sci Sports Exerc. 1990;22(3):316-24.

14. Sabourin PJ, Bieber LL. Formation of beta-hydroxyisovalerate by an alphaketoisocaproate oxygenase in human liver. Metabolism: clinical and experimental. 1983;32(2):160-4.

15. Sabourin PJ, Bieber LL. Subcellular distribution and partial characterization of an alpha-ketoisocaproate oxidase of rat liver: formation of beta-hydroxyisovaleric acid. Archives of biochemistry and biophysics. $1981 ; 206(1): 132-44$.

16. Rudney $\mathrm{H}$. The biosynthesis of beta-hydroxy-beta-methylglutaric acid. J Biol Chem. 1957;227(1):363-77. Epub 1957/07/01. 
17. Zanchi NE, Gerlinger-Romero F, Guimarães-Ferreira L, de Siqueira Filho MA, Felitti V, Lira FS, et al. HMB supplementation: clinical and athletic performance-related effects and mechanisms of action. Amino acids. 2011;40(4):1015-25.

18. Smith HJ, Mukerji P, Tisdale MJ. Attenuation of proteasome-induced proteolysis in skeletal muscle by $\{$ beta\}-hydroxy-\{beta\}-methylbutyrate in cancer-induced muscle loss. Cancer research. 2005;65(1):277-83.

19. dos Santos RA, Giannocco G, Nunes MT. Thyroid hormone stimulates myoglobin expression in soleus and extensorum digitalis longus muscles of rats: concomitant alterations in the activities of Krebs cycle oxidative enzymes. Thyroid : official journal of the American Thyroid Association. 2001;11(6):545-50.

20. Li JB, Goldberg AL. Effects of food deprivation on protein synthesis and degradation in rat skeletal muscles. The American journal of physiology. 1976;231(2):441-8.

21. Goldberg AL, Goodman HM. Relationship between cortisone and muscle work in determining muscle size. J Physiol. 1969;200(3):667-75. Epub 1969/02/01.

22. Verheul AJ, Mantilla CB, Zhan WZ, Bernal M, Dekhuijzen PN, Sieck GC. Influence of corticosteroids on myonuclear domain size in the rat diaphragm muscle. J Appl Physiol. 2004;97(5):1715-22.

23. Goldberg AL. Protein turnover in skeletal muscle. I. Protein catabolism during workinduced hypertrophy and growth induced with growth hormone. J Biol Chem. 1969;244(12):3217-22.

24. Anderson M, Capen C. The Endocrine System. In: Benirschke K, Garner FM, Jones TC, editors. Pathology of Laboratory Animals: Springer New York; 1978. p. 423-508.

25. Kimball SR, Farrell Pa, Jefferson LS. Invited Review: Role of insulin in translational control of protein synthesis in skeletal muscle by amino acids or exercise. Journal of applied physiology (Bethesda, Md : 1985). 2002;93(3):1168-80. 
26. Lowell BB, Ruderman NB, Goodman MN. Evidence that lysosomes are not involved in the degradation of myofibrillar proteins in rat skeletal muscle. Biochem J. 1986;234(1):23740 .

27. Croall DE, DeMartino GN. Calcium-activated neutral protease (calpain) system: structure, function, and regulation. Physiol Rev. 1991;71(3):813-47.

28. Tidball JG, Spencer MJ. Expression of a calpastatin transgene slows muscle wasting and obviates changes in myosin isoform expression during murine muscle disuse. J Physiol. 2002;545(Pt 3):819-28.

29. Saido TC, Sorimachi H, Suzuki K. Calpain: new perspectives in molecular diversity and physiological-pathological involvement. FASEB J. 1994;8(11):814-22.

30. Du J, Hu Z, Mitch WE. Molecular mechanisms activating muscle protein degradation in chronic kidney disease and other catabolic conditions. European journal of clinical investigation. 2005;35(3):157-63.

31. Goll DE, Neti G, Mares SW, Thompson VF. Myofibrillar protein turnover: the proteasome and the calpains. J Anim Sci. 2008;86(14 Suppl):E19-35.

32. Whitehouse aS, Tisdale MJ. Downregulation of ubiquitin-dependent proteolysis by eicosapentaenoic acid in acute starvation. Biochemical and biophysical research communications. $2001 ; 285(3): 598-602$.

33. Tawa NE, Jr., Odessey R, Goldberg AL. Inhibitors of the proteasome reduce the accelerated proteolysis in atrophying rat skeletal muscles. J Clin Invest. 1997;100(1):197203.

34. Jagoe RT, Goldberg AL. What do we really know about the ubiquitin-proteasome pathway in muscle atrophy? Curr Opin Clin Nutr Metab Care. 2001;4(3):183-90. Epub $2001 / 08 / 23$.

35. Ciechanover A. Intracellular protein degradation: from a vague idea thru the lysosome and the ubiquitin-proteasome system and onto human diseases and drug targeting. Cell death and differentiation. 2005;12(9):1178-90. 
36. Cao PR, Kim HJ, Lecker SH. Ubiquitin-protein ligases in muscle wasting. Int J Biochem Cell Biol. 2005;37(10):2088-97.

37. Lecker SH, Solomon V, Mitch WE, Goldberg AL. Muscle protein breakdown and the critical role of the ubiquitin-proteasome pathway in normal and disease states. J Nutr. 1999;129(1S Suppl):227S-37S.

38. Bodine SC, Stitt TN, Gonzalez M, Kline WO, Stover GL, Bauerlein R, et al. Akt/mTOR pathway is a crucial regulator of skeletal muscle hypertrophy and can prevent muscle atrophy in vivo. Nat Cell Biol. 2001;3(11):1014-9.

39. Wing SS, Banville D. 14-kDa ubiquitin-conjugating enzyme: structure of the rat gene and regulation upon fasting and by insulin. The American journal of physiology. 1994;267(1 Pt 1):E39-48.

40. Le Roith D, Bondy C, Yakar S, Liu JL, Butler A. The somatomedin hypothesis: 2001. Endocrine reviews. 2001;22(1):53-74.

41. Fiorotto ML, Schwartz RJ, Delaughter MC. Persistent IGF-I overexpression in skeletal muscle transiently enhances DNA accretion and growth. FASEB J. 2003;17(1):59-60.

42. Mavalli MD, DiGirolamo DJ, Fan Y, Riddle RC, Campbell KS, van Groen T, et al. Distinct growth hormone receptor signaling modes regulate skeletal muscle development and insulin sensitivity in mice. J Clin Invest. 2010;120(11):4007-20.

43. Rommel C, Bodine SC, Clarke BA, Rossman R, Nunez L, Stitt TN, et al. Mediation of IGF-1-induced skeletal myotube hypertrophy by $\mathrm{PI}(3) \mathrm{K} / \mathrm{Akt} / \mathrm{mTOR}$ and $\mathrm{PI}(3) \mathrm{K} / \mathrm{Akt} / \mathrm{GSK} 3$ pathways. Nat Cell Biol. 2001;3(11):1009-13.

44. Li F, Yin Y, Tan B, Kong X, Wu G. Leucine nutrition in animals and humans: mTOR signaling and beyond. Amino Acids. 2011;41(5):1185-93.

45. Dehoux M, Van Beneden R, Pasko N, Lause P, Verniers J, Underwood L, et al. Role of the insulin-like growth factor I decline in the induction of atrogin-1/MAFbx during fasting and diabetes. Endocrinology. 2004;145(11):4806-12. 
46. Favier FB, Benoit H, Freyssenet D. Cellular and molecular events controlling skeletal muscle mass in response to altered use. Pflugers Arch. 2008;456(3):587-600.

47. Shavlakadze T, White JD, Davies M, Hoh JF, Grounds MD. Insulin-like growth factor I slows the rate of denervation induced skeletal muscle atrophy. Neuromuscular disorders : NMD. 2005;15(2):139-46.

48. Day CS, Buranapanitkit B, Riano FA, Tomaino MM, Somogyi G, Sotereanos DG, et al. Insulin growth factor-1 decreases muscle atrophy following denervation. Microsurgery. 2002;22(4):144-51.

49. Yakar S, Liu JL, Stannard B, Butler A, Accili D, Sauer B, et al. Normal growth and development in the absence of hepatic insulin-like growth factor I. Proc Natl Acad Sci U S A. 1999;96(13):7324-9.

50. Gerlinger-Romero F, Guimarães-Ferreira L, Giannocco G, Nunes MT. Chronic supplementation of beta-hydroxy-beta methylbutyrate $(\mathrm{HM} \beta)$ increases the activity of the GH/IGF-I axis and induces hyperinsulinemia in rats. Growth hormone \& IGF research : official journal of the Growth Hormone Research Society and the International IGF Research Society. 2011;21(2):57-62.

51. Tatara MR, Sliwa E, Krupski W. Prenatal programming of skeletal development in the offspring: effects of maternal treatment with beta-hydroxy-beta-methylbutyrate (HMB) on femur properties in pigs at slaughter age. Bone. 2007;40(6):1615-22.

52. Kovarik M, Muthny $T$, Sispera L, Holecek M. Effects of $\beta$-hydroxy- $\beta$-methylbutyrate treatment in different types of skeletal muscle of intact and septic rats. Journal of physiology and biochemistry. 2010;66(4):311-9.

53. Wilson JM, Grant SC, Lee S-R, Masad IS, Park Y-M, Henning PC, et al. Betahydroxy-beta-methyl-butyrate blunts negative age-related changes in body composition, functionality and myofiber dimensions in rats. Journal of the International Society of Sports Nutrition. 2012;9(1):18-. 
54. Deutz NE, Pereira SL, Hays NP, Oliver JS, Edens NK, Evans CM, et al. Effect of beta-hydroxy-beta-methylbutyrate (HMB) on lean body mass during 10 days of bed rest in older adults. Clin Nutr. 2013.

55. Smith HJ, Wyke SM, Tisdale MJ. Mechanism of the attenuation of proteolysisinducing factor stimulated protein degradation in muscle by beta-hydroxy-betamethylbutyrate. Cancer research. 2004;64(23):8731-5.

56. Aversa Z, Alamdari N, Castillero E, Muscaritoli M, Rossi Fanelli F, Hasselgren P-O. $\beta$ Hydroxy- $\beta$-methylbutyrate (HMB) prevents dexamethasone-induced myotube atrophy. Biochemical and biophysical research communications. 2012;423(4):739-43.

57. Kornasio R, Riederer I, Butler-Browne G, Mouly V, Uni Z, Halevy O. Beta-hydroxybeta-methylbutyrate $(\mathrm{HMB})$ stimulates myogenic cell proliferation, differentiation and survival via the MAPK/ERK and PI3K/Akt pathways. Biochimica et Biophysica acta. 2009;1793(5):755-63.

58. Bagchi D, Nair S, Sen C. An Overview on beta-hydroxy-beta-methylbutyrate (HMB) Supplementation in Skeletal Muscle Function and Sports Performance. In: Pinheiro CHJ, Curi R, Guimarães-Ferreira L, Gerlinger-Romero F, editors. Nutrition and Enhanced Sports Performance. 1st ed2013.

59. Farrell PA, Fedele MJ, Hernandez J, Fluckey JD, John L, lii M, et al. Hypertrophy of skeletal muscle in diabetic rats in response to chronic resistance exercise exercise synthesis with acute exercise in rats Hypertrophy of skeletal muscle in diabetic rats in response to chronic resistance exercise. 2011:1075-82.

60. Chomczynski P, Sacchi N. Single-step method of RNA isolation by acid guanidinium thiocyanate-phenol-chloroform extraction. Anal Biochem. 1987;162(1):156-9.

61. Livak KJ, Schmittgen TD. Analysis of relative gene expression data using real-time quantitative PCR and the 2(-Delta Delta C(T)) Method. Methods. 2001;25(4):402-8.

62. Harcourt LJ, Holmes AG, Gregorevic P, Schertzer JD, Stupka N, Plant DR, et al. Interleukin-15 administration improves diaphragm muscle pathology and function in dystrophic mdx mice. The American Journal of Pathology. 2005;166(4):1131-41. 
63. Pinheiro $\mathrm{CH}$, Gerlinger-Romero F, Guimaraes-Ferreira L, de Souza-Jr AL, Vitzel KF, Nachbar RT, et al. Metabolic and functional effects of beta-hydroxy-beta-methylbutyrate (HMB) supplementation in skeletal muscle. Eur J Appl Physiol. 2011.

64. da Justa Pinheiro CH, de Queiroz JC, Guimaraes-Ferreira L, Vitzel KF, Nachbar RT, de Sousa LG, et al. Local Injections of Adipose-Derived Mesenchymal Stem Cells Modulate Inflammation and Increase Angiogenesis Ameliorating the Dystrophic Phenotype in Dystrophin-Deficient Skeletal Muscle. Stem Cell Rev. 2011.

65. Pinheiro $\mathrm{CH}$, Vitzel KF, Curi R. Effect of $\mathrm{N}$-acetylcysteine on markers of skeletal muscle injury after fatiguing contractile activity. Scand J Med Sci Sports. 2012;22(1):24-33.

66. Bassit RA, Pinheiro CH, Vitzel KF, Sproesser AJ, Silveira LR, Curi R. Effect of shortterm creatine supplementation on markers of skeletal muscle damage after strenuous contractile activity. Eur J Appl Physiol. 2010;108(5):945-55.

67. Schiaffino S, Dyar KA, Ciciliot S, Blaauw B, Sandri M. Mechanisms regulating skeletal muscle growth and atrophy. The FEBS journal. 2013.

68. Busquets S, Alvarez B, Lopez-Soriano FJ, Argiles JM. Branched-chain amino acids: a role in skeletal muscle proteolysis in catabolic states? J Cell Physiol. 2002;191(3):283-9.

69. Lang $\mathrm{CH}$, Pruznak A, Navaratnarajah M, Rankine KA, Deiter G, Magne $\mathrm{H}$, et al. Chronic alpha-hydroxyisocaproic acid treatment improves muscle recovery after immobilization-induced atrophy. Am J Physiol Endocrinol Metab. 2013.

70. Lecker SH, Jagoe RT, Gilbert A, Gomes M, Baracos V, Bailey J, et al. Multiple types of skeletal muscle atrophy involve a common program of changes in gene expression. FASEB J. 2004;18(1):39-51.

71. Kraemer WJ, Hatfield DL, Volek JS, Fragala MS, Vingren JL, Anderson JM, et al. Effects of amino acids supplement on physiological adaptations to resistance training. Med Sci Sports Exerc. 2009;41(5):1111-21. 
72. Zhao J, Brault JJ, Schild A, Cao P, Sandri M, Schiaffino S, et al. FoxO3 coordinately activates protein degradation by the autophagic/lysosomal and proteasomal pathways in atrophying muscle cells. Cell Metab. 2007;6(6):472-83.

73. Khamzina L, Veilleux A, Bergeron S, Marette A. Increased activation of the mammalian target of rapamycin pathway in liver and skeletal muscle of obese rats: possible involvement in obesity-linked insulin resistance. Endocrinology. 2005;146(3):1473-81.

74. Dann SG, Selvaraj A, Thomas G. mTOR Complex1-S6K1 signaling: at the crossroads of obesity, diabetes and cancer. Trends Mol Med. 2007;13(6):252-9.

75. Stitt TN, Drujan D, Clarke BA, Panaro F, Timofeyva Y, Kline WO, et al. The IGF1/PI3K/Akt pathway prevents expression of muscle atrophy-induced ubiquitin ligases by inhibiting FOXO transcription factors. Mol Cell. 2004;14(3):395-403.

76. Bouskila M, Hirshman MF, Jensen J, Goodyear LJ, Sakamoto K. Insulin promotes glycogen synthesis in the absence of GSK3 phosphorylation in skeletal muscle. Am J Physiol Endocrinol Metab. 2008;294(1):E28-35.

77. Pinheiro CHDJ, Gerlinger-Romero F, Guimarães-Ferreira L, de Souza-Jr AL, Vitzel KF, Nachbar RT, et al. Metabolic and functional effects of beta-hydroxy-beta-methylbutyrate (HMB) supplementation in skeletal muscle. European Journal of Applied Physiology. 2012;112(7):2531-7. 


\section{APENDICE - Lista de trabalhos publicados}

Eur J Appl Physiol. 2012 Jul;112(7):2531-7. doi: 10.1007/s00421-011-2224-5. Epub 2011 Nov 11.

\section{Metabolic and functional effects of beta-hydroxy-beta-methylbutyrate supplementation in skeletal muscle.}

(HMB)

Pinheiro $\mathrm{CH}$, Gerlinger-Romero F, Guimarães-Ferreira L, de Souza-Jr AL, Vitzel KF, Nachbar RT, Nunes MT, Curi R.

Department of Physiology and Biophysics, room 105, Institute of Biomedical Science, University of São Paulo, Av. Prof. Lineu Prestes, 1524, Prédio Biomédicas I, Cidade Universitária, Butantã, São Paulo, SP, CEP:05508-900, Brazil.chjpinheiro@gmail.com

\section{Abstract}

Beta-hydroxy-beta-methylbutyrate $(\mathrm{HMB})$ is a metabolite derived from leucine. The anticatabolic effect of HMB is well documented but its effect upon skeletal muscle strength and fatigue is still uncertain. In the present study, male Wistar rats were supplemented with HMB (320 mg/kg per day) for 4 weeks. Placebo group received saline solution only. Muscle strength (twitch and tetanic force) and resistance to acute muscle fatigue of the gastrocnemius muscle were evaluated by direct electrical stimulation of the sciatic nerve. The content of ATP and glycogen in red and white portions of gastrocnemius muscle were also evaluated. The effect of HMB on citrate synthase (CS) activity was also investigated. Muscle tetanic force was increased by HMB supplementation. No change was observed in time to peak of contraction and relaxation time. Resistance to acute muscle fatigue during intense contractile activity was also improved after HMB supplementation. Glycogen content was increased in both white (by fivefold) and red (by fourfold) portions of gastrocnemius muscle. HMB supplementation also increased the ATP content in red (by twofold) and white (1.2-fold) portions of gastrocnemius muscle. CS activity was increased by twofold in red portion of gastrocnemius muscle. These results support the proposition that HMB supplementation have marked change in oxidative metabolism improving muscle strength generation and performance during intense contractions. 
Eur J Appl Physiol. 2012 Nov;112(11):3905-11. doi: 10.1007/s00421-012-2378-9.

\title{
Short-term creatine supplementation decreases reactive oxygen species content with no changes in expression and activity of antioxidant enzymes in skeletal muscle.
}

Guimarães-Ferreira L, Pinheiro CH, Gerlinger-Romero F, Vitzel KF, Nachbar RT, Curi R, Nunes MT.

Department of Physiology and Biophysics, Institute of Biomedical Sciences, University of São Paulo, ICB-I, Cidade Universitária, Av. Prof. Lineu Prestes, 1524, Butantã, São Paulo, SP, 05508-900, Brazil. lucas@cefd.ufes.br

\begin{abstract}
The effect of short-term creatine $(\mathrm{Cr})$ supplementation upon content of skeletal musclederived-reactive oxygen species (ROS) was investigated. Wistar rats were supplemented with $\mathrm{Cr}(5 \mathrm{~g} / \mathrm{kg} \mathrm{BW})$ or vehicle, by gavage, for 6 days. Soleus and extensor digitorum longus (EDL) muscles were removed and incubated for evaluation of ROS content using AmplexUltraRed reagent. The analysis of expression and activity of antioxidant enzymes (superoxide dismutase 1 and 2, catalase and glutathione peroxidase) were performed. Direct scavenger action of $\mathrm{Cr}$ on superoxide radical and hydrogen peroxide was also investigated. Short-term $\mathrm{Cr}$ supplementation attenuated ROS content in both soleus and EDL muscles (by 41 and $33.7 \%$, respectively). Cr supplementation did not change expression and activity of antioxidant enzymes. Basal TBARS content was not altered by $\mathrm{Cr}$ supplementation. In cellfree experiments, $\mathrm{Cr}$ showed a scavenger effect on superoxide radical in concentrations of 20 and $40 \mathrm{mM}$, but not on hydrogen peroxide. These results indicate that $\mathrm{Cr}$ supplementation decreases ROS content in skeletal muscle possibly due to a direct action of Cr molecule on superoxide radical.
\end{abstract}

